\title{
SPACE WEATHER IMPACT ON GROUND-BASED TECHNOLOGICAL SYSTEMS
}

\author{
V.A. Pilipenko \\ Institute of Physics of Earth RAS, \\ Moscow, Russia, pilipenko_va@mail.ru
}

\author{
Geophysical Center RAS, \\ Moscow, Russia, pilipenko_va@mail.ru
}

\begin{abstract}
This review, offered for the first time in the Russian scientific literature, is devoted to various aspects of the problem of the space weather impact on ground-based technological systems. Particular attention is paid to hazards to operation of power transmission lines, railway automation, and pipelines caused by geomagnetically induced currents (GIC) during geomagnetic disturbances. The review provides information on the main characteristics of geomagnetic field variability, on rapid field variations during various space weather manifestations. The fundamentals of modeling geoelectric field disturbances based on magnetotelluric sounding algorithms are presented. The approaches to the assessment of possible extreme values of GIC are considered. Information about economic effects of space weather and GIC is collected. The current state and prospects of space weather forecasting, risk assessment for technological systems from GIC impact are discussed. While in space geophysics various models for predicting the intensity of magnetic storms and their related geomagnetic disturbances from observations of the interplanetary medium are being actively developed, these models cannot be directly used to predict the intensity and position of GIC since the description of the geomagnetic field variability requires the development of additional
\end{abstract}

models. Revealing the fine structure of fast geomagnetic variations during storms and substorms and their induced GIC bursts appeared to be important not only from a practical point of view, but also for the development of fundamentals of near-Earth space dynamics. Unlike highly specialized papers on geophysical aspects of geomagnetic variations and engineering aspects of the GIC impact on operation of industrial transformers, the review is designed for a wider scientific and technical audience without sacrificing the scientific level of presentation. In other words, the geophysical part of the review is written for engineers, and the engineering part is written for geophysicists. Despite the evident applied orientation of the studies under consideration, they are not limited to purely engineering application of space geophysics results to the calculation of possible risks for technological systems, but also pose a number of fundamental scientific problems.

Keywords: space weather, geomagnetically induced currents, power transmission lines, transformers, pipelines, railways automation, magnetospheric storms, substorms, Pi3/Ps6 pulsations.

\section{CONTENT}

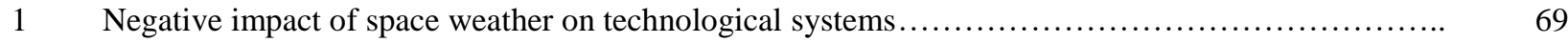

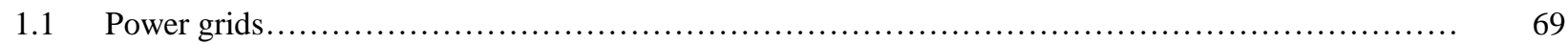

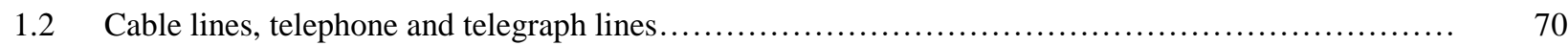

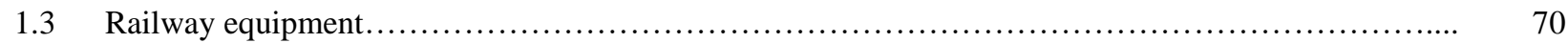

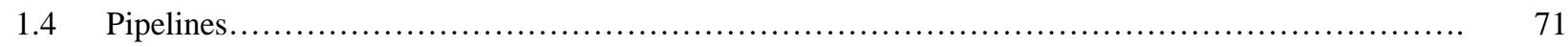

2 Geomagnetic and geoelectric field variations during various space weather manifestations........... 71

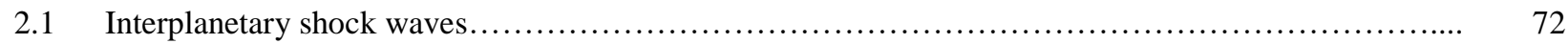

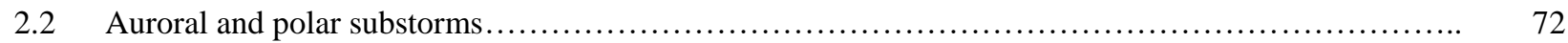

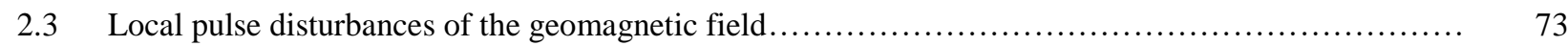

2.4 Substorm fine structure: series of Ps6/Pi3 magnetic pulses................................... 74

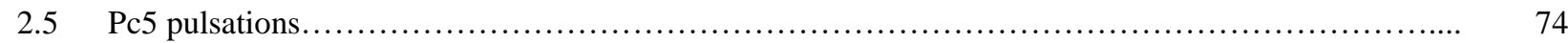

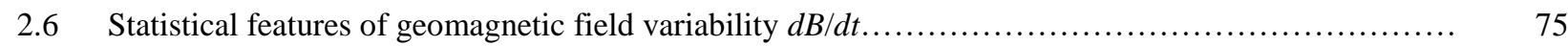

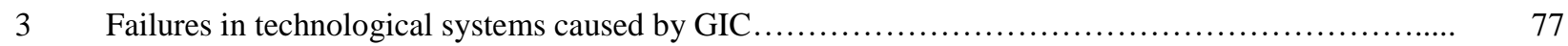

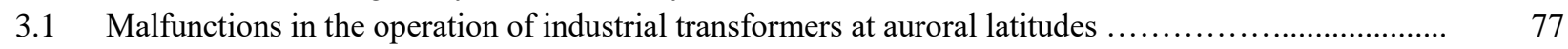

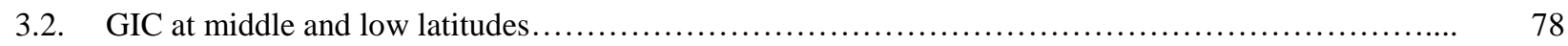

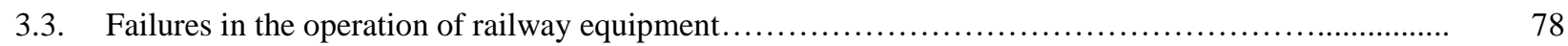

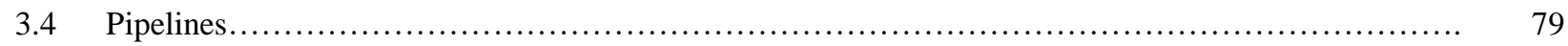

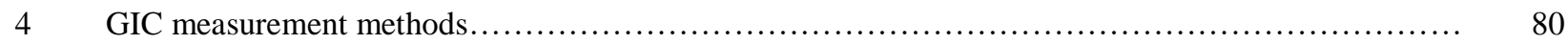

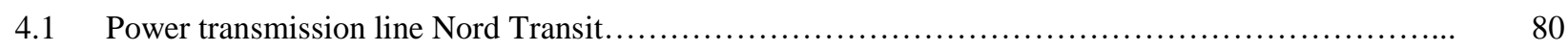

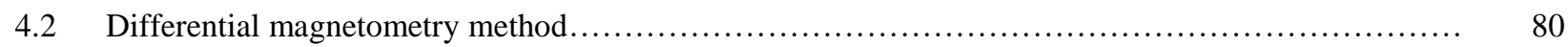

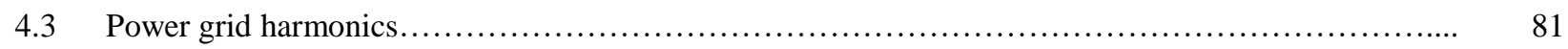

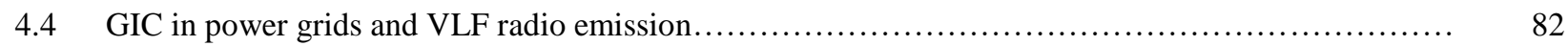




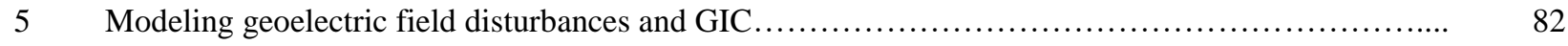

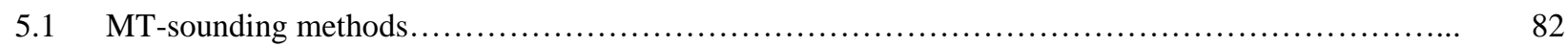

5.2 Variations in geomagnetic and telluric fields as a source of GIC ................................. 83

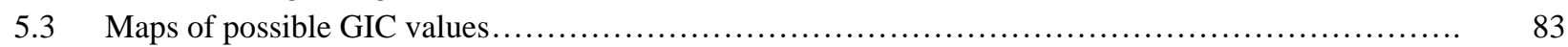

5.4 Transfer function method for assessing GIC in given systems during geomagnetic varia- 85

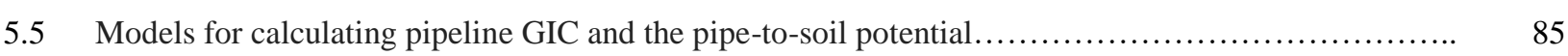

5.6. Influence of sharp irregularities of geoelectric conductivity on GIC ............................... 86

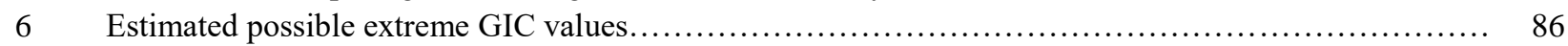

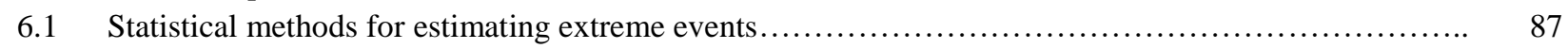

6.2 Estimated extreme values of variability in geomagnetic field and telluric fields...................... 87

$7 \quad$ PC index of geomagnetic activity and failures in power grids .................................... 87

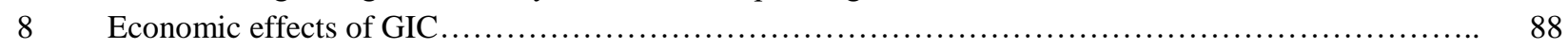

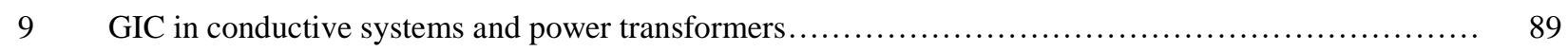

10 Development of physical and statistical models for assessing the risk from negative GIC effects 90

10.1 Statistical relationships between variations in the geomagnetic field, auroral electrojet, and geomagnetically 90 induced currents.

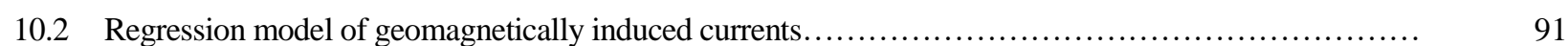

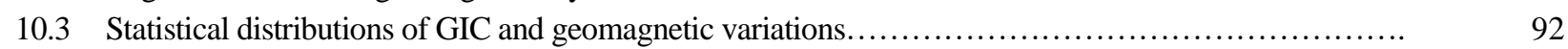

11 Forecast of space weather, auroral oval position, and risk for power grids with global MHD simula-

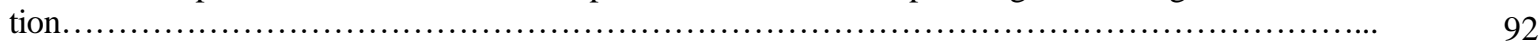

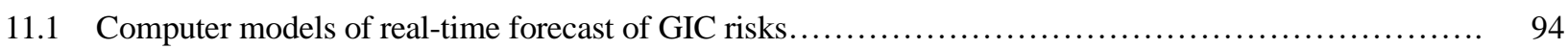

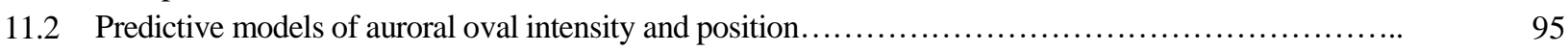

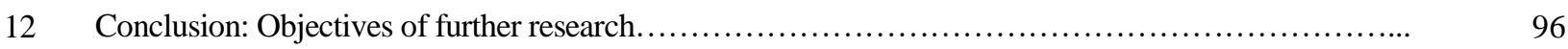

\section{NEGATIVE IMPACT OF SPACE WEATHER ON TECHNOLOGICAL SYSTEMS}

Research into the state of near-Earth space, called space weather (SW) for short, i.e. the state of electromagnetic fields, plasma, and particle fluxes in nearEarth space (NES), extends beyond purely academic interest as the number of problems associated with failures in satellite-borne and ground-based technological systems increases [Space Weather - Research Towards Applications in Europe, 2007]. Among these problems are failures in satellite and aviation systems, partial or total power outages, failures in signals from global navigation satellite systems (GPS, GLONASS), interference in radio communications [Space Storms and Space Weather Hazards, 2000; Extreme Space Weather: Impacts on Engineered Systems and Infrastructure, 2013]. The most active SW effects such as disturbances of the geomagnetic field and the ionosphere, excitation of geomagnetically induced currents (GICs) in conducting structures, failures in radio communications and navigation satellite systems, increasing corrosion in pipelines, etc. are observed at high latitudes [Space Weather, 2001].

At the same time, the more widely advanced technological systems are introduced, the more sensitive their failures and outages become for economy and life activity of mankind. Expansion of trunk power transmission lines (PTL) is accompanied by an increase in the occurrence rate of failures caused by GIC driven by geomag- netic storms and substorms [Boteler, 2001]. There are numerous examples of devastating impacts of SW events all over the world [Lanzerotti, 1979, 1983, 2001 ; Bolduc, 2002]. Variability of SW factors and their negative impact on the technological environment are a natural norm that cannot be avoided, but must be known and taken into account [Pirjola et al., 2005]. When addressing engineering problems, it is necessary to know SW characteristic parameters and the range of their variations in order to improve existing technical facilities and to properly develop new ones [Veeramany et al., 2016].

Space weather is generally determined by solar flares, coronal mass ejections, and high-speed plasma fluxes from solar holes (corotating interaction regions), which trigger geomagnetic storms and substorms. The total amount of energy released by a medium intensity magnetic storm is $\sim 1400 \mathrm{GW}$, which is almost double the capacity of all power plants in the United States. Extensive research on SW problems undertaken in the world is, on the one hand, defined by the fundamental scientific interest in the problem of studying solar-terrestrial relations and geophysical shells as a single dynamic system; on the other hand, by the need to ensure the stable operation of technological systems, radio communications, radar, and navigation.

\subsection{Power grids}

The frequency of solar plasma ejections into interplanetary space increases during solar maximum, but does not stop during solar minimum. The solar plasma ejections flying by Earth deform its protective magnetic field, causing amplification of electromagnetic fields 
both in near space and near Earth's surface [Love, 2008]. Variations in geoelectric currents induced in surface layers of the earth's crust are completed through grounded power systems, giving rise to GIC [Boteler, Pirjola, 2017, 2019]. In turn, GIC lead to voltage drops, overheating of power transformers, and loss of reactive power in high-voltage PTL [Pirjola, 1985a, b; Uspensky, 2017; Vakhnina et al., 2018]. To date, GIC have become a constant hazard for high-technology societies, posing a grave danger to regional high-voltage electric power networks, many of which cross national boundaries [Gaunt, 2016].

Modern power grids with extremely complex geometry, located up to high latitudes, are in fact a giant antenna, electromagnetically coupled with currents of Earth's ionosphere [Piccinelli, Krausmann, 2014]. In grounded power grids, currents up to $300 \mathrm{~A}$ were observed, while GIC with an intensity of only a few amperes is sufficient to affect the operation of a transformer [Overbye et al., 2013]. Although geomagnetic and ionospheric disturbances leading to excitation of GIC in conducting structures occur generally at auroral high latitudes [Myllys et al., 2014], it has recently been found that dangerous GIC values can be seen at middle and even low latitudes [Beggan et al., 2013].

Calculating possible GIC levels during typical and extreme magnetic storms, which can be used by network operators to take the necessary measures to reduce the risk of catastrophic consequences, is the most pressing challenge [Sokolova et al., 2021]. Solving the problems of minimizing the risk of occurrence and reducing the consequences of natural disasters requires clarifying the physical nature of some magnetospheric-ionospheric phenomena, and not just be limited to the engineering application of results of space physics to calculation of GIC in technological systems [Pulkkinen et al., 2017]. On the one hand, there is a need for a global planetary approach to the description of geomagnetic disturbances; on the other hand, to study GIC in each specific system [Hapgood, 2012; Viljanen, Tanskanen, 2011; Viljanen et al., 2013].

During industrial development, the length and interconnectedness of power lines sharply increase, which makes them more sensitive to the negative impact of GIC. In order to transmit a large amount of electric power over long distances, more and more extended power transmission lines are being built. However, such lines are especially affected by strong GIC. This circumstance makes electrical networks more and more susceptible to SW disturbances. For example, in Canada and the United States, GIC levels have become 2-3 times higher than those observed 20 years ago during magnetic storms of the same intensity [Molinski, 2002]. Moreover, failures in power grids can be caused not only by extreme SW disturbances, but also by premature aging of components of high-voltage transformers due to the cumulative effect of even moderate GIC, which are generally considered to be no-damage [Béland, Small, 2005]. The GIC impact can also be affected by network loading. For example, Wik et al. [2009] have shown that the July 13-14, 1982 magnetic storm would have had serious consequences but for favorable conditions in the power grid due to the low summer load.

Failures in PTL are the most obvious but not the only consequence of GIC. Unbalanced transformers with partially saturated cores increase the reactance and the content of harmonics of supplied power from electric power stations [Arrillaga et al., 1990]. Consequently, the efficiency of power distribution decreases, which may lead to a decrease in the power available to consumers. In extreme cases, electric power networks can become unstable and fail, causing large-scale power outages.

There are many examples of serious consequences of the SW impact on long-distance high-voltage electric power networks [Bozoki, 1996; Qiu et al., 2015]. GIC caused saturation, an increase in harmonics, overheating, and even damage to high-voltage transformers. The most intense currents (more than a hundred of A) were measured in neutral terminals of transformers at auroral latitudes during magnetic storms and substorms [Viljanen et al., 2014]. There is, however, no general rule on how strong GIC should be to pose a hazard to power grids as there are many types of transformers with different sensitivity to quasi-DC currents. Some power transformers require only a few amperes to be taken out of the linear mode [Vakhnina, 2012; Vakhnina et al., 2012; Vakhnina, Kretov, 2012a].

The constant expansion of high-voltage power networks, an increase in the connection between them, growth of the load, and transition to low-resistance power lines with a higher voltage lead to an increase in the probability of accidents during SW disturbances. However, catastrophic failures are not necessary to have a tangible economic impact on the functioning of wholesale electricity markets. Therefore, even if equipment for energy infrastructure is not destroyed during strong SW disturbances, GIC in regional power systems can still have a noticeable effect on the economy as a whole [Forbes, 2004].

\subsection{Cable lines, telephone and telegraph lines}

Through GIC, SW reveals itself in the operation of other technological systems - telegraph lines, submarine cables [Lanzerotti et al., 1995]. More than a century ago, the magnetic storm on June 17, 1915 disrupted telegraph services throughout most of the world. The GIC hazard to trunk and marine cable lines, telephone and telegraph lines was repeatedly confirmed later on [Anderson et al., 1974; Medford et al., 1981; Meloni et al., 1983; Boteler, Jansen van Beek, 1999].

\subsection{Railway equipment}

While in most of SW studies prominence is given to the impact on power networks, disruptions to the railway sector receive much less attention. Anomalies in train signaling and control systems associated with this phenomenon have, however, been documented [Liu et al., 2016; Eroshenko et al., 2010; Sakharov, et al., 2009]. Nonetheless, the mechanism of the impact of strong geomagnetic disturbances on the operation of railway au- 
tomation systems has not yet been clarified [Trishchenko, 2008]. Furthermore, railway systems rely on other potentially SW-affected technologies such as power supply, communications, positioning and time synchronization systems. Since during strong storms the impact of the disturbances is quite widespread and global, it is necessary to predict SW events and develop measures to reduce direct and indirect impacts of the disturbances on railway systems and services [Krausmann et al., 2015].

\subsection{Pipelines}

Space weather and related global electromagnetic disturbances pose a hazard to pipelines, especially those located in the zone of intense geomagnetic activity [Pulkkinen et al., 2001a, b; Gummow, Eng, 2002]. The effects of geomagnetic disturbances on pipelines are not instantaneous, but have a cumulative effect due to susceptibility to corrosion [Boteler, Cookson, 1986; Martin, 1993; Boteler, Trichtenko, 2015; Marshall et al., 2010]. Electrocorrosion is an electrochemical process that occurs when current flows from the pipe into the soil. To prevent corrosion, steel pipelines are covered with an insulating coating and equipped with a cathodic protection system. Cathodic protection of pipelines from electrocorrosion maintains a negative potential of the order of $-1 \mathrm{~V}$ with respect to the ground. During a magnetic storm in November 2004 on a gas pipeline in Finland, the pipe-to-soil potential ranged from $1.6 \mathrm{~V}$ to $4 \mathrm{~V}$ [Pirjola et al., 2003].

Under the GIC impact, the cathodic protection of pipelines, which maintains the negative potential of the pipe with respect to the ground, is distorted, thereby increasing sharply the corrosion rate and reducing the service life of pipelines. High-frequency $(50-60 \mathrm{~Hz})$ electric fields in pipelines can also be induced by nearby power transmission lines. To protect against GIC, pipelines are divided into shorter sections with insulating inserts. This reduces the extreme potential values between the pipe and the ground, but increases the number of non-zero potential sections, which increases the risk of corrosion.

The fundamental difference between pipelines and PTL is that the former are grounded continuously. A pipeline that is grounded at many points actually shunts the electric field induced on the surface. The electric field component parallel to a pipeline can induce currents in it up to 100 A [Viljanen et al., 2006b]. Near pipe ends, pumping stations, at junctions of pipes of different diameters, as the direction of the pipe is changed, the distribution of ground currents changes, the pipe-to-soil potential is redistributed, which can significantly affect the corrosion rate and the cathodic protection. Similar effects can also occur in places of local changes in ground conductivity [Viljanen, 1989; Sackinger, 1991; Fernberg et al., 2007], as well as when a pipeline moves from the ground to the sea. For pipelines located on the seabed (Nord Stream-2 type), the environment is well-conductive seawater. In such systems, GIC have not been detected; however, the GIC impact is to be expected in this case too.

Thus, the influence of geomagnetic variations should be taken into account when designing pipelines, choos- ing and organizing a cathodic protection system [Henriksen et al., 1978; Lundstend, 1992]. Since the GIC impact can appear both directly during the development of a disturbance and be cumulative, it is advisable to organize a system for continuous monitoring of GIC level and pipe-to-soil potentials at a number of intermediate stations and a system for continuous recording of magnetic variations. Information on the response of individual pipeline sections to magnetic disturbances during the operation of a pipeline will make it possible to choose optimal ground and cathodic protection circuits. To assess the degree of influence of geomagnetic and geoelectric fields on a specific system, it is wise to draw up a map of the probability of deviations of fields from a quiet level [Trichtchenko, Boteler, 2002]. Since in Russia the length of existing pipelines connecting the Arctic regions with midlatitudes is quite considerable, the problem of the negative GIC impact on pipelines deserves special attention.

\section{GEOMAGNETIC AND GEOELECTRIC FIELD VARIATIONS DURING VARIOUS SPACE WEATHER MANIFESTATIONS}

One of the most significant SW factors is the electrical GIC in technological conductor systems, which is associated with abrupt changes in the geomagnetic field $d B / d t$ [Knipp, 2015]. The most considerable magnetic disturbances on Earth's surface are caused by an extended auroral electrojet, which generates magnetic disturbances oriented in the latitudinal (NS) direction on Earth's surface. There are, therefore, widespread concepts and computational models in which the main source of GIC is the auroral electrojet intensity variations producing GIC in the longitudinal (EW) direction [Hakkinen, Pirjola, 1986; Viljanen, Pirjola, 1994; Boteler, Pirjola, 1998; Boteler et al., 2000]. Based on this fact, it was believed that magnetic disturbances pose a hazard mainly to the technological systems extended in the longitudinal direction [Pirjola, 1982].

Small-scale ionospheric current structures can nonetheless make a significant contribution to the rapid changes in the magnetic field, which are essential for the excitation of GIC [Viljanen, 1997; Viljanen et al., 2001]. They create almost isotropic disturbances of horizontal magnetic fields on Earth's surface. Data on the excitation and development of GIC in real conducting systems is of fundamental interest in terms of the fine structure of the development of disturbances and is of practical importance in terms of protecting technological systems from the SW impact.

Specific examples of SW disturbances of various types able to induce high-intensity currents in power transmission lines are given below. Analysis of individual events shows that the amplification of a large-scale auroral electrojet during the substorm expansion phase, Pi3/Ps6 and Pc5 geomagnetic pulsations, daytime sudden impulses, and nighttime sporadic magnetic impulses can lead to significant increases in GIC. Energy of such impulsive or quasiperiodic disturbances is much lower 
than that of magnetospheric storms or substorms; yet rapidly changing fields of such disturbances can cause GIC bursts of great intensity. In general, amplitudes of geomagnetic variations decrease with frequency, whereas induced electric field intensities are expected to increase with frequency. Accordingly, the GIC response to a geomagnetic disturbance, which is a combination of both factors, should have a maximum at some frequencies. Studies of GIC bursts have shown that this characteristic time scale is $\sim 2-10 \mathrm{~min}$, i.e. it falls into the frequency range of $\mathrm{Pc5} / \mathrm{Pi} 3$ pulsations, being in the lowfrequency interval of the ultra-low-frequency (ULF) band.

\subsection{Interplanetary shock waves}

Among the wide variety of MHD disturbances in NES, particular emphasis is given to the study of the storm sudden commencement (SSC), caused by the interaction of the interplanetary shock wave with the magnetosphere. The impulse action of the shock wave can bring a significant amount of energy and momentum into the magnetosphere for a very short period of time. Pulse SSC disturbances are precursors of strong geomagnetic storms. The shock action on the geomagnetic field has an important practical aspect as a source of GIC [Belakhovsky et al., 2017]. The GIC effect on power systems was observed at $d B / d t>100 \mathrm{nT} / \mathrm{min}$ [Kappenman, 1996]. Some power system failures were associated with the occurrence of SSC even before the onset of the magnetic storm main phase [Zhang et al., 2015]. For example, the destruction of the power grid transformer in New Zealand [Béland, Small, 2005] coincided with SSC. While the SSC associated disturbance $\Delta B$ is rather weak as compared to $\Delta B$ during the storm or substorm main phase, $d B / d t$ can be great enough to induce hazardous GIC in power grids. At the same time, the magnetic field variation $d B / d t$ during SSC is not unambiguously related to the intensity of the subsequent magnetic storm [Fiori et al., 2014].

Due to the global nature of the interplanetary shock wave action on the geomagnetic field, $d B / d t$ at the equator may be comparable to the levels in high-latitude regions [Carter et al., 2015]. At near-equatorial latitudes, the influence of the equatorial electrojet may turn out to be significant for the development of induction effects. During SSC on February 17, 1993, peak values of the geoelectric field were as high as $300 \mathrm{mV} / \mathrm{km}$ at a geomagnetic latitude of $\sim 5^{\circ}$ [Doumbia et al., 2017].

A typical example is the burst in the system for GIC detection in power transmission lines on the Kola Peninsula during SSC on March 17, 2015 (Figure 1) [Pilipenko et al., 2018a]. At the moment of the interplanetary shock wave action on Earth's magnetosphere, which appeared on Earth's surface as an SSC pulse at $~ 06$ UT, a sudden burst of GIC occurred at stations of the Nord Transit system. Variations in GIC at VKH are similar to those in the derivative of the magnetic field $d X / d t$ at the nearby magnetic station IVA ( 10 nT/s). The amplitude of SSC driven GIC variations $(\sim 55 \mathrm{~A})$ is approximately two times higher than that of GIC $(<30 \mathrm{~A})$ during subse-

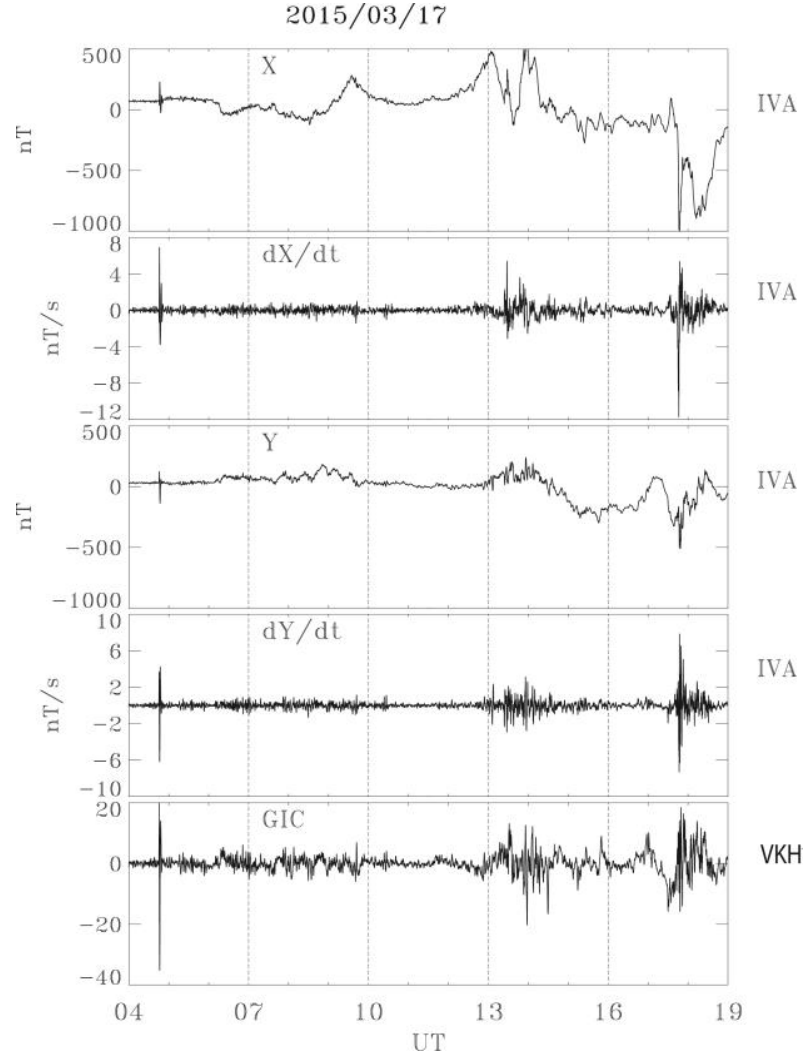

Figure 1. Variations in the magnetic field ( $X$ component) at IVA, derivative of $d X / d t$; the same for the $Y$ component; GIC values at the VKH substation during the March 17, 2015 magnetic storm

quent intensifications of the substorm, although the SSC amplitude $(\sim 200 \mathrm{nT})$ is lower than that of the magnetic bay associated with the substorm $(\sim 1000 \mathrm{nT})$. This is consistent with a higher amplitude of $d X / d t$ during SSC compared to that observed during the intensification of the substorm at $\sim 13 \mathrm{UT}$ and $\sim 17 \mathrm{UT}$.

Thus, such an SW phenomenon as SSC can produce very high $d B / d t$ at latitudes from the auroral region to the geomagnetic equator. For PTL operators, SSC appears as a short circuit in the line. The SSC impact may be a significant factor affecting stability of power transmission.

\subsection{Auroral and polar substorms}

Unlike planetary disturbances such as magnetic storms, substorms develop only in the nightside magnetosphere. During one typical 11-year solar cycle, strong magnetic storms can be observed on average for $~ 200$ days. If a magnetic storm is a relatively rare event (approximately several tens of strong and moderate storms during the year depending on solar cycle phase), substorms of different intensity occur on average once every three days. A substorm is a kind of "spacequake", the development of which outwardly resembles an earthquake. As in seismology, the energy coming from the solar wind and interplanetary magnetic field (IMF) and accumulating in the magnetotail is spontaneously released during the substorm expansion phase. If a substorm can develop in isolation, substorm activations will 
surely occur against the background of a magnetic storm. There are no physical and qualitative difference between an isolated substorm and a substorm during a storm, except for increased amplitudes of the latter.

As an example of a substorm during a storm, we present observations made during a magnetic storm on March 17, 2013 [Belakhovsky et al., 2018]. It began at $\sim 06$ UT, when the solar wind velocity sharply increased from $\sim 400$ to $\sim 650-700 \mathrm{~km} / \mathrm{s}$, and IMF became antiparallel to the geomagnetic field, which provided reconnection of fields and a long-term energy input into the magnetosphere. Amplitude of the $|D s t|$ index, which characterizes the magnetic storm intensity, was as high as $\sim 120 \mathrm{nT}$ at the maximum of the storm ( 21 UT). The auroral $A E$ index, which characterizes the auroral electrojet intensity, sharply increased to $\sim 1000 \mathrm{nT}$. In total, on March 17 the $A E$ index showed the occurrence of three auroral activations.

Several noticeable bursts of GIC intensity were recorded (Figure 2) in the Nord Transit PTL. The peak amplitude of GIC variations at the terminal station VKH was as high as $\sim 70 \mathrm{~A}$. To the beginning of the $A E$ increase during each of the activations correspond bursts of $|d \mathbf{B} / d t|$ and GIC intensity (at $\sim 06, \sim 08, \sim 16$ UT). There is however no unambiguous relationship between substorm intensity and GIC value. Comparison of amplitudes of magnetic disturbances for the NS component $\Delta X$ and the EW component $\Delta Y$ with amplitudes of derivatives $|d X / d t|,|d Y / d t|$ and full derivative $|d \mathbf{B} / d t|$ shows that although $\Delta X>>\Delta Y,|d X / d t|$, and $|d Y / d t|$ prove to be comparable, i.e. small $\Delta Y$ do not mean smallness of $d Y / d t$

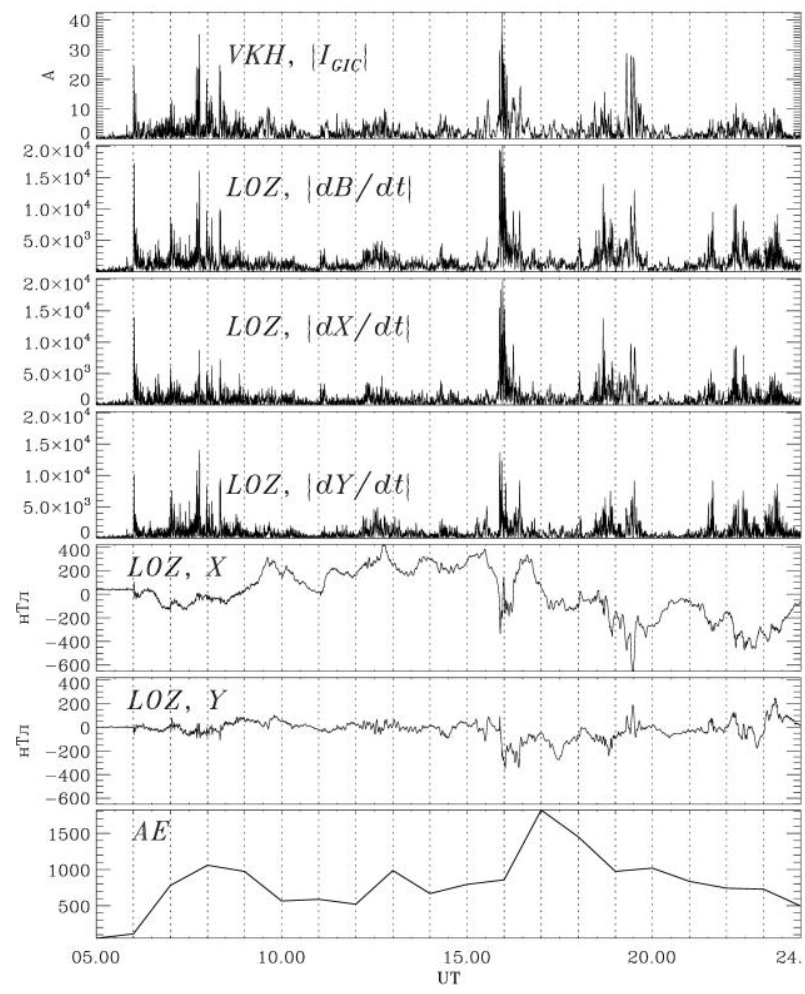

Figure 2. Variations in the GIC amplitude at VKH during the March 17, 2013 magnetic storm, in the geomagnetic field variability at $\mathrm{LOZ}$, in the magnetic field at $\mathrm{LOZ}(X, Y$ component), and in the $A E$ index and make a commensurate contribution to the increase in the magnetic field variability $|d \mathbf{B} / d t|$. Thus, during a substorm the geomagnetic field varies not only in strength, but also in direction, and its variations cannot be considered as driven only by variations in the westward auroral electrojet intensity. Further studies [Kozyreva et al., 2018] have shown that the regions of maximum magnetic disturbance $\Delta \mathbf{B}$ and the greatest field variability $|d \mathbf{B} / d t|$ are spaced apart.

Unlike typical auroral substorms, the center of development of polar substorms is at very high geomagnetic latitudes $74^{\circ}-75^{\circ}$. Despite the high intensity of such substorms (magnetic bays up to $1000 \mathrm{nT}$ ), GIC observed in this case are not very high $(<10 \mathrm{~A})$. The reason is that the epicenter of the $d B / d t$ increase during polar substorms is higher than latitudes of power systems.

The conditional threshold of the possible electromagnetic impact on power systems (high $d B / d t$ ) is near the $50^{\circ}-55^{\circ}$ geomagnetic latitude, while the position of the threshold is associated with the motion of the auroral oval [Ngwira et al., 2018].

\subsection{Local pulse disturbances of the geomag- netic field}

When considering SW impacts on power transmission lines, it is usually assumed that the extreme geomagnetic and geoelectric fields are spatially homogeneous throughout the power system. However, spatially localized pulse geomagnetic disturbances are often observed against the background of an overall increase in the geomagnetic field strength during substorms [Engebretson et al., 2019]. The structure of a local geoelectric field during these extreme disturbances can differ greatly from those of globally and regionally averaged geoelectric fields [Pulkkinen et al., 2015; Ngwira et al., 2015]. An example of global geoelectric fields exhibiting localized bursts at geomagnetic stations in Europe and the United States during the March 13, 1989 event is given in Figure 3. The telluric field disturbance of $\sim 5.9 \mathrm{~V} / \mathrm{km}$ turns out to be sharply localized. The physical processes that determine the generation of these extreme values are still not clearly understood. The occurrence of local increases in the geoelectric field suggests that intense GIC can occur not only at high, but also at middle latitudes, as the auroral electrojet shifts to middle latitudes under strongly disturbed geomagnetic conditions. Irregularities in the structure of the earth's crust conductivity (for example, the transition from the sea to the land) can also lead to local amplifications of the geoelectric field.

Further studies [Pulkkinen et al., 2015] have shown that under strong disturbances against the background of a regular increase in the geoelectric field there are local irregularities associated with characteristic features of the conductivity distribution; in this case, significant isolated bursts of the electric field may occur.

In the October 29, 2003 event, for instance, the maximum electric field in a relatively "homogeneous" situation was $3.1 \mathrm{~V} / \mathrm{km}$, and a local extremum of $\sim 11.4 \mathrm{~V} / \mathrm{km}$ developed at the station Narsarsuaq in Greenland. 


\section{Geoelectric field distribution on 1989-03-13 21:46 UT. Max. IEI: 5.91 V/km.}

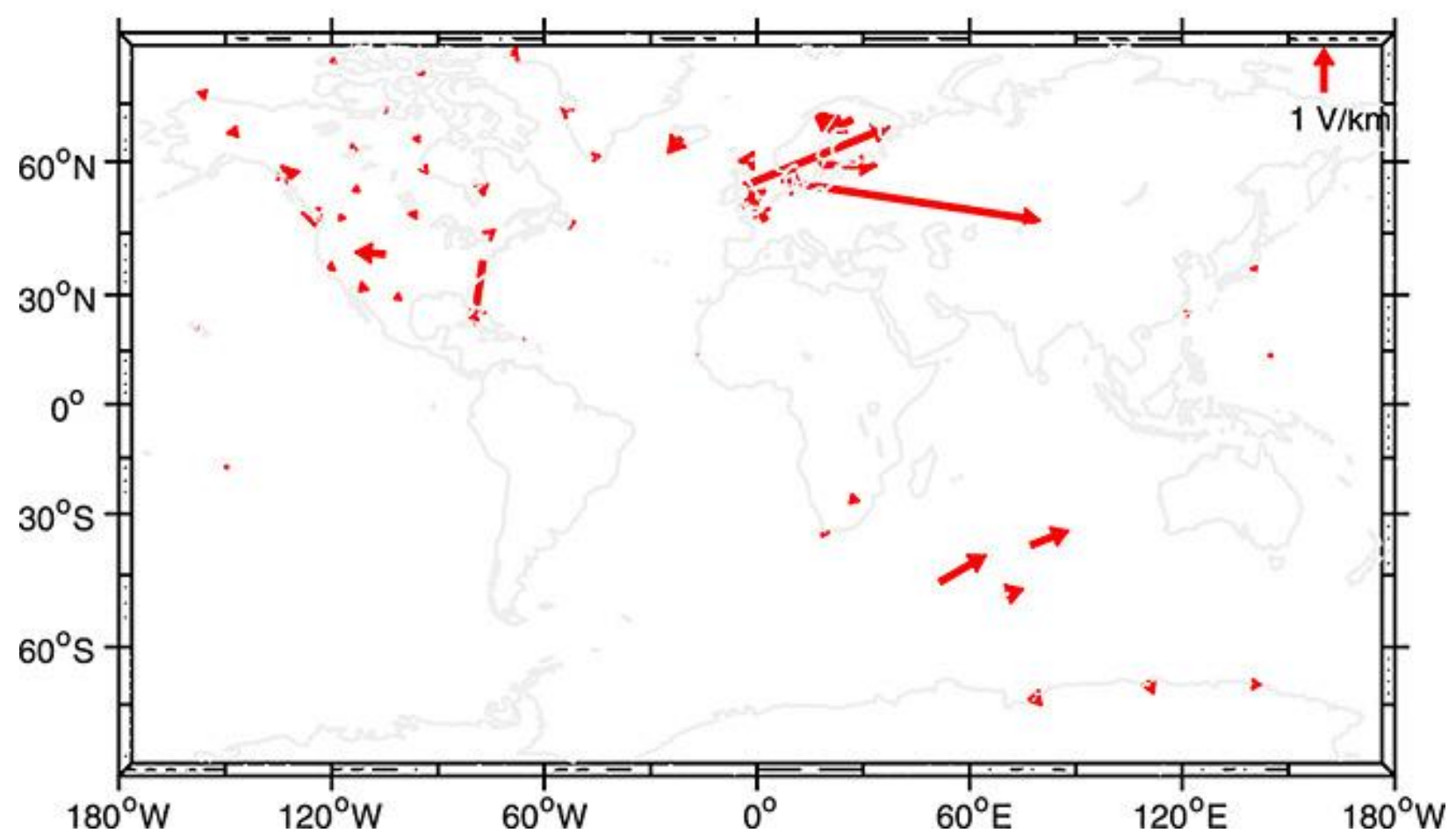

Figure 3. Planetary distribution of the disturbed geoelectric field vector during the March 13, 1989 storm from [Ngwira et al., 2015]

Physical reasons for such local increases in the electric field require additional research.

\subsection{Substorm fine structure: series of Ps6/Pi3 magnetic pulses}

After the substorm expansion phase, intense irregular Pi3/Ps6 pulsations - a quasi-periodic sequence of pulses 5-20 min long — are often observed. These pulsations are not harmonic oscillations, but a series of magnetic disturbances with steep fronts. Ps6 pulsations are most pronounced in the $Y$ component, and the field variability is also the greatest in the $Y$ component, i.e. $|d Y / d t|>>|d X / d t|$ and $|d Y / d t|>>|d Z / d t|$. Due to the steep fronts of these pulses, the time derivative of the magnetic field reaches $\sim 20 \mathrm{nT} / \mathrm{s}$. The irregular quasiperiodic Ps6 magnetic disturbances are often accompanied by auroral phenomena - omega band auroras.

Ps6 pulsations cause quasiperiodic bursts of GIC. While amplitudes of quasiperiodic Pi3/Ps6 disturbances are lower than the magnetic bay during substorms, the rapidly changing fields of such disturbances can generate significant GIC bursts [Viljanen, 1998; Apatenkov et al., 2004; Belakhovsky et al., 2018; Yagova et al., 2018]. In substorms with such pulsations, GIC peaks not at the beginning of a substorm, but during one of the subsequent Ps6 pulses. Belakhovsky et al. [2019] and Apatenkov et al. [2020] have described events in which geomagnetic Ps6 pulsations excited GIC in PTL with an intensity up to $120 \mathrm{~A}$.

Current systems in the ionosphere responsible for the pulse geomagnetic disturbances and the GIC bursts can be localized vortex structures [Dimmock et al., 2019]. A special technique for analyzing data from a 2D network of magnetometers has been developed to identify localized small-scale vortex structures [Chinkin et al., 2020]. Analysis of the June 29, 2013 event [Chinkin et al., 2021] has shown that in fact the source of GIC bursts in PTL in northwestern Russia is not the global intensification of the ionospheric electrojet, but the appearance of short-lived small-scale structures in ionospheric currents. The results of this technique, presented in Figure 4, indicate that extreme GIC bursts (>200 A) during early morning hours are unambiguously linked to pulses comprising Ps6 pulsations - a sequence of localized ( 200-250 km radius) eddy currents supported by jets of field-aligned magnetospheric currents having alternating direction with a density up to $\sim 5 \mathrm{~A} / \mathrm{km}^{2}$ and propagating in azimuth eastward (towards the Sun).

Small-scale vortex disturbances of this type, by analogy with meteorological phenomena, can be qualitatively thought of as cosmic tornadoes [Pilipenko et al., 2018b]. It is precisely such tornadoes that have caused the most intense GIC in the Nord Transit system for eight years of observation.

\subsection{Pc5 pulsations}

During early morning hours at auroral and subauroral latitudes there are quasi-monochromatic Pc5 pulsations with periods $\sim 3-5 \mathrm{~min}$ and up to several hours long. An example of these pulsations on October 8,2015 , recorded at stations in Scandinavia, is given in Figure 5 from [Kozyreva et al., 2020]. Amplitudes of $X$ 


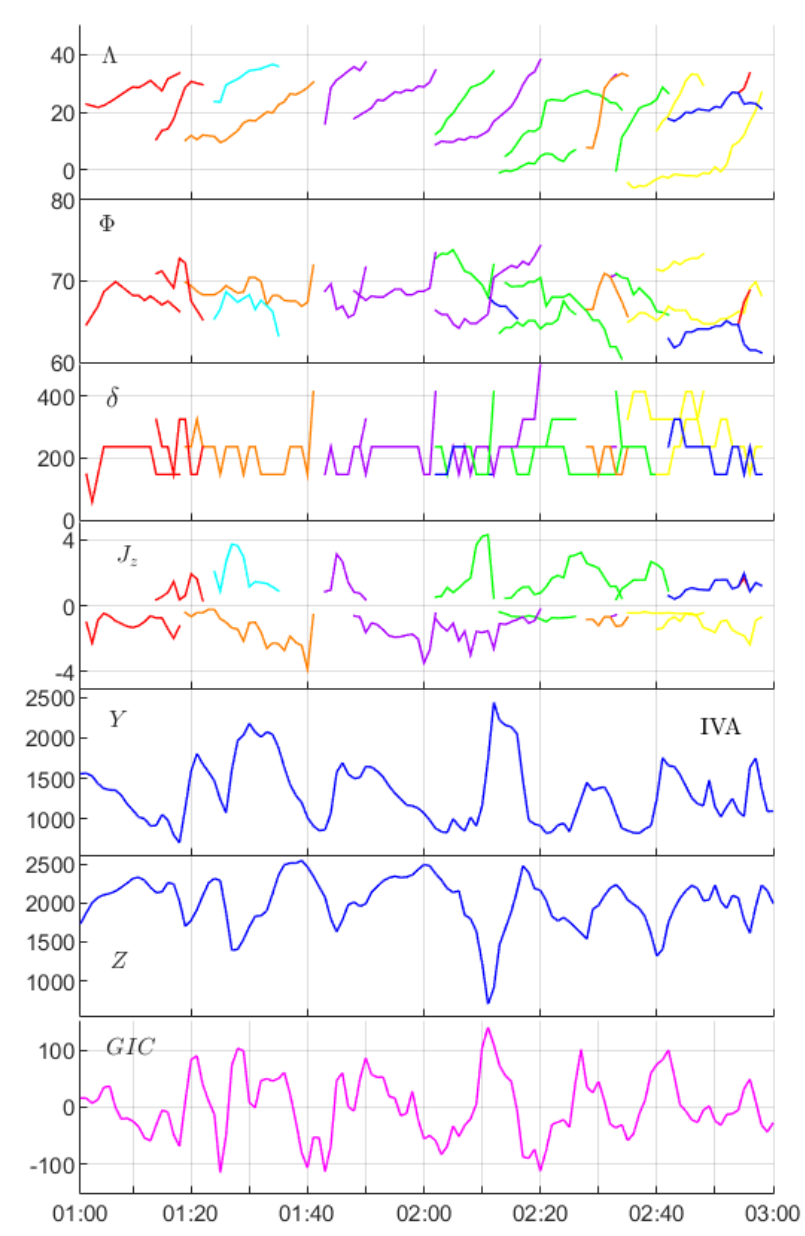

Figure 4. Result of the analysis of data from the 2D magnetometer network IMAGE in order to identify localized vortex structures in ionospheric currents on June 29, 2013. From top to bottom: longitude of vortex centers; latitude of their centers; vortex scale; field-aligned current density at a vortex center; magnetic disturbance at IVA ( $Y$ and $\mathrm{Z}$ components; GIC at VKH

and $Y$ pulsations are comparable (peak-to-peak amplitude up to $\sim 200 \mathrm{nT}$ ), while the peak in the $Z$ component is larger (up to $\sim 600 \mathrm{nT}$ ), but more localized in latitude. The same relations are valid for the field variability $|d Z / d t| \sim 15 \mathrm{nT} / \mathrm{s}$, which is approximately two times higher than $|d X / d t|$ and $|d Y / d t|$. Due to the high magnetic variability in the geomagnetic field of Pc5 pulsations, the amplitude of GIC they generate is as high as $\sim 12 \mathrm{~A}$.

Failures in electrical equipment can be caused by premature aging of some parts of high-voltage transformers due to the cumulative effect of even moderateintensity GIC. At the same time, due to hysteresis phenomena in transformers, even GIC of the order of several Amperes can pose a potential hazard to the proper operation of relay protection. Therefore, the long-term existence (several hours) of moderate-intensity GIC, generated by geomagnetic Pc5 pulsations, may be even more hazardous for the long-term operation of networks than short-term and intense GIC bursts during onsets of substorms and storms. Long-term wave activity of the Pc5 range can also lead to such cumulative effects as pipeline corrosion [Lehtinen, Pirjola, 1985].

Global Pc5 pulsations can be especially effective sources of GIC. Pc5 pulsations of this subtype have amplitudes almost by an order of magnitude higher than typical Pc5 pulsations, occur in a wider latitude range, and are excited during the magnetic storm recovery phase at high solar wind velocities [Marin et al., 2014]. The actual driver of GIC - the telluric electric field $E$ - can be estimated for a given magnetic field $B(f)$ varying with frequency $f$ over a homogeneous ground with conductivity $\sigma$ from the boundary impedance condition (in the plane wave approximation) $E / B=\sqrt{\omega / \mu \sigma}$. For Pc5 pulsations with a frequency $\omega=0.01 \mathrm{~s}^{-1}$ for the average conductivity of Earth's surface $\sigma=10^{-4} \mathrm{~S} / \mathrm{m}$, this ratio yields $E[\mathrm{mV} / \mathrm{km}] / B[\mathrm{nT}] ; 12.6(\mathrm{mV} / \mathrm{km}) / \mathrm{nT}$. For global Pc5 pulsations with an amplitude $B=100 \mathrm{nT}$, the expected telluric field may be as great as $E \sim 1.2$ $\mathrm{V} / \mathrm{km}$. This is almost the same value as that obtained in [Lucas et al., 2018] for the extreme telluric field, which could be observed once a century in the United States.

\subsection{Statistical features of geomagnetic field variability $d B / d t$}

Statistically spatio-temporal geomagnetic variations according to data from the network of stations may be characterized by a structural function

$$
S^{2}(\Delta \mathbf{r}, \tau)=\langle|B(t, \mathbf{r})-B(t+\tau, \mathbf{r}+\Delta \mathbf{r})|\rangle,
$$

where $\langle>$ means time averaging. For white noise, the time structure function abides by the law $S_{2}(t) \sim$ const; and for the diffuse Brownian motion, by $S_{2}(t) \sim t$. In the general case, the scaling of a self-similar process with exponent $H$ obeys the law $S_{2}(t) \sim t^{2 H}$. This method has been applied to data from the IMAGE network to identify structural features of geomagnetic variations on scales ranging from 100 to $1000 \mathrm{~km}$ [Pulkkinen et al., 2006]. For magnetic field disturbance fluctuations for both horizontal components, the structure function was power-law - its linear growth was observed in the loglog scale. Power laws of statistical characteristics prove to be a characteristic feature of geophysical processes, which are likely to be dynamic systems. Nonetheless, for the field variability $d B / d t$ a significant change in the dynamics of fluctuations was found on scales $\sim 80-100$ s. Here, the magnetic field time derivative undergoes a transition from correlated (linearly growing structure function) to uncorrelated (transition to const) temporal behavior. Moreover, $S(\Delta r, 0)$ demonstrates a slow power-law growth with increasing spatial scales. This spatio-temporal behavior of $d B / d t$ on time scales over $100 \mathrm{~s}$ resembles uncorrelated white noise. This result imposes restrictions on the possible horizon of forecast of the magnetic field time derivative.

The main difficulty in predicting GIC is the high variability of scales of the ionospheric current producing GIC. The diurnal variation in the occurrence of large GIC values has a clear maximum near magnetic midnight, which corresponds to the time of occurrence of substorms. Evidently, increased geomagnetic activity is a necessary condition for the occurrence of strong GIC, yet a large magnetic disturbance value $\Delta B$ does not necessarily mean that $d B / d t$ is also high, and vice versa. As shown by 

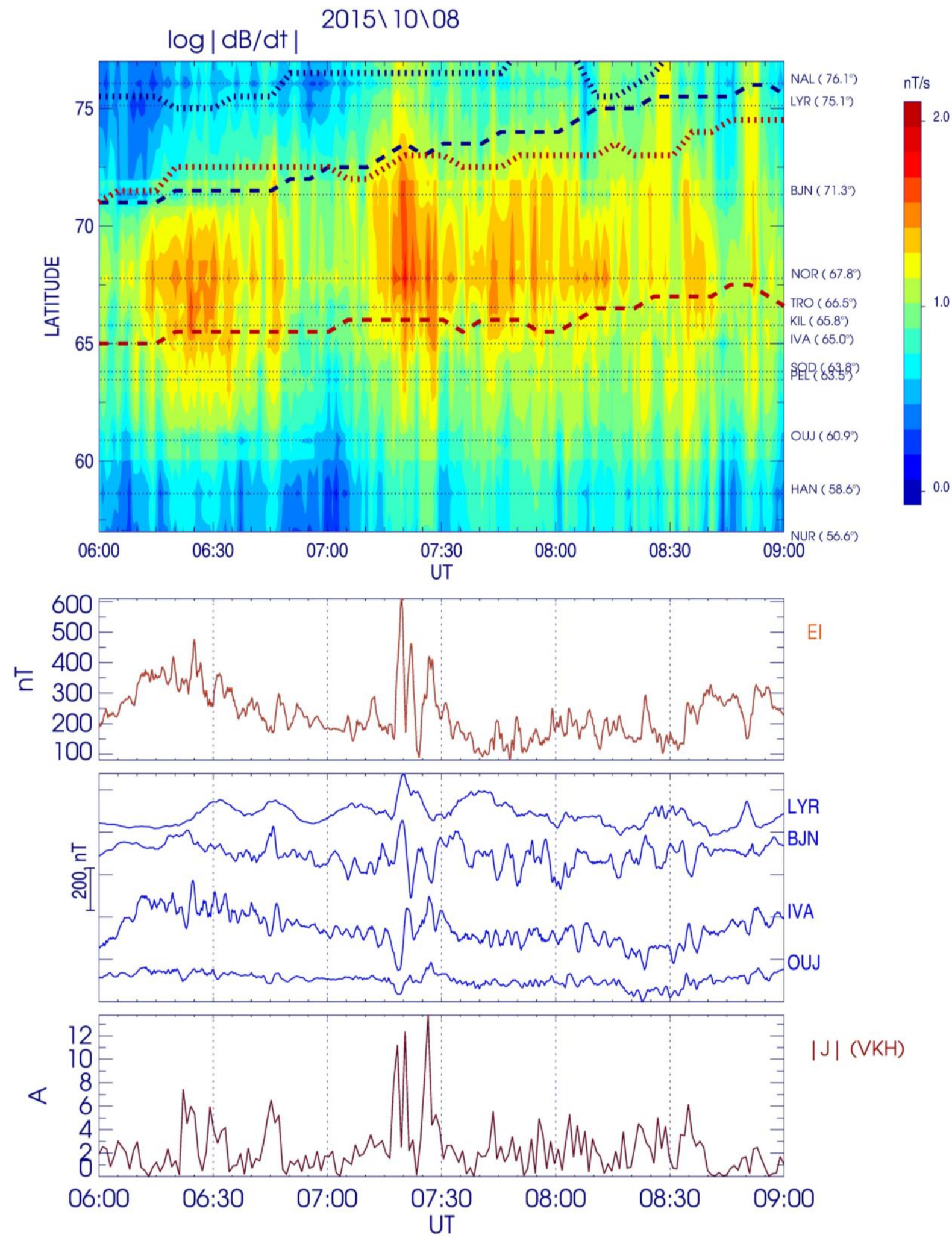

Figure 5. Magnetic keogram (distribution of the geomagnetic field variability $d B / d t$ over latitude) of Pc5 pulsations recorded on October 8, 2015. The upper of the three panels at the bottom shows variations in the local auroral electrojet index EI. Below are geomagnetic variations ( $X$ component) at stations of the IMAGE network and the GIC amplitude $|J|$ at VKH

Viljanen et al. [1998], high $d B / d t$ observed is almost always linked to the westward electrojet. The spread of directions of the horizontal vector of the time derivative $(d \mathbf{B} / d t)$ appears to be much wider than the spread of the horizontal magnetic disturbance vector $(\Delta \mathbf{B})$, thereby indi- cating the presence of rapidly changing ionospheric current structures with scales of $100 \mathrm{~km}$ or smaller, superimposed on background variations of the westward electrojet [Viljanen et al., 2006a; Viljanen, Tanskanen, 2011].

The key value determining GIC is the horizontal 
magnetic field derivative $d \mathbf{B} / d t$ [Oliveira, Ngwira, 2017]. An important question is how closely $|d B / d t|$ is related to $|\Delta B|$. Knowledge of such relations will help to increase the capability of predicting GIC events because considerable advances have been made in predicting amplitudes of magnetic disturbances $|\Delta B|$ or indices calculated from them (e.g., $A E$ ). The highest $d B / d t$ is noted soon after the onset of the substorm expansion phase, although many events later also have higher derivatives. Statistically, the $d B / d t$ maximum occurs at the fifth minute after the onset of the substorm at geomagnetic latitudes of $<72^{\circ}$ [Viljanen et al., 2006a]. This distribution has, however, a long tail up to tens of minutes. The presence of such long tails in the distribution is characteristic of complex multiscale systems. The time of occurrence of maximum $d B / d t$ after the onset of a substorm increases with latitude from $\sim 15 \mathrm{~min}$ at $\Phi \sim 56^{\circ}$ to $\sim 45 \mathrm{~min}$ at $\Phi \sim 75^{\circ}$. In this case, substorms during a storm can have twice the maximum amplitude of $|d B / d t|$ at all latitudes as compared to isolated substorms.

Statistical laws are somewhat different for isolated substorms and substorms during storms. The latitudinal maximum of $|d B / d t|$ during a storm is $\sim 5^{\circ}$ southward than for an isolated substorm, which reflects the well-known equatorward shift of the auroral oval as magnetic activity increases. The median time of occurrence of $\max (|d B / d t|)$ increases as a function of latitude for substorms of both types. Analysis of the relations between $\max (|\Delta B|)$ and $\max (|d B / d t|)$ for substorms of different types shows a high correlation between $|\Delta B|$ and $|d B / d t|-\sim 0.75$ for isolated substorms and $\sim 0.66$ for substorms during a storm. The regression curve slope is almost the same for substorms of both types, indicating that the mechanism responsible for disturbances of $\Delta B$ and $d B / d t$ during substorms does not depend on the presence of a magnetic storm.

The clear majority of the $\max (|d B / d t|)$ values are associated with the westward electrojet. The scatter of the $d B / d t$ values means that the rapid changes not always involve the amplification of the electrojet, but often smaller-scale ionospheric structures. The eastward electrojet dominates in late afternoon at $\sim 13-21 \mathrm{LT}$; the westward one, at $\sim 01: 30 \mathrm{LT}$. The diurnal variation in mean $d B / d t$ exhibits an increase during nighttime hours, which is consistent with the electrojet intensity variation. However, the pronounced morning maximum of $d B / d t$ near $05 \mathrm{LT}$ has no analogue in the diurnal variation of the electrojet intensity. The probability of occurrence of large $d B / d t$ values in the vicinity of the eastward electrojet is low.

\section{FAILURES IN TECHNOLOGICAL SYSTEMS CAUSED BY GIC}

\subsection{Malfunctions in the operation of indus- trial transformers at auroral latitudes}

GIC excited by abrupt changes in the geomagnetic field are hazardous, first of all, to transformer substations of high-voltage power transmission lines [Trishchenko, 2008]. Since GICs have a very low frequency as compared to the industrial frequency $50-60 \mathrm{~Hz}$, the flow of a quasi-DC current through transformer windings leads to saturation of magnetic cores of transformers. The constant current component in a power transformer also appears when it is switched on; therefore, power transformer protection relays are usually adjusted so that not to react to the constant current component. As a result, conventional relay protection will not react to GIC saturating the transformer, and it will simply burn out. In history there are cases of damage to power transformers by GIC during strong magnetic storms [Gaunt, Coetzee, 2007], when all over the world relay protection systems were activated and blackouts in power transmission lines occurred [Boteler et al., 1989; Kappenman, 2003, 2005; Pulkkinen et al., 2003, 2005]. Recovery of power systems after power outages can take from several hours to several months (due to the lack of standby power transformers in many power systems). This is to cause a real collapse for modern humanity, too dependent on modern technology and vulnerable to disasters of this kind.

The most intense GIC (up to hundreds of Amperes) and electric fields in Earth's surface layers $(>10 \mathrm{~V} / \mathrm{m})$ are excited at auroral latitudes during magnetic storms and substorms [Boteler, 2001]. However, accurately estimating GIC in power transmission lines during a magnetic storm requires knowledge of the earth's crust surface layer conductivity and the PTL geometry. During the development of a storm or a substorm against the background of relatively smooth regularities, extreme bursts of the disturbance amplitude are observed. From the point of view of ensuring the stable operation of a power grid, these extreme events can be the most dangerous. For example, magnetic field variations over time with $d B / d t=1 \mathrm{nT} / \mathrm{s}$ induced a current of the order of several Amperes in Finnish high-voltage networks; and variations with $d B / d t>40 \mathrm{nT} / \mathrm{s}$ led to malfunctions in the operation of Scandinavian energy networks [Viljanen, Pirjola, 1994]. During magnetospheric disturbances, multiple cases of excitation of power frequency harmonics in neutrals of high-voltage autotransformers were detected, which indicates an overload of transformers, a shift in their operating point, and a threat to the stable operation of a power grid [Sivokon et al., 2011]. Here are some examples of catastrophic consequences of strong magnetic storms that occurred in different countries.

The March 13, 1989 magnetic storm caused power transformer disruption and a total blackout in HydroQuébec's electricity transmission system in Canada [Thomson et al., 2010]. The cost of damage to this system alone was about $\$ 13$ million [Bolduc et al., 1998, 2000; Bolduc, 2002]. This accident left more than six million people without electricity for eight hours. If such a storm affected the northeastern United States, the economic damage could exceed $\$ 10$ billion [National Research Council, 2008], not counting serious social upheavals. This storm is responsible for the overheating of a power step-up transformer and its outage at the Salem Nuclear Power Plant (USA). According to [Kappenman, 2010], the GIC that caused the transformer to fail was $\sim 95$ A. Since the region covered by the geomagnetic storm is large, distortions occur almost simultaneously in many transformers. The result may be a 
strong, rapidly increasing cumulative effect. During the Hydro Quebec event (Canada), it took only $1.5 \mathrm{~min}$ from the initial failure to the total blackout. Fortunately, this event did not spread beyond the borders of Quebec Province. However, if the storm had developed during the peak load, the cascade of failures would have spread down to Washington, D.C. [Guillon et al., 2016]. On the day of the blackout in Quebec, five power lines $(130 \mathrm{kV})$ were cut off in Sweden, and at 21.20 UT GIC caused a rotor of one of the generators at the nuclear power plant to overheat [Wik et al., 2008].

On April 29, 1994, shortly after the onset of the strong geomagnetic storm, a powerful step-up transformer was completely destroyed at the Maine Yankee Nuclear Power Plant.

The strong magnetic storm on October 30, 2003 caused failures in the Swedish power grids; the total blackout lasted from 20 to 50 min [Pulkkinen et al., 2005]. During the substorm sudden commencement, the power grid was damaged so much that Malmö, the largest city in southern Sweden, experienced power outages for an hour. The geomagnetic field variability was as great as $\sim 10 \mathrm{nT} / \mathrm{s}$ in most of Sweden. At the magnetic station Abisko, $d B / d t$ was as high as 23 $\mathrm{nT} / \mathrm{s}$. These disturbances triggered protection circuits of the high-voltage power transmission line, which led to malfunctions in its operation in northern Sweden. In southern Sweden that time, the $d B / d t$ variability was rather low. How failures in high voltage power transmission lines in northern Sweden caused power outages in Malmö in southern Sweden (at geomagnetic latitudes $55^{\circ}-60^{\circ}$ ) remains unclear.

During a magnetic storm in November 2003, 15 transformers failed and were damaged due to internal heating in the trunk high-voltage power transmission system in South Africa, which was associated with the excitation of GIC by geomagnetic disturbances [Gaunt, Coetzee, 2007; Kappenman, 2005].

\subsection{GIC at middle and low latitudes}

Power grids at midlatitudes seem not to be threatened by GIC, yet this is not the case. Sudden jumps in reactive load and failures in the operation of transformers of networks of Great Britain [Erinmez et al., 2002], France [Kelly et al., 2017], and Spain [Torta et al., 2014], which were caused by GIC, were recorded. Scotland's power system ran into problems during a magnetic storm in October 2003, when GIC increased to 40 A. During this storm, telluric electric fields were 50 times greater than under geomagnetically quiet conditions [Thomson et al., 2005; McKay, Whaler, 2006]. The impact of geomagnetic disturbances on the operation of power transmission lines has been extensively studied and modeled in New Zealand [Divett et al., 2017, 2018; Rodger et al., 2017]. Recording GIC in Japan has shown the presence of a relationship between the intensity of geomagnetic disturbances during magnetic storms and the GIC intensity [Watari et al., 2009]. Research has begun on the potential risk of GIC in extended power transmission lines in South Africa [Ngwira et al., 2008]. In Brazil, during the November 7-10, 2004 storm at power transmission line substations, GIC was as strong as 15 A [Trivedi et al., 2007]. Circumstances of these events suggest that equipment failures in all these cases were caused by geomagnetic processes.

\subsection{Failures in the operation of railway equipment}

Historically, the first reported event of railway signaling disruption was the storm on the New York Railway on May 13, 1921, in the fourth year after the maximum of solar cycle 15 [Love et al., 2019]. A prelude to this magnetic storm was a double flare on the solar limb, visible even to the naked eye [Hapgood, 2019]. During the storm, auroras were observed on the east coast of the United States and even in California. In the morning of May 15, the alarm system at the central station in New York failed, then a control tower caught fire, and the fire destroyed the entire railway station. During the same storm, a telephone station in Sweden caught fire, and the storm damaged telephone, telegraph, and cable communications throughout much of Europe.

An example of modern accidents is the storm of July 13-14, 1982 with $D s t=-325 \mathrm{nT}$, when failures in railway automation were observed in the south of Sweden [Wik et al., 2009]. On the railway, there were problems with light signaling: the signal traffic light switched between red and green light for no apparent reason. Since the battery voltage in the alarm relay control system is $3-5 \mathrm{~V}$, the additional voltage produced by the geoelectric field is highly likely to cause malfunction in the relay system. This assumption is consistent with the estimates of the induction electric field of the order of 4-5 V/km, obtained by modeling with a two-layer model of Earth's conductivity.

In the Russian Federation, a number of works have been carried out to study the relationship of anomalies in the operation of railway signaling with geomagnetic disturbances. The statistical relationship between the geomagnetic activity level and the duration of failures in automation systems of the Siberian Railway in 2004 was examined [Kasinsky et al., 2007; Ptitsyna et al., 2007, 2008]. Analysis of the anomalies listed in reports and journals of railway services has shown that approximately $45 \%$ of the anomalies were not deliberately caused by geomagnetic factors. These cases were omitted; and for the remaining anomalies it has been found that the total daily duration $T$ of anomalies in all sections of the road changes as a geomagnetic storm develops. Upon reaching the peak of geomagnetic activity, $T$ increases $\sim 3$ times. There is a correlation between $T$ and the local index of geomagnetic activity. In particular, for two superstorms on July 17 - August 2 and November 5-12, 2004, the correlation coefficient was rather high $(0.83$ and 0.71 respectively).

Failures in automation systems of the Northern Railway have been documented [Belov et al., 2005]. When analyzing failures in alarm systems during 16 strong geomagnetic storms over the period 1989-2005, almost each storm has been found to cause anomalies in the operation of signaling automation [Eroshenko et al., 2010]. The local time distribution of the anomalies ob- 
tained in the work (Figure 6) is consistent with the known distribution of periods of GIC development [Vorobev et al., 2019]. The failures in automation systems, in particular false alarms of traffic lights, were attributed to induction of an electric field to rails across the track, which could cause an imitation of a passing locomotive.

Analyzing failures in the signaling automation system of the Northern and Oktyabrskaya railways during strong geomagnetic storms of solar cycle 23 (20092010) [Sakharov et al., 2009] has shown that the anomalies develop almost synchronously in close connection with the excitation of significant geoelectric fields. Analysis of the relationship between the frequency of the manifestation of the anomalies and the geomagnetic activity level, carried out for the Oktyabrskaya Railway for 2002-2006, has revealed that at low and moderate activity in the auroral and subauroral zones the anomalies were observed with a frequency of 1 to $10 \%$ of the time intervals considered, whereas at mean and high activity the frequency of detection of the anomalies was $\sim 30$ and $80 \%$ respectively.

\subsection{Pipelines}

Space weather and related global electromagnetic disturbances pose a threat to pipelines, especially to those located in the zone of intense geomagnetic activity. The response of pipelines to geomagnetic disturbances is being studied very intensively [Campbell, 1980]. Geomagnetic disturbances and associated geoelectric field variations generate voltage oscillations that push the pipeline voltage out of the safe protection range for a long period of time. During strong storms in November 2004 on a pipeline in Australia for $\sim 12 \mathrm{hrs}$, fluctuations in the pipe-to-soil potential exceeded the set limits about three times [Trichtchenko, Boteler, 2002]. In the general case, a result of the development of GIC in pipelines is the cumulative effect of increased corrosion at ground points or an insulation defect, as well as disruption in the operation of cathodic protection or failures in electronic control systems. For example, on a pipeline (TQM) in Quebec, Canada, corrosion damage to one of the pipeline sections developed after five years of operation instead of the expected 20-30 years.

Local tectonic features of pipeline location can significantly affect the GIC associated corrosion rate. Ingham and Rodger [2018] report results of an analysis

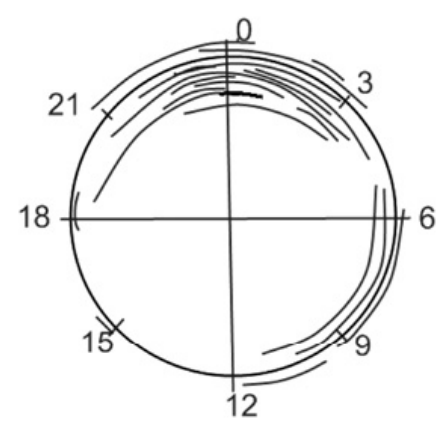

Figure 6. Distribution of anomalies in the operation of signaling on the Northern Railway at local time during strong geomagnetic storms in 1989 and 2000-2005 [Eroshenko et al., 2010] of GIC in a pipe and variations in the pipe-to-soil potential on a $200 \mathrm{~km}$ natural gas pipeline in New Zealand. The analysis of data led to the conclusion that the pipeto-soil potential and current variations are closely linked to the telluric field perpendicular to the pipeline. The most likely reason for the discrepancy is the features of the ground conductivity structure and the position of the coastline, which can affect the distribution of the local ground potential.

Campbell [1978] when evaluating currents excited in the pipeline in Alaska has shown that more than $50 \%$ of time the currents do not exceed $1 \mathrm{~A}$ and cannot have a significant effect on the metal corrosion rate. Current in the pipeline was measured from an induced magnetic field with several magnetometers [Campbell, Zimmerman, 1980]. At the same time, it has been found that current waves up to $200 \mathrm{~A}$ occur in a pipeline during strong magnetic disturbances.

Huttunen et al. [2008] have summarized SW effects in a pipeline in southern Finland (latitude $56^{\circ}-58^{\circ} \mathrm{N}$ ) in solar cycle 23 . The number of cases of development of significant $(>10 \mathrm{~A})$ currents in the pipeline has been established to correlate well with the number of sunspots, which confirms the direct relationship of GIC with solar activity. Lehtinen and Pirjola [1985] have calculated currents in a pipeline and in the pipeline grounding in the south of Finland for a telluric field of $1.0 \mathrm{~V} / \mathrm{km}$. The values ( $\sim 0$ and $\sim 25$ A respectively) obtained seem to be significant and in case of insulation failure can lead to a noticeable change in the time of corrosion attack. Monitoring the pipe-to-soil potential in the pipeline in Northern Alberta (Canada) made it possible to identify cathodic protection failures associated with geomagnetic disturbances. Organizing a distributed grounding provided a way of significantly reducing the number of excesses of the pipe potential over the safe operation of the protection system. In a pipeline in Northern Norway, the pipe-to-soil potential has been found to fluctuate with an amplitude of $\sim 5 \mathrm{~V}$ during magnetic disturbances [Henriksen et al., 1978].

Although GICs are mainly a source of problems for technological systems at high geomagnetic latitudes, strong geomagnetic disturbances can also cause quite significant effects at midlatitudes [Hejda, Bochnicek, 2005]. Analysis of the pipe-to-soil potential measured in oil pipelines in the Czech Republic during a magnetic storm in 2003 indicates that the simple method of determining the electric field in the plane wave and uniform ground conductivity model approximations matches well the estimated pipe-to-soil potential. Geomagnetic field amplitudes were the highest at the beginning of the geomagnetic storm; however, high potentials are also induced during the main and recovery phases due to Pc5 oscillations. For a pipeline in northern Bavaria [Brasse, Junge, 1984], the pipe current and the pipe-tosoil potential were measured. The pipeline was equipped with cathodic corrosion protection; moreover, every $30 \mathrm{~km}$ the pipe was additionally charged with a potential of $2 \mathrm{~V}$. Peak current values in the pipe at an average geomagnetic activity level were as high as $\sim 12 \mathrm{~A}$; potential variations were $\sim 3 \mathrm{~V}$ during a magnetic storm. The total time of insufficient corrosion protection did 
not exceed two days during the year $(\sim 0.5 \%$ of the total time).

In Russian scientific literature there are not so many publications reporting results of measurements of GIC in pipelines or changes in the pipe-to-soil potential. A current up to $3.2 \mathrm{~A}$ was detected in a gas pipeline near Yakutsk during the geomagnetic disturbance on January 21, 2005 [Mullayarov et al., 2006]; the current was estimated using the differential magnetometry method. In a section of the Bovanenkovo-Ukhta gas pipeline, protection potentials were measured in a continuous mode. During the September 12-13, 2014 geomagnetic disturbance, the estimated potentials underwent changes with an amplitude up to $10 \mathrm{~V}$ [Ivonin, 2015]. The discovered effect of the emergence of the non-classical source of stray current prompts a question about a possible impact on electrochemical protection systems in gas pipelines [Panyushkin, 2014]. At the same time, some experts assume that although absolute values of geomagnetic stray currents may be as great as hundreds of Amperes, such currents are distributed along pipelines throughout their considerable length. As a result, the density of leakage currents when they are discharged to the ground does not exceed the natural current density of traditional soil corrosion; therefore, the problem of the influence of magnetic storms on corrosion damage to trunk pipelines is not so critical.

The cumulative effect of moderate geomagnetic activity is often an overlooked aspect of SW as compared to the interest in severe events, which can seriously disrupt critical infrastructures. It is, however, feared that the low-intensity, but more frequent geomagnetic effect can accumulate, disrupting infrastructures, and thus has a significant economic impact. Khanal et al. [2019] have studied temporal variations in GIC in a pipeline at middle and high latitudes during long periods of moderate geomagnetic activity, which was conditioned by a fast solar wind stream with numerous periods of southward IMF due to Alfven wave activity in the solar wind at intervals from $0.5-2 \mathrm{hrs}$ to $12-14 \mathrm{hrs}$. These periods, known as HILDCAA (High Intensity Long Duration Continuous Auroral-Electrojet Activity) events, are distinct from geomagnetic storms, although they sometimes follow the storms. GIC variations during HILDCAA events were found to involve short bursts of strong GIC against a more slowly changing background. Long-term strengthenings of GIC may lead to increased corrosion of pipelines. The results indicate that the cumulative effects of SW require more attention from the research community. Gradual pipeline corrosion is a prime example of why it is necessary to better understand how long-term exposure to moderate SW can have a significant economic impact, slowly destroying vulnerable systems.

\section{GIC MEASUREMENT METHODS}

The main problem of studying the SW impact on technological systems is the lack of information on failures in space, energy systems, gas pipelines, and railway lines, which is publicly available for scientific analysis. Industrial companies around the world are extremely reluctant to provide the global scientific community with information about failures and anomalies in their systems. Therefore, attempts are being made to perform not only direct measurements of GIC at transformer substations, but also to develop remote methods for assessing GIC intensity in power transmission lines and pipelines.

\subsection{Power transmission line Nord Transit}

The Polar Geophysical Institute (PGI) jointly with the North Energy Center (NEC) on the Kola Peninsula and in Karelia have created Russia's unique system for continuous monitoring of the impact of magnetospheric disturbances on the power transmission line Nord Transit [Sakharov et al., 2007; Sakharov et al., 2019]. From 2010 to the present, four substations (Loukhi, Kondopoga, Vykhodnoy, Revda) have been measuring the GIC-produced quasi-DC current flowing in the grounded neutral of an autotransformer [Danilin et al., 2010]. The choice of the measurement points makes it possible to study the distribution of GIC along the south-to-north $330 \mathrm{kV}$ trunk line and along the west-to-east $110 \mathrm{kV}$ line at the substation Revda. Location of the stations is shown in Figure 7. Data from this network of stations are transfered to the European Risk for Geomagnetically Induced Currents (EURISGIC) [http://eurisgic.org], created to assess the risk of geomagnetic disturbances to European power systems. Data from the PGI-NEC system can be used to test GIC models and to estimate the contribution of geomagnetic disturbances to abrupt load jumps in power grids [Efimov et al., 2013].

To measure GIC in a power system, a method of detecting the current in the neutral of a power transformer was chosen [Vakhnina, Kuznetsov, 2013], for which a special current sensor was developed; it is included in the distributed monitoring system facilitating near real time measurements [Barannik et al., 2012]. The value of GIC flowing in the neutral of a particular transformer, apart from external influence, depends on the switching circuit of power equipment at a substation. The GIC bursts recorded during observations in the Nord Transit pipeline did not lead to failures in high-voltage distribution equipment; however, significant anomalies were observed in the operation of power transformers [Selivanov et al., 2017].

\subsection{Differential magnetometry method}

The differential magnetometry method (DMM) has been proposed for remote measurement of GIC in power transmission lines. It is an indirect method for calculating GIC flowing in a power transmission line or in an extended conducting system. When using DMM, lowfrequency GIC in PTL wires is estimated from the difference between magnetic records made directly under the line and at a certain distance with two identical magnetometers (its qualitative scheme is shown in Figure 8).

In this case, one magnetometer is located under the power transmission line and measures both the natural geomagnetic field and the magnetic field created by GIC in the line. The second magnetometer, located at a distance of more than $300 \mathrm{~m}$ from the first one, measures only the natural geomagnetic field. Difference between these fields is determined by GIC contribution. 


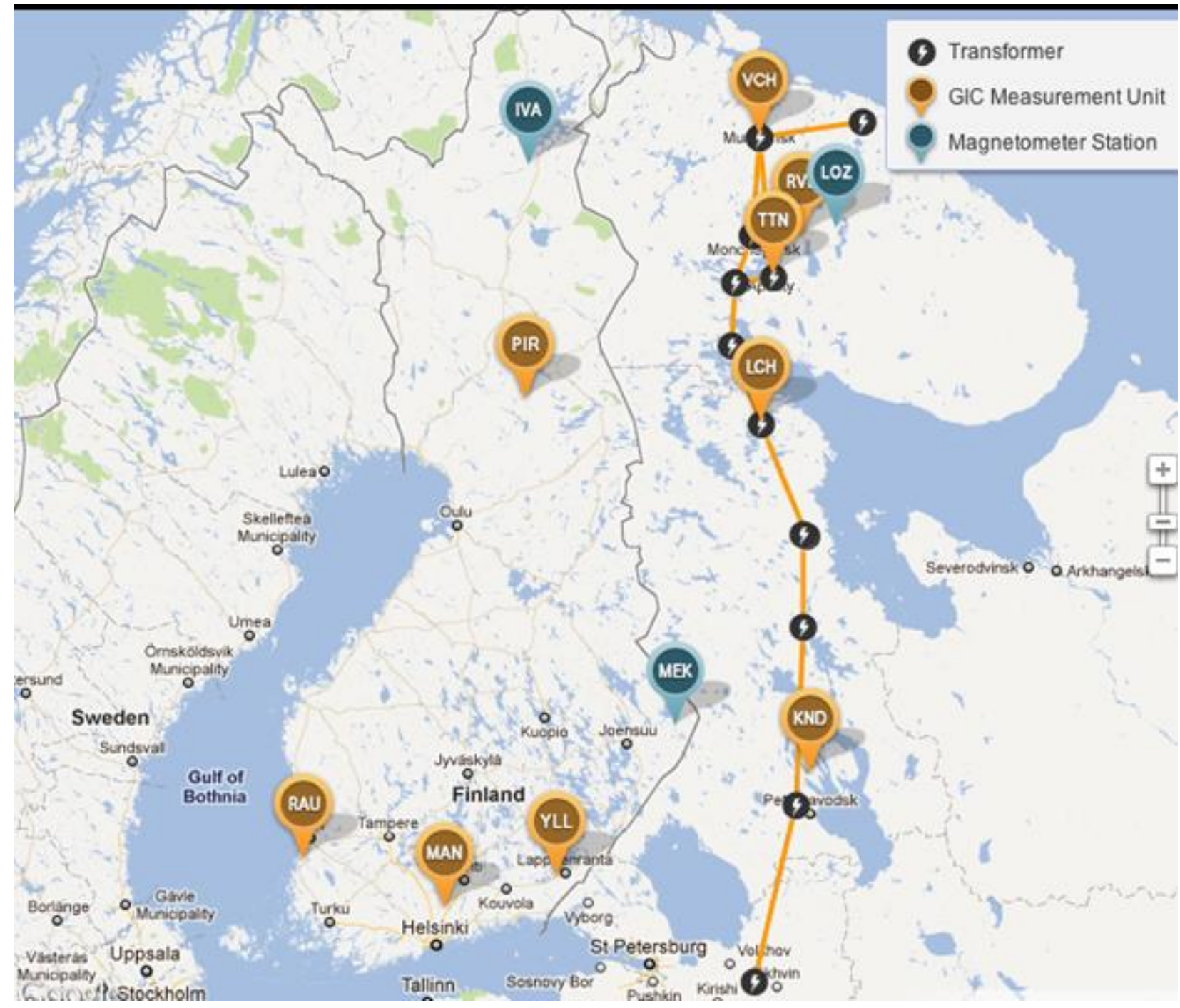

Figure 7. Map of a GIC monitoring system at Nord Transit PTL substations

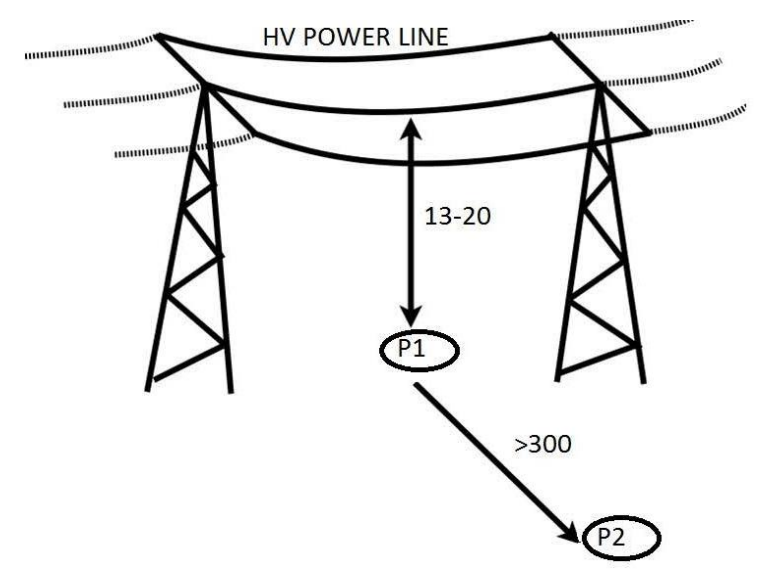

Figure 8. Qualitative scheme of DMM for remote measurement of GIC in power transmission lines with two identical magnetometers at points $\mathrm{P} 1$ and $\mathrm{P} 2$

Since the direct measurement of GIC at a transformer substation generally faces opposition from energy companies, the indirect method of differential magnetic measurements is the only possible. DMM with magnetometers spaced by $40 \mathrm{~km}$ apart has been used since the 1990s for measuring GIC in the $400 \mathrm{kV}$ line in the Finnish network and gas pipelines [Mäkinen, 1993; Viljanen, Pirjola, 1994]. GIC measurements in the oil pipeline running through Alaska were carried out with two magnetometers located at different distances from the pipe [Campbell, 1980].

\subsection{Power grid harmonics}

An alternative method for detecting GIC in electric power systems is based on monitoring the level of harmonics generated by power transformers of an electrical grid when a constant component appears in the current of their windings (qualitatively, the mechanism of occurrence of harmonics is shown in Figure 15) [Kobelev, Zybin, 2011; Selivanov et al., 2012]. The method has advantages such as the absence of the need to apply expensive equipment and the possibility of organizing an observation point on the basis of a conventional personal computer at any point in the power grid. The proposed approach has been tested on the basis of the power grid of the Kamchatka Territory [Sivokon et al., 2011, Sivokon, Serovetnikov, 2013, 2015]. Long-term observations of variations in the harmonics of the supply-line voltage were carried out at vari- 
ous observation points, characterized by different supply line topology and system load conditions. Results have been obtained which confirm the relationship of variations in the level of power grid harmonics with geomagnetic disturbances.

\subsection{GIC in power grids and VLF radio emission}

VLF radio receivers can be a means of remote detection of GIC in power grids. When transformers are loaded with GIC, they generate high harmonics of 50 $60 \mathrm{~Hz}$ alternating current flowing through these grids. Part of the power of these harmonics is emitted as radio waves at frequencies up to several $\mathrm{kHz}$ and is even detected by satellites. Existence of these VLF emissions in a power grid was first discovered more than forty years ago. However, in those years the interest in SW and GIC was very limited, in contrast to the present day when these issues are of global concern. Clilverd et al. [2018] have reminded in time that industrial network frequency harmonic VLF emissions have significant potential as a diagnostic tool for monitoring GIC in power grids without intervention in network equipment. This can provide significant practical advantages in terms of safety and cost.

\section{MODELING GEOELECTRIC FIELD DISTURBANCES AND GIC}

Modern power systems are a huge network with an extremely complex topology that covers vast areas of Earth's surface whose local geoelectric properties (for example, conductivity) can differ by several orders of magnitude. In media with low conductivity, the occurrence rate of negative effects of strong magnetic disturbances increases sharply since induced currents mainly flow through conductive elements of industrial networks. Geoelectric fields induced in Earth's surface during magnetic storms can affect the operation of electrical networks. The danger remains that the occurrence of an extreme magnetic storm in the future could lead to a large-scale loss of energy capacity, which will significantly affect the economies of countries at risk.

Attempts to develop devices blocking GIC in a large electrical network have not yet yielded results. Therefore, the main hopes are pinned on the on-line control and prevention of relatively rare problems associated with strong magnetic storms. The potential difference in the surface layers of the earth's crust causes overloads in grounded electric power grids. It is however difficult to get direct information on geoelectric fields. While geomagnetic variations are tracked by the worldwide network of magnetometers $(>300)$, regular observations of telluric electric fields are still extremely rare. Long-term measurements of the geoelectric field at observatories are much rarer. Since 1983, such observations of the geoelectric field have been made only at observatories by the Japan Meteorological Agency, Geo Forschungs Zentrum (Germany), the British Geological Survey (UK), and the Institute of Earth Physics of Paris (France).

\subsection{Magnetotelluric sounding methods}

Correct calculation of telluric electric fields and currents requires a sufficiently dense network of magnetometers and information about the geoelectric section of the earth's crust. There is no optimal global model of the geoelectric conductivity; therefore, various approximate schemes have to be used for the calculations [Boteler et al., 1998]. Comparison between the methods has shown that the impedance relation in the plane wave and plane geometry approximations may be employed to calculate telluric fields with high accuracy [Pirjola, 2002; Viljanen et al., 2015]. This approximation is valid under the assumption that the horizontal scale of the disturbance is much larger than the skin length [Wait, 1982]. The situation is greatly simplified by the fact that integral estimates of the potential difference between nodes of an extended system (at least several hundred kilometers) are important for GIC calculations, and hence the required estimates can also be made with sufficient accuracy in a network of relatively widely spaced magnetometers with a crude conductivity model [Beggan, 2015].

The main cause of GIC is the geoelectric field that in the plane wave approximation is related to geomagnetic variations through the surface impedance of Earth's surface [Liu et al., 2009; Boteler, Pirjola, 2019]. Impedance is determined by the depth distribution of electrical conduction in the earth's crust. The magnetic field variability $d \mathbf{B} / d t$ is more sensitive to local anomalies in the conductivity of the underlying surface than $\Delta \mathbf{B}$ [Thomson et al., 2009]. The electrical conductivity $\sigma$ ranges from $10^{-4}$ within the earth's interior to $3 \mathrm{~S} / \mathrm{m}^{2}$ in the ocean. Power grids are most sensitive to interference from natural geoelectric fields with periods from 10 to $1000 \mathrm{~s}$. Variations in geomagnetic and geoelectric fields with such periods penetrate into Earth's surface layers to a depth of the order of the skin length ranging from 2 to $3000 \mathrm{~km}$.

Direct measurement of the geoelectric field $\mathbf{E}$ is conceptually simple: it is proportional to the potential difference between a pair of buried electrodes. For magnetotelluric (MT) studies, geoelectric measurements are usually carried out with a magnetic variometer. Qualitatively, the interaction of an electromagnetic disturbance with the earth's crust can be represented as leakage of an incident wave with a frequency $\omega$ to a depth of order of skin length $\delta$. If the horizontal scale of a disturbance is much larger than the skin length (strong skin effect condition), the impedance relation $\mathbf{E}(\omega)=Z(\omega) \mathbf{H}(\omega)$ between spectral amplitudes of vectors of horizontal electric $\mathbf{E}=\left\{E_{x}, E_{y}\right\}$ and magnetic $\mathbf{B}=\{X$, $Y$ \} components is valid for Earth's surface. Here, $\mathrm{Z}(\omega)$ is the surface impedance determined by Earth's internal resistivity distribution $\rho(z)$. For a homogeneous earth's crust, the impedance $Z=\sqrt{\mu_{0} \omega \rho}$ depends on the period of geomagnetic disturbance $T$ as $Z(T) \propto T^{-1 / 2}$. The telluric field $E$ can be synthesized from measured geomagnetic variations, using the impedance relation in the frequency domain between the horizontal components of electric $\mathbf{E}(\omega)$ and magnetic $\mathbf{B}(\omega)$ fields through the 
complex impedance tensor $\mathbf{Z}(\omega)$ as follows

$$
\left(\begin{array}{l}
E_{x}(\omega) \\
E_{y}(\omega)
\end{array}\right)=\mu_{0}^{-1}\left(\begin{array}{ll}
Z_{x x} & Z_{x y} \\
Z_{y x} & Z_{y y}
\end{array}\right)\left(\begin{array}{l}
X(\omega) \\
Y(\omega)
\end{array}\right) .
$$

Information on the impedance of Earth's surface requires preliminary MT sounding, which has been done only for certain areas of Earth's surface. Calculations of the telluric field are significantly complicated for a 3D inhomogeneous medium or for high-resistivity rocks, where the strong skin effect condition is not met [Kelbert et al., 2017].

To date, the most advanced model of planetary lithosphere conductivity distribution is the 3D model [Kuvshinov, Olsen, 2006]. It has been exploited to calculate the planetary distribution of telluric fields from large-scale magnetospheric sources [Kuvshinov, 2008]. Peak values of the telluric fields are as high as $\sim 50$ $\mathrm{mV} / \mathrm{km}$ for a storm with $D s t \sim 300 \mathrm{nT}$ at midlatitudes $\left(<55^{\circ}\right)$. Nonetheless, this model cannot be applied to high latitudes, where more intense disturbances are generated by more localized and dynamic substorm processes. For example, $>80 \%$ of the spectral power of geomagnetic variations at auroral latitudes is concentrated on time scales of $<8$ min [Wintoff, 2005].

\subsection{Variations in geomagnetic and telluric fields as a source of GIC}

The GIC intensity $\mathbf{J}$ was generally assumed to be proportional to the time derivative of the geomagnetic field, $\mathbf{J} \sim d \mathbf{B} / d t$. But this relationship is valid for a closed circuit only in free space. In real situations, the circuit through which GIC flows is formed by power transmission lines, ground contacts, terminal transformers, and the ground. Electrical parameters of these elements, as well as their frequency dependence, are known very approximately. The actual relationship between the spectral composition of magnetic variations $\Delta \mathbf{B}$, telluric electric field $E$, and current $J$ should be studied for each power system separately [Bonner, Schultz, 2017].

An example of such a study for the Nord Transit system is given in [Kozyreva et al., 2019]. The results from the following groups of stations are presented here: closely located LOZ - B50 - RVD sites, and magnetic and GIC stations at the same geomagnetic latitudes IVA-VKH (Figure 9). Telluric electric fields have been calculated using available impedance data in the range of periods 8-5000 s from the BEAR experiment results [Korja et al., 2002]. The spatial distribution of the electrical conductivity in the Eastern Baltic shield is very inhomogeneous. Comparison between impedances of several characteristic sections is shown in Figure 10. For the period $T=90.5 \mathrm{~s}$, the largest value of the impedance modulus $|Z|$ falls on the region of the PEL/B31 stations $(\sim 10 \mathrm{mV} / \mathrm{km} \cdot \mathrm{nT})$, whereas in the vicinity of the OUJ/B33 stations the impedance is $\sim 4$ times lower $(\sim 2.4$ $\mathrm{mV} / \mathrm{km} \cdot \mathrm{nT}$ ).

Thus, for the same magnetic disturbance, the contrast of a telluric electric field between different points may be as high as 3-4 times. The significant values of both diagonal and off-diagonal elements of $\mathbf{Z}$ tensor indicate

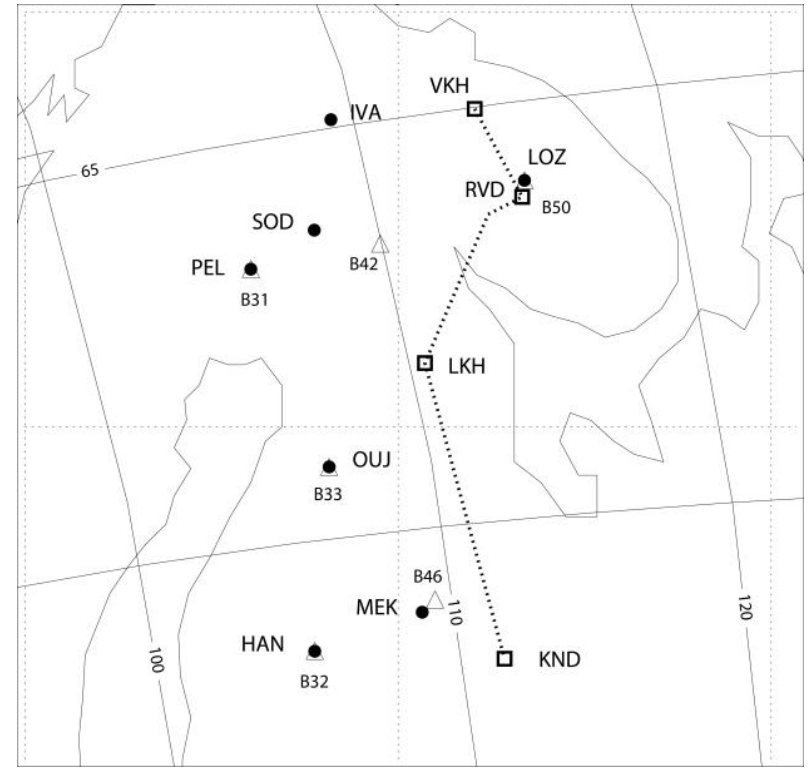

Figure 9. Magnetic stations IMAGE (black dots), selected points of MT sounding in the BEAR project (triangles), and GIC detection stations in the Nord Transit power transmission line

that geoelectric properties of the earth's crust are highly anisotropic. Time series of the synthesized telluric fields have been calculated using the Fourier transform of magnetic variations with the removed trend from impedance relation (1), and the subsequent inverse Fourier transform from the spectrum convolution $B(f)$ with the impedance $Z(f)$.

The magnetic storm on November 12-14, 2012 $(|S Y M-H|>100 \mathrm{nT})$ was triggered by fast solar wind streams. In November 14 at 00-04 UT, a series of enhancements of the local electrojet took place (EI 1500 $n T)$. During this period, intense GIC variations were recorded in all PTL elements, and up to $\sim 60 \mathrm{~A}$ at the terminal station VKH. The $J$ bursts occurred synchronously with an increase in $d X / d t$ to $\sim 10 \mathrm{nT} / \mathrm{s}$ and in the telluric field to several $\mathrm{V} / \mathrm{km}$.

Even the visual comparison in Figure 11 shows that the $d X(t) / d t$ fluctuations are more high-frequency than those of $E(t)$ and $J(t)$. Spectral analysis of simultaneous geomagnetic, telluric, and GIC variations (Figure 12) confirms this fact. Spectral components at frequencies of $\sim 4$ and $\sim 6 \mathrm{mHz}$ were identified in the spectrum of $J(f)$ and $X^{\prime}(f)\left(X^{\prime}=d X / d t\right)$. These components are due to the contribution of fast $\mathrm{Pi} 3$ fluctuations superimposed on an enhancement of the auroral electrojet. As such, the $X^{\prime}(f)$ spectrum deviates considerably from the $J(f)$ spectrum at frequencies of $>5 \mathrm{mHz}$ and appears to be much closer to the $E_{x}(f)$ spectrum. Thus, the geoelectric properties serve as a filter that diminishes the influence of high frequencies of $d B / d t$

\subsection{Maps of possible GIC values}

Information about geoelectrical resistance is a big problem for geoelectric mapping because conductivity of the earth's crust fluctuates by at least four orders of 

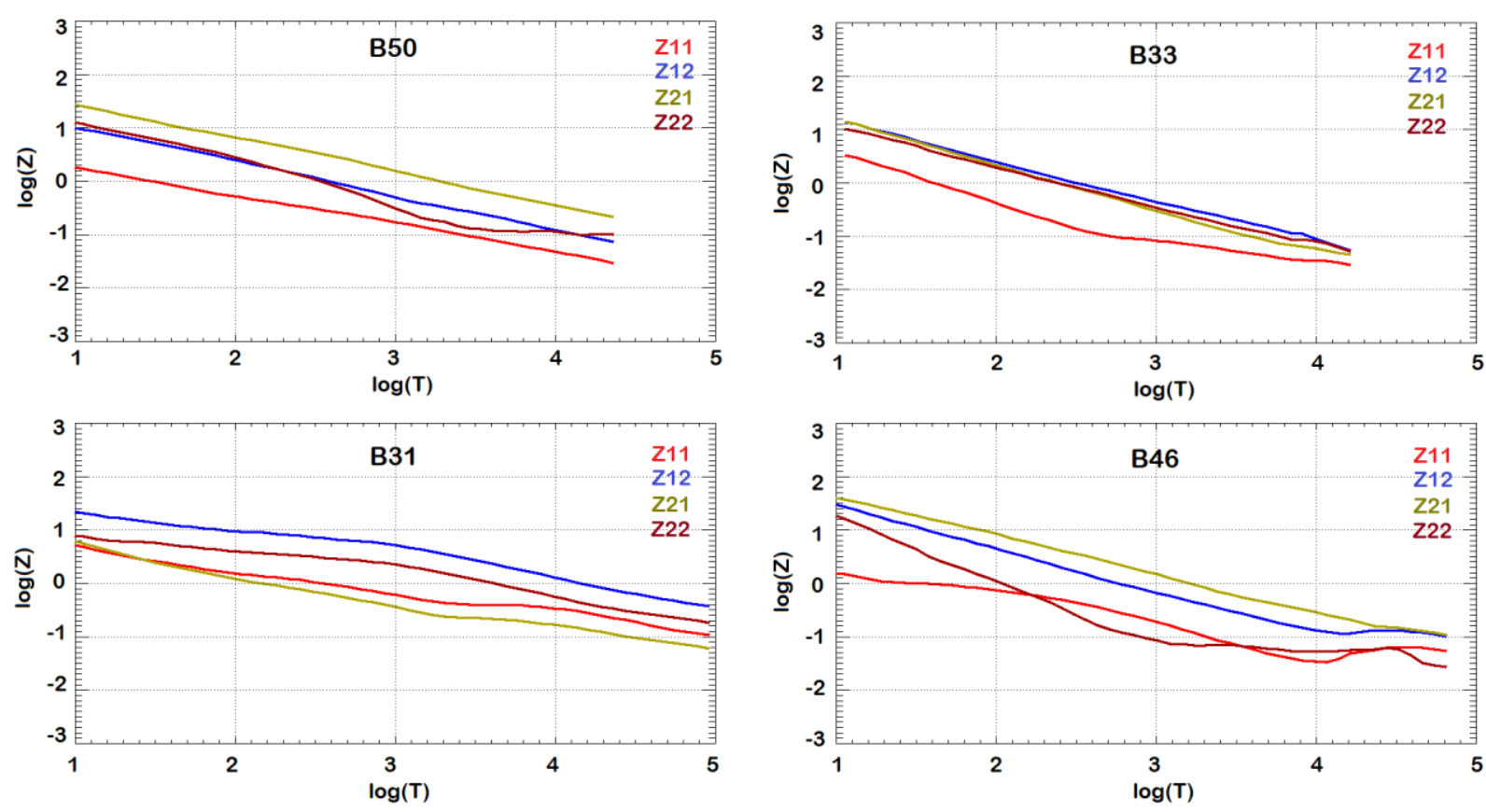

Figure 10. Amplitudes of impedance tensor elements $Z_{i, j}$ (the $\mathrm{X}$-axis is directed to the north; $\mathrm{Y}$-axis, to the east) as a function of $T$ at some BEAR stations

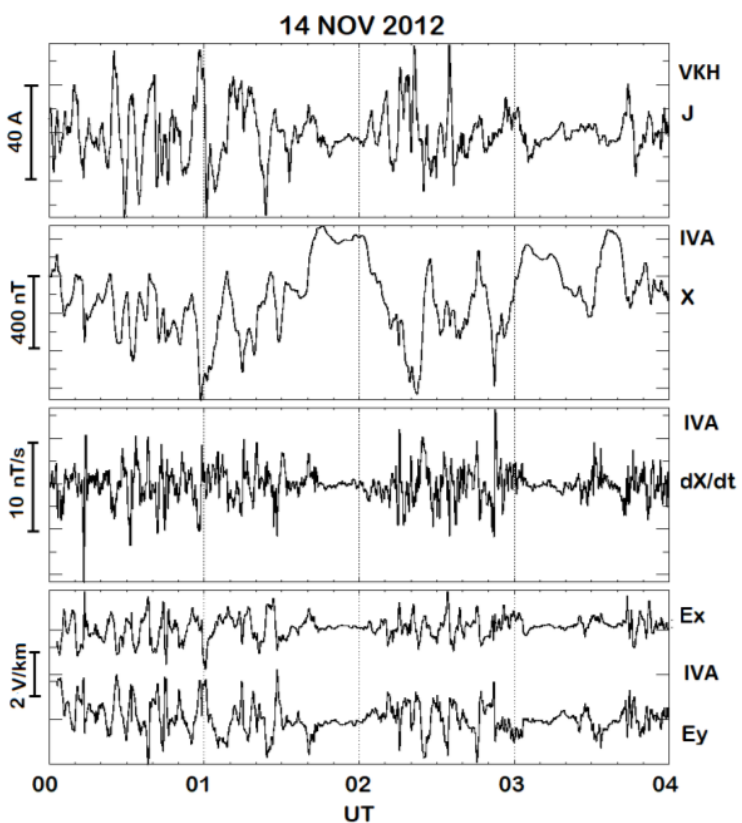

Figure 11. GIC intensity $J[\mathrm{~A}]$ at $\mathrm{VKH}$, magnetic variations in $X[\mathrm{nT}]$, time derivative $d X / d t[\mathrm{nT} / \mathrm{s}]$ at IVA, and telluric fields $E_{x}[\mathrm{~V} / \mathrm{km}]$ and $E_{y}[\mathrm{~V} / \mathrm{km}]$ at IVA/B5

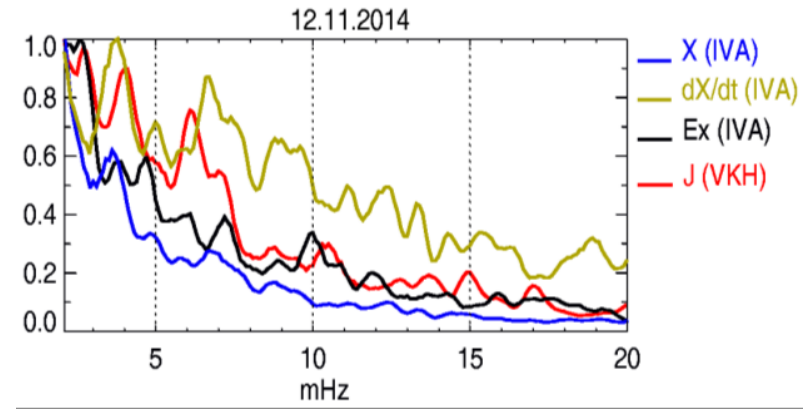

Figure 12. Normalized spectra for the 01-03 UT interval of the November 14, 2012 event: $J(f)$ at VKH, $X(f), X^{\prime}(f)$, and $E_{x}(f)$ at IVA magnitude. In 2006 under the EarthScope Project [https://www.earthscope.org], an MT survey of the United States on a network of stations spaced by $70 \mathrm{~km}$ apart was launched [Schultz et al., 2009]. The project ended in 2018 when the MT sounding of approximately $2 / 3$ of the United States had been completed. For each location, mobile facilities were deployed which included a fluxgate magnetometer and a pair of electric dipoles to measure three magnetic field components and two horizontal electric field components [Love et al., 2017]. Then, simultaneous measurements of geomagnetic and geoelectric fields were used to calculate the magnetotelluric impedance tensor as a function of frequency $Z(\omega)$. The impedance tensors obtained from survey areas cover the range of periods from 10 to $20000 \mathrm{~s}$ with an estimated error of less than $5 \%$.

The empirical impedance tensors obtained from EarthScope MT data were used to explore the possibility of mapping geoelectric fields induced by magnetic disturbances and to identify Earth's conductivity effects [Bedrosian, Love, 2015]. The US Geological Survey has created a map of synthetic geoelectric fields that could be excited by a given spatially homogeneous geomagnetic disturbance. Such a map allows one to quickly assess the possible risks from GIC during different expected disturbances. For geomagnetic oscillations with $T=100 \mathrm{~s}$, induced geoelectric field vectors exhibit significant differences in amplitude (up to 100 times), direction (up to $130^{\circ}$ ), and phase (more than a quarter of the wavelength) in different regions (Figure 13). Horizontal geoelectric field vectors $\mathbf{E}$ induced by a sinusoidal geomagnetic field $B_{\mathrm{x}}(t)$ with $1 \mathrm{nT}$ amplitude range from 1.2 to $33.5 \mathrm{mV} / \mathrm{km}$.

Love et al. [2016, 2018] have estimated possible extreme variability in the geomagnetic field and geoelectric currents for the mid-latitude part of the United States. From the analysis of the MT survey data and the 


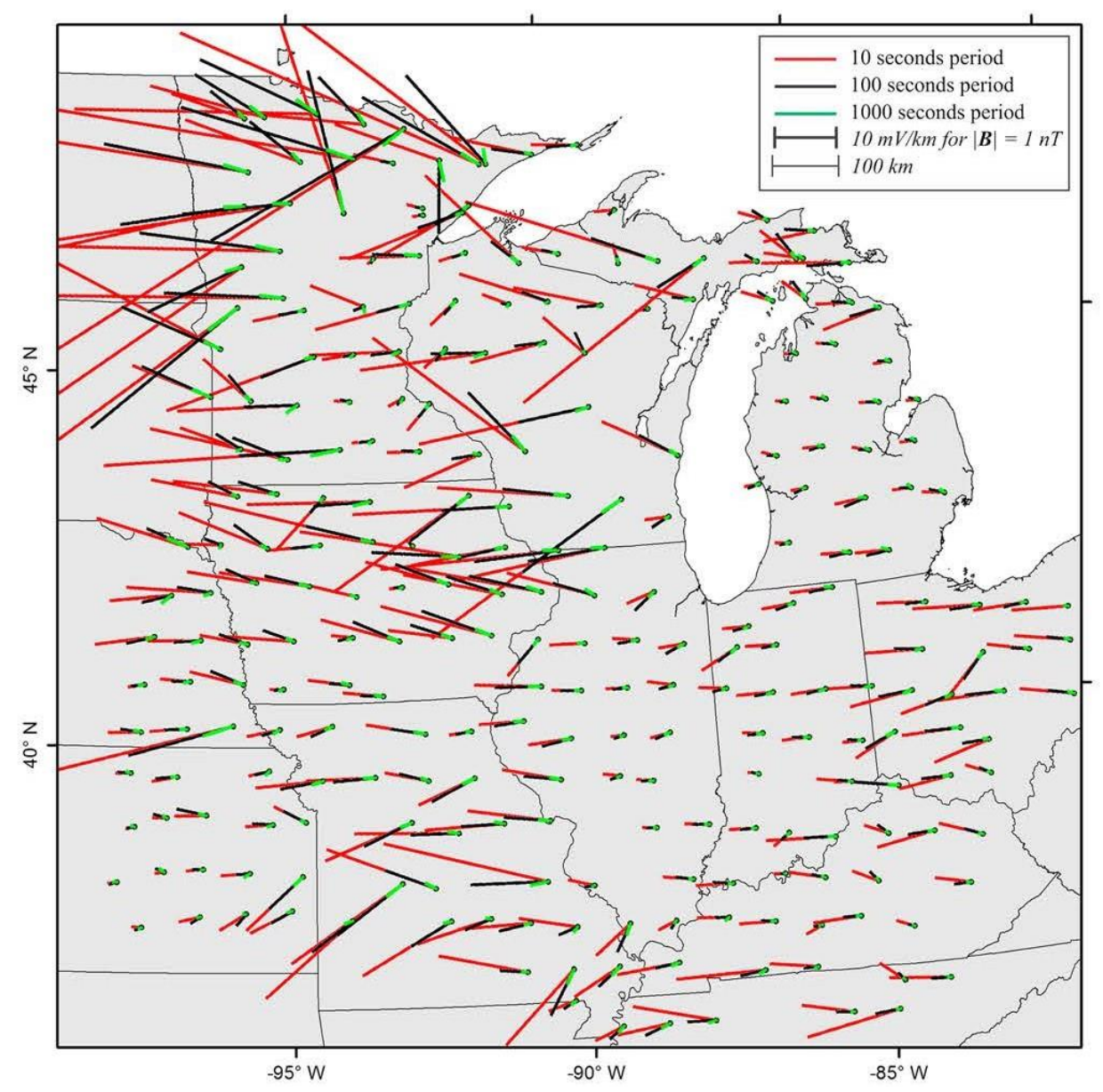

Figure 13. Vector field of geoelectric disturbances $E$ induced by a sinusoidal geomagnetic field $B_{x}(t)$ with periods of 10 (red), 100 (black), and $1000 \mathrm{~s}$ (green) in the United States (from [Bedrosian, Love, 2015])

archive of magnetic observatory data, extreme geoelectric field amplitudes have been calculated which could occur once every 100 years. The geography of the GIC hazard is directly related to the complex geoelectric structure since the geological structure significantly affects the strength and direction of the geoelectric fields generated by magnetic storms. In particular, USGS models show a high level of hazard to igneous and metamorphic rocks; on the contrary, sedimentary rocks have a lower hazard level. Such a map contains critical information for grid operators in case of extreme magnetic storms. These maps will enable utility companies to better anticipate the threat and response to future magnetic storms; the maps will be useful for planning future power grids, and will also help to develop a strategy to reduce outages and failures in power systems [Lotz, Danskin, 2017].

\subsection{Transfer function method for assessing GIC in given systems during geomagnetic varia- tions}

A key issue in research into the SW impact on technological systems is how to model GIC that can flow through an electrically grounded infrastructure, in particular through power transmission lines. However, in real situations the circuit in which GIC flows and its characteristics are known very roughly. The actual relationship between the spectral composition of magnetic variations $\Delta B(f)$ and GIC should be determined separately for a specific power system and a particular region. The frequency dependence $Z(f)$ leads to the fact that the interaction between the geomagnetic field and the conducting earth's crust acts as a filter after which the high-frequency part of the spectrum in telluric field variations turns out to be weakened as compared to $d B / d t(f)$ [Kozyreva et al., 2019]. This effect can be taken into account by introducing a proxy telluric field

$$
E_{\mathrm{p}}(t)=\left|F^{-1}\{Z(f) B(f)\}\right|,
$$

where $F^{-1}$ denotes the inverse Fourier transform [Marshall et al., 2012, 2017].

Ingham et al. [2017] have adopted a method based on calculating the transfer function $E_{\mathrm{p}}(t)$ (proxy telluric field), which numerically describes the GIC response to variations in the local geomagnetic field at different frequencies. They applied this method to the large GIC dataset for the power grid of New Zealand. With suitable scaling, this method can be used to simulate GIC time variations in any given system during magnetic storms.

\subsection{Models for calculating pipeline GIC and the pipe-to-soil potential}

There is not much information on the GIC effect on pipelines; the most long-term studies of the SW effect on pipelines were carried out for the Finnish gas pipeline 
from 1998 to 1999 [Pulkkinen et al., 2001a, b]. They were aimed at developing a model for assessing GIC in the pipeline and the pipe-to-soil potential and for obtaining statistical predictions of GIC and potentials in different parts of the pipeline network [Lundstend, 2006]. The study has shown the greatest changes in the pipe-to-soil potential occur at ends of the pipelines, whereas the strongest GIC are in middle parts of the pipelines.

Currents in conducting systems have been calculated using the DSTL method (Distributed-Source Transmission Line) [Boteler, 1997], the method of complex images [Pirjola, Viljanen, 1998], the method of matrix equations [Lehtinen, Pirjola, 1985], the method of source elementary current systems [Viljanen et al., 1999, 2004], and the transmission line method in which the conductivity matrix in the pipeline model is constructed taking into account grounding parameters of individual pipeline sections and branches [Boteler, 2013]. The calculations have shown that the telluric voltage depends not only on the telluric field direction and magnitude but also on the length and grounding resistance of the pipe. These calculations, applied to modern pipelines with good coating, suggest that the effect of telluric currents may not be as harmless as originally assumed [Gummow, Eng, 2002].

\subsection{Influence of sharp irregularities of geoe- lectric conductivity}

Assessing the SW effect on power grids in coastal regions requires taking into account features of the conductivity structure. Risk assessments should involve assessments of whether the geoelectric fields produced by geomagnetic disturbances can increase on the coast, affecting power transmission lines in coastal areas. Tozzi et al. [2019] have assessed the risk from SW for the Italian power grid. It consists of 380-400 and 220 $275 \mathrm{kV}$ transmission lines, as well as a high-voltage DC transmission line running under the sea surface to the island of Sardinia. The authors show that strong GIC can flow in power systems even at low geomagnetic latitudes during magnetic storms and substorms. Taking into account the proximity of the coast increases the estimate of expected telluric fields and GIC.

Telluric fields for the real 3D inhomogeneous structure of the conductivity of the earth's crust and upper mantle during magnetic storms have been modeled in [Marshalko et al., 2020]. Using a combined approach involving 3D modeling of electromagnetic field and magnetohydrodynamic (MHD) modeling of NES, the dynamics of telluric fields during the March 17, 2015 magnetic storm was successfully simulated. Various conductivity models were adopted including the realistic 3D model derived from EarthScope project data. Conductivity contrasts were shown to have a great effect not only on the local telluric field, but also on the global distribution of the electric field potential and hence on GIC. Comparison of modeling for the realistic spatially inhomogeneous and plane-wave approximation, which is the most common approach to modeling GIC, has revealed significant differences between results even at midlatitudes. The difference is especially large at boundaries of conductivity contrasts.
Joint MT research and soil-to-pipe potential distribution study are a useful tool for identifying potential GIC hazards to pipelines. When modeling soil-to-pipe potential variations based on the distributed-source transmission line theory, a good fit with the potential observed can be obtained if impedance jumps are taken into account. Thus, the large difference between soil-to-pipe potentials is due to the presence of resistive intrusive bodies in the upper crust. In particular, an abnormally high potential between pipe and soil is observed along the gas pipeline in eastern Ontario (Canada), where the geological contact runs between highly resistive rocks and more conductive sediments, which supports the hypothesis that considerable potential variations are linked to changes in the ground conductivity around the pipeline.

\section{ESTIMATED POSSIBLE EXTREME GIC VALUES}

The problem of estimating the probability of extreme GIC is a part of the more general problem of determining the probability of extreme geophysical events (earthquakes and magnetic storms) [Coles, Lam, 1998; Love, 2012]. The most intense magnetic storm, the Carrington event, occurred on September 1-2, 1859. During that storm, auroras were seen even in Hawaii, a maximum geomagnetic disturbance $\Delta H \sim 1600$ nT was recorded at the equatorial station Bombay, and the Dst index was estimated as $-850 \mathrm{nT}$. After the beginning of the space age in 1957, the strongest magnetic storm with $|D s t| \sim 590$ nT occurred on March 13, 1989. Other historically powerful storms were observed on July 4, 1941 $(\Delta H>700 \mathrm{nT})$ and March 24, $1940(\Delta H>660 \mathrm{nT})$ [Wei et al., 2013].

Attempts have been made to assess the probability of recurrence of such events [Cid et al., 2015]. Riley [2012] has estimated the probability of recurrence of a Carrington-type storm over the next decade at $12 \%$. Tsubouchi and Omura [2007] believe that storms similar to that occurring in 1989 can happen once every 60 years. Statistical analysis of the archive of magnetic storm records (more than hundred events with $\Delta H>100 \mathrm{nT}$ ) at Kakioka Observatory since 1924 for 89 years has estimated the probability of a Carrington level storm in the next decade at $\sim 13 \%$. If a storm like the storm of March 13, 1989 or January 09, 1859 occurred today, it would create serious problems in the operation of technological systems around the world. According to some possible scenarios, the occurrence of a rare and abnormally powerful storm will cause an avalanche of outages and failures in power grids, possibly destructive to economies of developed countries [National Research Council, 2008].

However, if we assume that extreme magnetic disturbances simply exceed the maximum values observed during instrumental observations a given number of times $(10,3 \sigma)$, adjusting to such unreasonably large values would require unnecessary expenses. The value that occurs once every 100 years is supposed to be taken as extreme GIC [Pulkkinen et al., 2008, 2012]. An ex- 
treme event is estimated by analyzing the statistical distribution of the occurrence rate of disturbances of given amplitude for a region under study. It is approximation of the dependence of the occurrence rate per event once every 100 years that gives the extreme value for a given region [Bernabeu, 2013]. By analyzing the archive of geomagnetic data, we can estimate the occurrence rate of extreme geomagnetic disturbances at different latitudes. By combining the data, it is possible to compile a regional map of geomagnetic risks, similar to the seismic hazard map - the maximum possible number of geoelectric disturbances once a century. This approach is used to estimate extreme telluric fields and GIC for different regions [Langlois et al., 1996].

\subsection{Statistical methods for estimating ex- treme events}

The form of the probability function $F(x)$ of disturbance amplitude $x$ is determined by physical mechanisms of the process under study. Thus, under random independent effects a normal Gaussian distribution is formed; in a closed system, the energy of its components is distributed according to the exponential Boltzmann - Laplace law; self-similar (Pareto-like) powerlaw distributions are often attributed to self-organized criticality; a random multiplicative selection from several parameters leads to a log-normal distribution, etc. The presence of heavy distribution tails is of great importance [Pisarenko, Rodkin, 2007]. With such powerlaw distributions, the variance of the magnitude considered is mainly determined by rare intense deviations, not by frequent small ones. If we do not know to the full the nature of distribution, and use only averages, we will come to false conclusions about properties of the system.

In geophysical studies, a log-normal distribution ( $\sigma$ is a shape parameter)

$$
F(x)=\frac{1}{\sigma x \sqrt{2 \pi}} \exp \left(-\frac{1}{2}\left(\frac{\ln (x)}{\sigma}\right)^{2}\right),
$$

and the generalized power-law Pareto distribution (the shape parameter $c>0$ )

$$
F(x)=(1+c x)^{-1-\frac{1}{c}} .
$$

are often used. Distribution of extreme values is described by a generalized distribution with a cumulative probability $p$, which is defined as

$$
p(X<x)=\exp \left\{-\left[1+\gamma \frac{x-\mu}{\sigma}\right]^{-1 / \gamma}\right\},
$$

where the parameters $\sigma$ and $\mu$ are positive. For $\gamma>0$, this probability function is called the Fréchet distribution, and the case $\gamma<0$ refers to the Weibull distribution.

In the distribution of extreme values, a certain level is taken as a threshold for the tail. The relationship above the threshold can be extrapolated to estimate extreme values with a return period $T$ (for example, 50 and 100 years). The return period $T$ can be calculated using the cumulative probability function

$$
T=[1-p(X<x)]^{-1} .
$$

\subsection{Estimated extreme values of variability in geomagnetic and telluric fields}

Magnetic data obtained from 13 geomagnetic observatories over 40 years has been analyzed to estimate extreme geomagnetic and geoelectric activity levels in different places in Canada [Nikitina et al., 2016]. Hourly ranges of geomagnetic variations $\Delta B$ and hourly average maxima of the rate of change of magnetic variations $d B / d t$ were used as measures of geomagnetic activity. In the auroral zone, estimated extreme values of disturbances for 50 years fall within the range $\Delta B=1750 \div 2560 \mathrm{nT}$; and for 100 years, within $\Delta B=1950 \div 3000 \mathrm{nT}$. In the subauroral zone, the extreme values were even higher: $\Delta B=3880 \mathrm{nT}$ for 50 years and $\Delta B=4630 \mathrm{nT}$ for 100 years. This may be due to the fact that the expansion of the auroral zone during magnetic storms leads to an increase in magnetic activity at these latitudes. Very high values of maximum possible disturbances were obtained near the cusp region - at the station Iqaluit $\Delta B=6870 \mathrm{nT}$ for 50 years and $\Delta B=9170$ nT for 100 years. The rate of change of geomagnetic fields at subauroral stations over 50 years may be as high as $d B / d t=490 \div 605 \mathrm{nT} / \mathrm{min}$; and over 100 years, $d B / d t=600 \div 680 \mathrm{nT} / \mathrm{min}$. For extreme values in geoelectric fields, the local maximum of predicted values is near the boundary between subauroral and auroral zones: $\Delta E=3610 \mathrm{mV} / \mathrm{km}$ over 50 years and $\Delta E=4060$ $\mathrm{mV} / \mathrm{km}$ over 100 years. Very large predicted values $(\Delta E=7900 \mathrm{mV} / \mathrm{km}$ over 50 years and $\Delta E=9970 \mathrm{mV} / \mathrm{km}$ over 100 years) were obtained for cusp stations.

The scenario of an extreme disturbance of the "once per 100 years" type was used in [Pulkkinen et al., 2012] to estimate distributions of horizontal magnetic field derivative (for data with a time step of $10 \mathrm{~s}$ ) and the geoelectric field as a function of geomagnetic latitude and ground conductivity. For the events occurring in March 1989 and October 2003, electric field values were the highest at $\sim 55^{\circ}-60^{\circ}$ latitude. When simulating the electric field under conditions of minimum and maximum conductivity of the earth's crust, maximum field values of 20 and $5 \mathrm{~V} / \mathrm{km}$ respectively were obtained.

Sharp boundaries in the distribution of amplitudes of geoelectric field and geomagnetic field derivative maxima approximately coincide with the sharp boundary of the disturbed geomagnetic field at a latitude of $\sim 55^{\circ}$ [Thomson et al., 2011]. The effect of the formation of the boundary can probably be explained by the location of the auroral electrojet, which makes the main contribution to the geoelectric field excitation during the development of a disturbance.

\section{PC INDEX OF GEOMAGNETIC ACTIVITIES AND FAILURES IN POWER SYSTEMS}

During the impact of coronal mass ejections (CMEs) on Earth's magnetosphere, which trigger intense magnetic storms, an increased solar proton flux may cause an outage of basic equipment on board interplanetary 
satellites (as happened with ACE before the October 29, 2003 storm), which are used for forecasting the solar wind. As a result, standard satellite-borne SW forecast systems will not work. Such intense high-energy solar proton fluxes usually accompany the largest solar flares. In this case, the use of specialized geomagnetic indices can give a warning about a magnetic storm as a support for the missing forecast from an interplanetary spacecraft such as ACE/WIND [Trichtchenko, Boteler, 2004].

Monitoring geomagnetic indices can provide additional warnings about SW disturbances to power system operators. A promising index could be the $P C$ (Polar Cap) index, calculated from magnetic variations in polar caps [Troshichev, Janzhura, 2012]. These variations are generated by ionospheric currents related to ionospheric and magnetospheric plasma convection over polar caps. Transpolar convection is driven by the dawn-dusk electric field resulting from the electrodynamic relation between the polar cap and the solar wind. Thus, the $P C$ index can characterize the electric field of the solar wind applied to the entire magnetosphere. This electric field induces transpolar plasma convection corresponding to plasma movement from the tail to Earth. This convection is potentially unstable and can cause magnetospheric substorms. The occurrence of high $P C$ levels may indicate an impending substorm. Hence, monitoring the $P C$ level can provide a forecast of possible substorms and resulting power grid failures. The alarm condition is indicated by the threshold level $P C=10$ $\mathrm{mV} / \mathrm{m}$ [Stauning, 2013].

\section{ECONOMIC EFFECTS OF GIC}

There are numerous examples of catastrophic consequences of strong magnetic storms that occurred in the USA, Canada, Scandinavia, and Japan [Lanzerotti, 2001]. However, even in the absence of catastrophic violations, GIC cause saturation of transformers and disrupt voltage control so that losses in a transformer increase and overloads occur in electricity transmission [Oughton et al., 2017]. For instance, during the magnetic storms on July 15, 2000 and March 31, 2001, the energy transmission limit was lowered by operators of the PJM electrical network (USA) by $20 \%$ [Forbes, 2004]. At the same time, the actual volume of transmitted energy also decreased. The shortage of energy led to an almost fourfold increase in present-day regional prices. Econometric analysis accounting for the influence of all possible factors shows that even relatively weak magnetic storms affect present-day prices. Only for a year and a half (June 2000 - December 2001), the economic impact of SW on the US power system amounted to \$ 500 million.

Serious economic effects for the global electric power market reveal themselves even when no severe SW-induced disruptions occur. Forbes and St. Cyr [2008] have shown that market prices in various national electricity markets are statistically related to local geomagnetic disturbances. Even if during magnetic storms there is no loss of technological equipment, GIC in regional power grids have a significant effect on economic resilience [Schrijver et al., 2014, 2015]. These and many other examples dictate the need for a deeper study of the SW effect on global infrastructure. The above estimates take into account only direct damage from the SW impact, but indirect losses for the world economy can be much greater [Schulte in den Baumen et al., 2014].

In the joint press release from AGU and BAS dated January 18, 2017, direct and indirect economic losses to the United States from the temporary outage of power grids due to GIC, similar to the blackout in Quebec in 1989, have been estimated. The US National Power System includes over 6000 generating capacities, over $800000 \mathrm{~km}$ of power transmission lines, and countless step-down transformers. All these elements may prove to be potential points for GIC inflow through their grounding. This huge network is controlled by more than 100 centers responsible for the real-time management of the network. It is currently unclear when network operators may set off or call off an alarm since it is impossible to say with certainty when a magnetic storm begins and ends. Powerful solar flares often occur, but ejection of a solar plasma cloud is not always directed toward Earth.

While the probability of an extreme magnetic storm, the level of the 1859 Carrington event, is relatively low at a given time, it is almost inevitable that it will eventually occur. The probable shutdown zone and daily lost GDP have been estimated in accordance with different scenarios of magnetic storm development [Eastwood et al., 2017]. If a magnetic storm covers $55^{\circ} \pm 2.75^{\circ}$ geomagnetic latitudes, it causes direct economic losses for the US economy in the amount of $\$ 3.2$ billion per day ( 8 $\%$ of daily GDP). A scenario under which a magnetic storm covers $45^{\circ} \pm 2.75^{\circ}$ geomagnetic latitudes leads to economic losses of $\$ 16.5$ billion per day. Finally, a scenario where a magnetic storm occurs at $50^{\circ} \pm 7.75^{\circ}$ latitudes results in potential economic losses for the US economy in the amount of $\$ 41.5$ billion per day along with daily losses for the global economy of $\$ 7$ billion [Oughton et al., 2017].

Generally, estimated potential damage caused by extreme SW relates to direct economic expenditures in a shutdown zone, whereas indirect losses of domestic and international electric power supply chains are ignored. On average, the direct economic expenditures associated with power outages represent only $49 \%$ of the total potential macroeconomic cost. In the most extreme scenario of power outage affecting $66 \%$ of the US population, there could be $\$ 41.5$ billion daily domestic economic losses, plus additional $\$ 7$ billion for failures in the international electric power supply chain. There is no agreement among electrical engineering experts regarding possible criticality of outages caused by a strong magnetic storm. Some believe that the outages can last only for a few hours or days because an electrical failure in a power transmission system will protect electrogenerating facilities, while others fear that a power outage can last for weeks or months because many transformers will be damaged and need to be replaced.

Because of the potential risk to production facilities, the US Federal Energy Regulatory Commission has 
required the North American Power Supply Reliability Corporation to develop reliability standards to mitigate the potential impact of geomagnetic disturbances on the operation of the national electric power grid [Jonas, McCarron, 2015].

\section{GIC IN CONDUCTIVE SYSTEMS AND POWER TRANSFORMERS}

Technologically developed countries are actively creating systems for monitoring and forecasting the impact of various SW factors on ground-based technological and satellite-borne systems [Weigel et al., 2003]. Nonetheless, the results obtained are commercial property and are not available for detailed analysis by the global scientific community. It should also be taken into account that since the Quebec accident the population of energy consumers has radically changed - networks have been satiated with nonlinear consumers [Pirjola, 1985b], which significantly increased the probability of destructive effects of GIC.

The GIC frequency $0.001-1 \mathrm{~Hz}$ is low, and for power grids using the $50-60 \mathrm{~Hz}$ standard, they are equivalent to DC current. In a three-phase power grid, GIC flow through the neutral and windings of transformers as shown in Figure 14. This GIC path results in a biasing of magnetic cores of the transformers and in a displacement of the transformer regime (see Figure 15) [Vakhnina, Kretov, 2012a, b]. Such a displacement of the transformer regime causes the magnetizing current shape to distort, which is equivalent to the appearance of higher harmonics in the magnetizing current spectrum.

The presence of higher harmonics in power grids has a number of consequences for their stability [Kartashev, Din-Duc, 2007], but here we will note only one that played a key role in the Quebec event. A frequency increase with increasing contribution of higher harmonics leads to a deterioration in dielectric properties of materials included in electrical installations and hence to an increase in heat losses. In turn, heating of the material worsens its dielectric properties, a positive feedback is created, which ultimately causes a dielectric breakdown and a failure in the electrical installation, which was observed in the Quebec event.

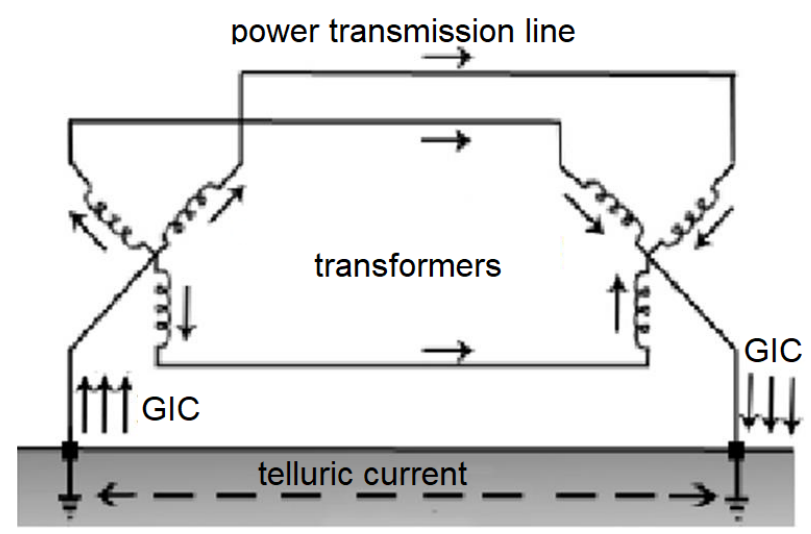

Figure 14. Current loop formed by GIC in a three-phase power grid

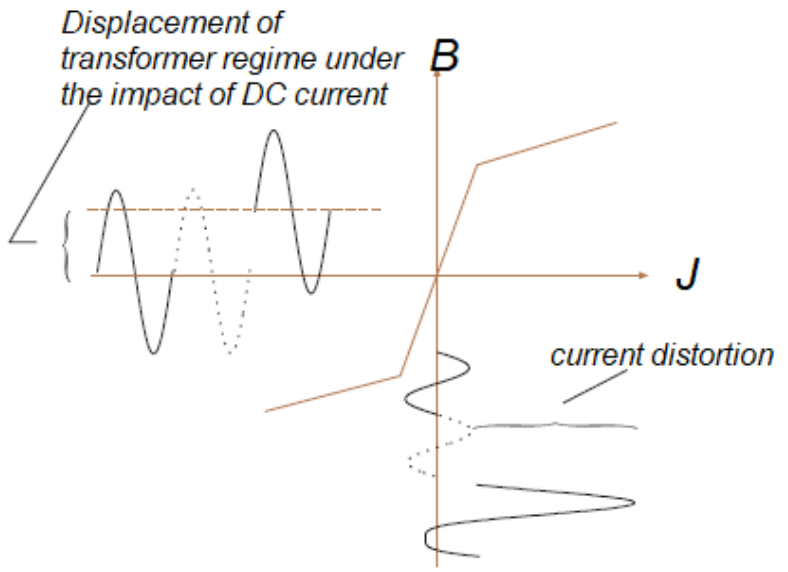

Figure 15. Qualitative illustration of a mechanism of distortion of the harmonic current composition in a transformer, loaded by GIC. It is shown how the transformer regime is displaced, the current shape is distorted, and higher harmonics appear in the current spectrum.

Since an increase in the level of harmonics occurs at one of the stages of the development of the process, it is logical to use this anomaly as a source of information on the GIC effect. The problem of higher harmonics in a power grid takes on particular importance due to the wide application of high-tech equipment with nonlinear electromagnetic characteristics [Girgis, Vedante, 2015]. When nonlinear consumers make up an insignificant part (to $10 \%$ ) of the power of the electric power supply system, their influence on the power grid and its elements is minor and does not lead to significant negative consequences. Otherwise, we should be ready for various kinds of failures, and sometimes accident situations. Additional heating from higher harmonic currents can lead to overheating of neutral wires and premature operation of protective devices (overheat controls and circuit breakers) [Vakhnina, Kretov, 2012a, b; Gurevich, 2010, 2014]. Higher harmonics cause additional magnetic reversal losses and eddy currents in the steel of a magnetic core.

Overheating of a transformer drastically reduces its service life. To limit the overheating, it is necessary to reduce the transmitted power or deliberately overestimate the capacity of the transformer itself [Marti et al., 2013]. Harmonics significantly increase motor losses. Here, along with losses in copper and steel, similar to losses in a transformer, due to the significant difference between speeds of rotating fields created by higher harmonics and the motor rotor, additional losses arise in damper windings and the magnetic core of the motor. A long-term GIC impact can bring about a cumulative effect that shortens the operating life of the transformer [Albertson et al., 1992].

The main GIC effect on power grids is saturation of the magnetic system of power transformers [Kappenman et al., 1981]. Passing through the grounded neutral of a power transformer, GIC produce additional onesided bias of the magnetic system of the power transformer. When the core of a power transformer operates in the nonlinear part of the hysteresis, part of the magnetic flux is driven out of the core, generating a leakage flux. Leakage fluxes cause additional heating of metal 
structural elements and current-carrying parts of power transformers and hence heating of oil. Due to the saturation of the magnetic system of power transformers, nonsinusoidal magnetizing currents, which also circulate through the electrical network, increase. A power transformer with a core operating in the non-linear part of the hysteresis loop becomes a generator of higher harmonics, which are multiples of the operating frequency. In a power grid, the reactive power consumption increases and the network transmission capacity decreases, voltage drops, false alarms of relay protection and automation may occur; hence an abnormal operation for consumers [Gusev et al., 2020].

Studies of electrical networks of different configurations have shown that power transformers (autotransformers) of terminal substations suffer from the most intense effect of GIC when the overhead power transmission line routing coincides with the geoelectric field direction. Transformers (autotransformers) of doubleended substations are less susceptible to the GIC effect if the geographic direction of overhead power transmission lines before and after a substation remains unchanged.

An example of a comprehensive approach to power system security is the rebuilding of the Quebec power grid. After a catastrophic accident in March 1989, HydroQuebec has significantly revised the organization of the protection of the power grid from possible magnetic storms. The power grid has been equipped with 17 GIC detection stations; in the vicinity of the power transmission line, apart from the main geomagnetic observatory, six new magnetometers have been deployed. Changes of power grid parameters, the GIC intensity in each node, the level of harmonics, and temperature change at critical points are controlled by a special program that simulates the operation of the 500 and $300 \mathrm{kV}$ system networks [Marti, Yiu, 2015]. The total expenditures on modernization of the system were approximately $\$ 1.2$ billion.

\section{DEVELOPMENT OF PHYSICAL AND STATISTICAL MODELS FOR ASSESSING THE RISK FROM NEGATIVE GIC EFFECTS}

In Canada, the United States, and Nordic countries, works are underway to create systems for monitoring and forecasting the impact of various SW factors on ground technological systems. However, they are mostly regional and cannot be directly applied to the Russian Arctic.

\subsection{Statistical relationships between varia- tions in the geomagnetic field, auroral electrojet,} and geomagnetically induced currents

Knowledge of the statistical relationships is necessary as a first step in constructing diagnostic GIC models based on general SW characteristics. The possibility of developing and testing statistical GIC models is provided by data on currents in the Nord Transit power transmission line on the Kola Peninsula. As magnetometric observations are impossible in the immediate vicinity of PTL, data from IMAGE magnetic stations in the region under study can be used [www.geo.fmi.fi/image].

Vorobev et al. [2020c] have constructed histograms of averages of different geomagnetic disturbance and GIC characteristics for 2015 at $1 \mathrm{hr}$ intervals of local time (LT). Diurnal variation of magnetic disturbance $|\Delta X|$ at IVA (Figure 16) indicates the presence of midnight (LT 24) and afternoon (LT 15) maxima. These maxima are caused by the intensification of the westward and eastward electrojets over the station during substorm activations. The diurnal variation of the geomagnetic field variability $|d \mathbf{B} / d t|$ has a different character with wide nighttime $(\mathrm{LT} \sim 21 \div 01)$ and morning (LT 5 $\div 6$ ) maxima. The night maximum is obviously related to an increase in the westward electrojet. The increased field variability in the morning is presumably due to intense Pc5 - Pi3 geomagnetic pulsation, which most often occur during these hours. Large values of $|d \mathbf{B} / d t|$ during Pi3 pulsations were observed by Yagova et al. [2018]. The diurnal variation of the mean GIC intensity at $\mathrm{VKH}$ repeats that of the geomagnetic field variability $|d \mathbf{B} / d t|$.

The calculation, carried out in [Viljanen, Tanskanen, 2011; Viljanen et al., 2012], of the diurnal variation in $d \mathbf{B} / d t$ for a long-term period at IMAGE high-latitude stations has also shown the presence of the morning and midnight maxima whose relative values varied depending on the season. The restoration of the auroral electrojet along the $\sim 22^{\circ}$ E meridian from IMAGE data has revealed the following regularities of the diurnal variation: the eastward electrojet prevails in the afternoon (13-21 MLT), the westward electrojet with a maximum at 01:30 MLT prevails the rest of the time. The morning maximum in the diurnal variation of $|d \mathbf{B} / d t|$ has no equivalent in the distribution of the intensity of disturbances generated by the electrojet; and no increase in the level of $|d \mathbf{B} / d t|$ variations is observed in the region of the maximum eastward electrojet.

To what extent are the geomagnetic indices characterizing substorm activity $(A E, P C N$, etc.) sufficient to predict the GIC value? For this purpose, Vorobev et al. [2020c] have calculated correlations between the absolute GIC value $|J|$, recorded at VKH, and the main geomagnetic indices for 2015. The maximum correlation dependence between $|J|$ and global indices holds for $A E$ $(R=0.56)$ and $A L(R=0.55)$. Although the $P C N$ index is considered to characterize substorm activity well, the correlation of GIC with $A E$ is higher than with $P C N$ $(R=0.44)$. The field variability $|d \mathbf{B} / d t|$ also depends on substorm activity, characterized by the $A E$ index. Nonetheless, the correlation coefficient with $A E R \sim 0.6$ corresponds to the determination coefficient $D=R^{2} \sim 0.36$, i.e. the field variability is determined by the electrojet intensity (the $A L$ index) only by $\sim 40 \%$.

Correlations of $|J|$ with the rate of change in the horizontal magnetic field components $|d X / d t|$ and $|d Y / d t|$ appear to be higher than with the magnitude of the field disturbance $|\Delta X|,|\Delta Y|$ by an average of $31.5 \%$. In this case, the contribution of the variability of the $Y$ component to the $|J|$ intensity is comparable to the contribution 


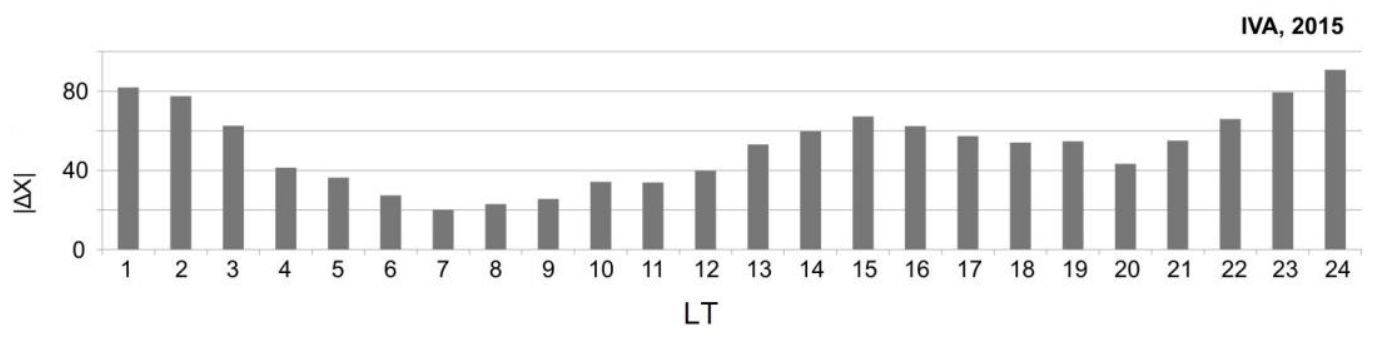

IVA, 2015

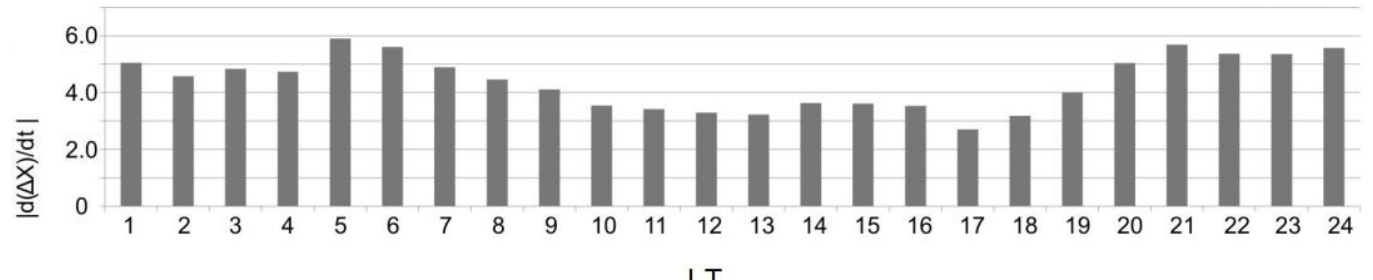

LT

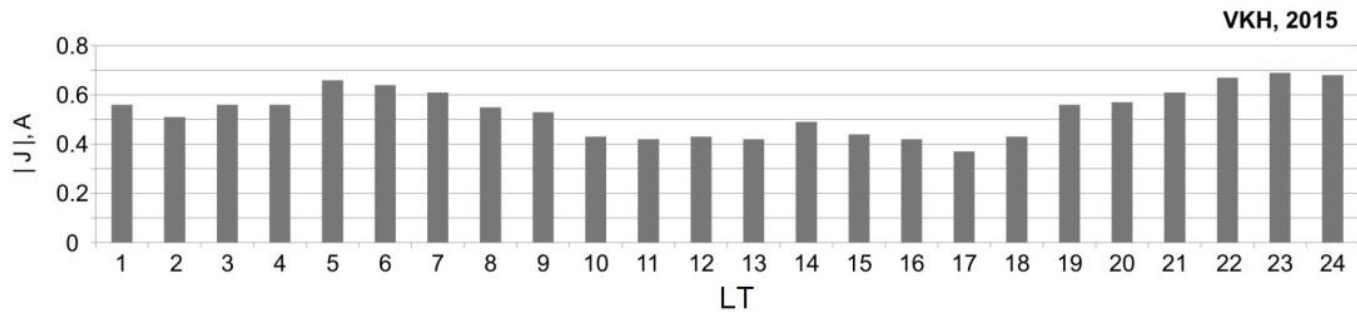

Figure 16. Diurnal variation in the mean magnitude of magnetic disturbance $|\Delta X|$ for 2015 at IVA (top panel); diurnal variation in the mean geomagnetic field variability $|d \mathbf{B} / d t|$ at IVA (middle panel), diurnal variation in the mean GIC intensity $|J|$ at VKH (bottom panel)

of the variability of the $X$ component both for the magnetic storm period and for non-storm intervals. This result confirms that the field derivative $d \mathbf{B} / d t$ fluctuates not only in magnitude, but also in direction, which can in fact be due to the presence of rapidly changing local vortex structures superimposed on the magnetic field of the auroral electrojet.

\subsection{Regression model of geomagnetically induced currents}

To solve applied problems, it is important to know what GIC value can be expected in the current state of the electrojet, characterized by the $A E$ index, and the current level of geomagnetic field variability.

To answer this question, statistical models are constructed on the basis of either neural networks [Gleisner, Lundstedt, 2001] or regression analysis. For example, Vorobev et al. [2020c] have designed a linear regression model as follows

$$
|J|=w_{0}+\sum_{i=1}^{N}\left(w_{i} C_{i}\right) \pm \Delta,
$$

where $C_{i}$ are driving parameters $(i=1, N) ; w$ are weight coefficients of the model; $\Delta$ is the average modeling error. The model of type (2) can statistically estimate $|J|$ from $N$ values of $C_{i}$. If we build a model using all values recorded, it will be determined by minor GIC disturbances, which are not very interesting. Therefore, only values greater than a certain threshold have been select- ed to devise a regression model. Linear regression models have been developed for $A E$ and $|d \mathbf{B} / d t|$ at IVA.

$$
\begin{gathered}
|J|=w_{0}+w_{1}|d \mathbf{B} / d t| \pm \Delta_{1}, \\
|J|=w_{0}+w_{2}|A E| \pm \Delta_{2} .
\end{gathered}
$$

Calculation for 2015 by a reduced model (excluding $|d \boldsymbol{B} / d t|<1 \mathrm{nT} / \mathrm{min}$ from the sample) for IVA yields the following values of the coefficients: $w_{0}=0$, $w_{1}=0.074 \mathrm{~A} \cdot \mathrm{min} / \mathrm{nT}$, and $w_{2}=0.0022 \mathrm{~A} / \mathrm{nT}$. Figure 17 presents the result of comparison between model GIC values and actual observations of the complex magnetic storm on March 17, 2015 occurring with a series of substorm activations. Comparing model values (3) with measured ones shows that the $A E$-based model predicts well the moments of GIC occurrence, but not its value. The model relying on $|d \mathbf{B} / d t|$ predicts well the moments of GIC amplification, but underestimates its extreme values. In the time interval considered, models (2) provide a mean error $\Delta_{1}= \pm 0.91 \mathrm{~A}$ and $\Delta_{2}= \pm 1.78 \mathrm{~A}$. In general, a statistical model using the parameter $|d \mathbf{B} / d t|$ works well (small $\Delta_{1}$ ) for intermediate values of $|d \boldsymbol{B} / d t|$ whose occurrence rate is at least $\sim 1 \%$ (statistically, this corresponds to $|d \boldsymbol{B} / d t|<40 \mathrm{nT} / \mathrm{min}$ and to the level $|J|<3 \mathrm{~A}$ ) and for intermediate $A E$ values. For large GIC values $(|J|>20$ A), the regression model based on the field variability data takes the form of (17) at $\Delta_{1}= \pm 2.3 \mathrm{~A}$, $w_{0}=11.677 \mathrm{~A}, w_{1}=0.11 \mathrm{~A} \mathrm{~min} / \mathrm{nT}$. At the same time, the $A E$-based simulation of large GIC values leads to significant errors and becomes unreasonable. 


\section{GIC modeling for the period 2015/03/17 06 UT - 2015/03/18 06 UT}

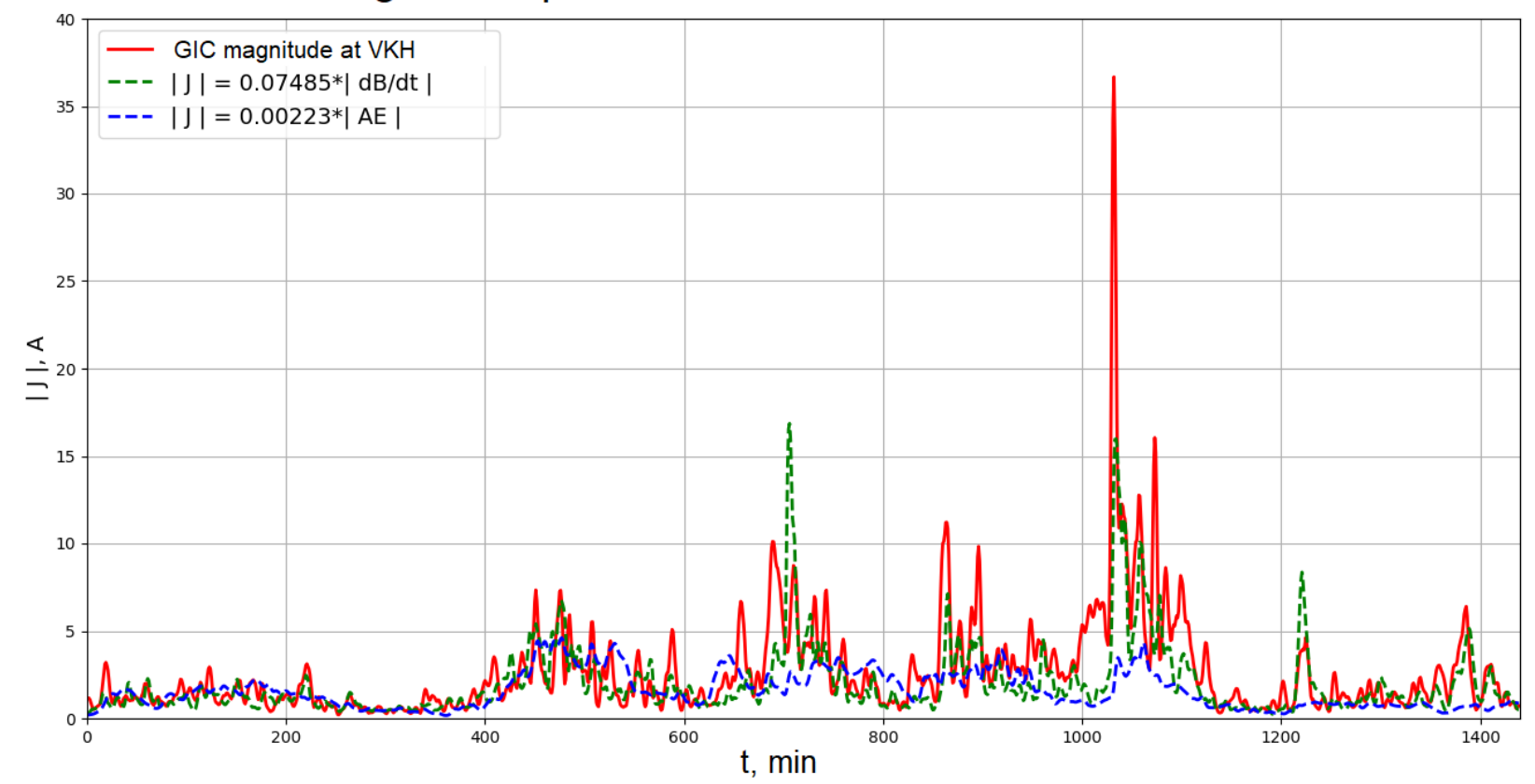

Figure 17. Result of GIC simulation for the storm period from 00 to 24 UT on March 17, 2015 by regression models (3)

\subsection{Statistical distributions of GIC and ge- omagnetic variations}

Knowledge of the statistical distribution of the probability of fluctuations enables us to estimate the probability of an extreme event, which may not even be observed during an observation period (under the assumption that it obeys the same laws). The probability curve statistically estimates what maximum disturbance is possible for the given period of observation.

The distribution of the probability density of values of the field component perturbation $|\Delta X|$ at SOD for 2015 is most consistent with the generalized Pareto distribution (Figure 18). Probability density distribution of $|d B / d t|$ and $|J|$ is best approximated by the lognormal distribution (Figure 19). The results given for SOD are the same for other IMAGE stations.

The resulting non-Gaussian distributions allow us to correctly determine the median, expectation, and probability of observation of the parameters analyzed in the given range, to estimate whether the values recorded are abnormal or not. Statistics shows that $|A E|>1000 \mathrm{nT}$ is observed $\sim 1 \%$ of time; $|J|>10 \mathrm{~A}, 0.03$ $\%$ of time; $|d B / d t|>60 \mathrm{nT} / \mathrm{min}, 0.2 \%$ of time. With a probability of $0.01 \%$ (approximately 50 times a year), disturbances with $|A E|>2000 \mathrm{nT}$, regional GIC and magnetic field disturbances with $|J|>13 \mathrm{~A},|d B / d t|>113$ $\mathrm{nT} / \mathrm{min}$, and $|\Delta X|>880 \mathrm{nT}$ may occur. Significant GIC variations $(|J|>1 \mathrm{~A})$ happen with a probability of $\sim 9.7 \%$.

Evaluating and analyzing statistical characteristics of the time series under study, we can talk about the similarity in their statistics, and hence about the similarity in their physical mechanisms. To test the hypothesis that the sample analyzed obeys a certain known distribution law, the Kolmogorov criterion has been used which characterizes the discrepancy between experimental curves and the expected distribution. Statistics of the $|\Delta X|$ distribution is quite well described by the generalized Pareto distribution, and the field and GIC variability better conforms to the log-normal distribution law. The fact that the probability distribution of both $F(|J|)$ and $F(|d B / d t|)$ has the form similar to the log-normal one may indicate that this distribution results from the multiplicative stochastic effect. Interestingly, according to many observations, the near-Earth plasma turbulence often has a log-normal form, implying that it is largely responsible for the geomagnetic field variability and thereby for the occurrence of GIC.

Planetary indices (of the $A E$ type) do not appear to be able to identify the conditions under which extreme values of currents occur at a given substation. More precisely, GIC can be characterized by regional geomagnetic indices. The local GIC value is determined not only by the local $d B / d t$ value and geoelectric conditions, but also by the spatial relationships between the extension of power transmission lines and the scale of fast geomagnetic disturbances [Sakharov et al., 2021; Yagova et al., 2021].

\section{FORECAST OF SPACE WEATHER, AURORAL OVAL POSITION AND RISK FOR POWER GRIDS WITH GLOBAL MHD SIMULATION}

Analysis of past events can provide insight into physical foundations of SW effects on technological systems and recommendations for improving methods of predicting the effects. While examples of GIC modeling for individual events seem quite convincing, the problem of predicting possible GIC by models describing the development of SW disturbances from the solar 

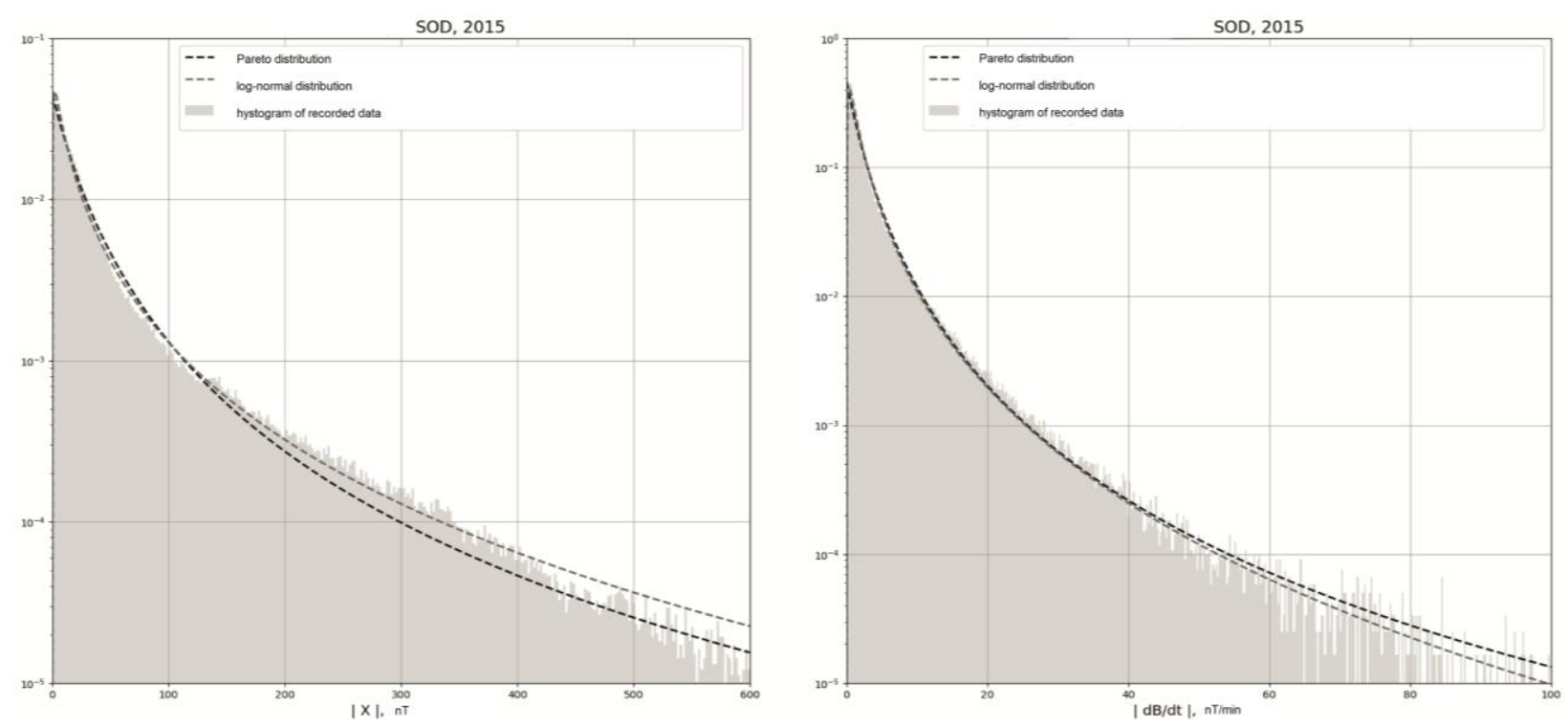

Figure 18. Distributions of the probability density of a geomagnetic disturbance $|\Delta X|$ and the geomagnetic field variability $|d B / d t|$ for SOD in 2015

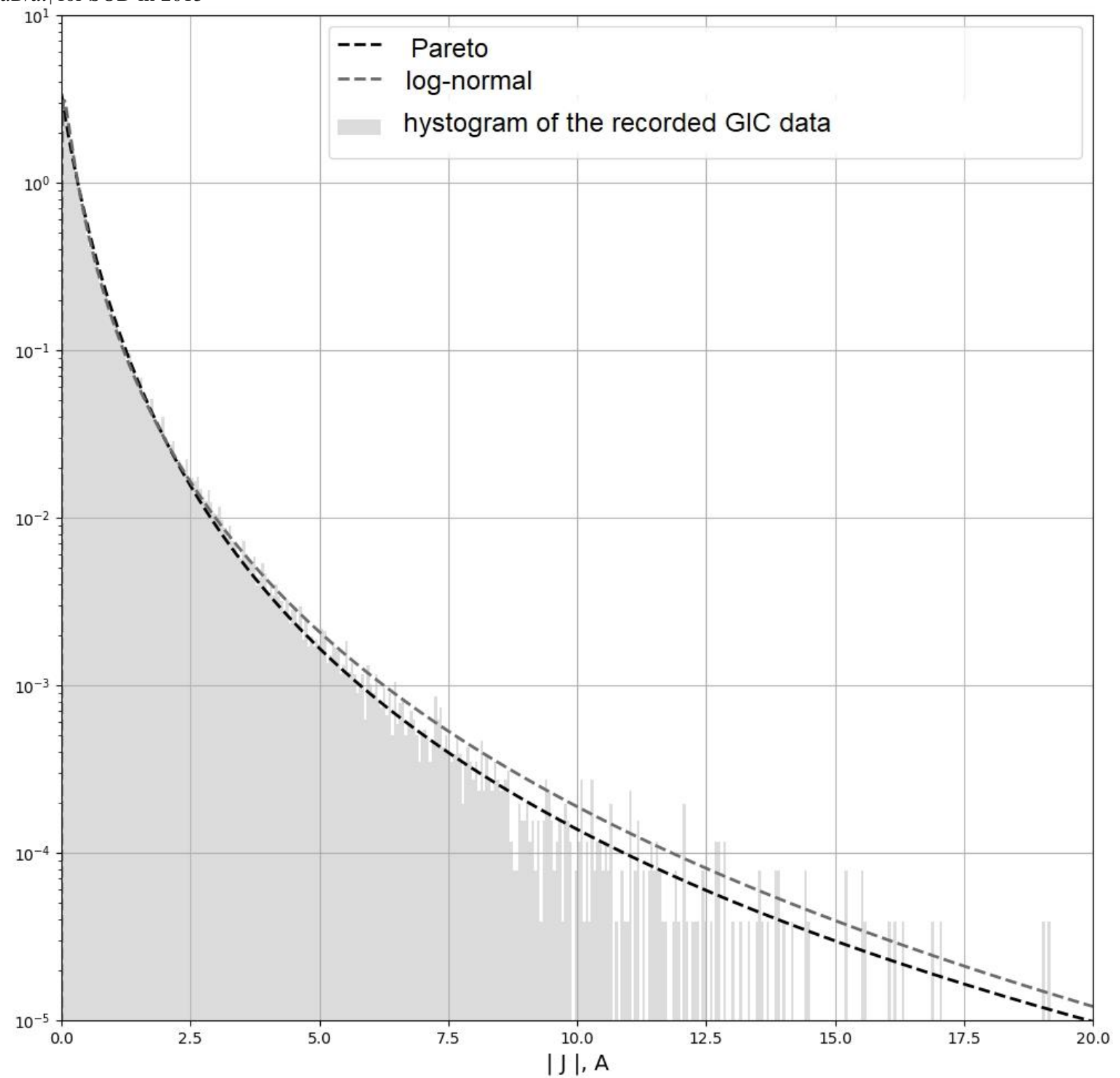

Figure 19. Distribution of the probability density of GIC values for VKH in 2015 
wind to Earth's surface is still far from being solved. Constant observations of the solar wind at the Lagrange point L1 between Earth and the Sun make it possible in practice to make a forecast with a 30-60 min horizon. Such a GIC forecast, at least one hour before expected extreme events, would be extremely important because works on transformer protection in large industrial systems may take $1-2 \mathrm{hrs}$. In this case, the expected $d B / d t$ value is required to be predicted specifically for the places, where technological systems are located, although spatial resolution of the predictive model may be rather low $(\sim 100 \mathrm{~km})$.

The fundamental cause of geomagnetic disturbances is global processes on the Sun, in the solar wind, and in the magnetosphere. The main cause of strong GIC or, which is almost equivalent, high $d B / d t$ is CME [Kataoka, Pulkkinen, 2008]. Huttunen et al. [2008] have compared the efficiency of generation of strong GIC by different CME structures (sheath, ejecta, boundary layers). When CME interacts with the magnetosphere, the most intense GIC occur in passing through the turbulent sheath of the plasma cloud shell, which is due to its ability to induce substorms and create a higher level of magnetospheric turbulence. The strongest GIC are generated during magnetospheric storms, although significant ones can be observed in the absence of high magnetospheric activity in terms of the Dst index. Weigel et al. [2003] have examined different solar wind parameters separately to assess how they affect variations in the geomagnetic field and its time derivative. The authors came to the conclusion that the process responsible for $X$-component variations differs from that determining $d X / d t$.

At present, the level of SW forecast on different temporal and spatial scales is still far from satisfactory, but future high-resolution ground and space observations may expand the fundamental concepts that form the basis for modeling and forecasting. Predictive models based on the chaos theory and nonlinear dynamics qualitatively correctly reproduce observable features of solar-terrestrial relations, whereas models based on statistics and artificial neural networks appear to be more effective for real-time forecast [Messerotti et al., 2009].

\subsection{Computer models of real-time forecast of GIC risks}

For technological systems, one of the practical steps taken by the international geophysical community to mitigate damage from SW events is to develop numerical models capable of predicting possible electromagnetic disturbances on-line [Veeramany et al., 2016]. A promising method able to provide such a prediction is a combination of global SW models and simulations of near-surface electromagnetic fields [Pulkkinen et al., 2007, 2010; Zhang et al., 2012; Ngwira et al., 2013a, b, 2014; Püthe, Kuvshinov, 2013]. This simulation can provide a forecast of GIC in technological systems since these currents can be calculated if data on the telluric electric field as well as parameters and geometry of a technological network are available [Zheng et al., 2013; Love,
Swidinsky, 2014].

The SW models are based on the physical principles of the interaction of the solar wind and the interplanetary magnetic field (IMF) with Earth's magnetosphere [Tsagouri et al., 2013]. The main input parameters of these models are satellite data on the solar wind and IMF, as well as $F 10.7$ solar radio flux data, transmitted in real time from satellites at the Lagrange point L1 along the Earth - Sun line (at a distance of $\sim 200 R_{\mathrm{E}}$ ). Considerable funds and efforts are applied to the development of numerical models that could predict possible geomagnetic disturbances on-line. An important but still unresolved aspect of the problem remains the quantitative normalization of the models because a purely qualitative forecast with unreliable errors and without geographical reference could lead to unreasonable and highly costly protective measures. NOAA's Space Weather Prediction Center (SWPC) carries out a comparative analysis and testing of the models developed. At the same time, special attention is paid to capabilities of the models to adequately predict fast magnetic field fluctuations, which are the main indicator of the occurrence of dangerous GIC levels. Nonetheless many additional factors such as Earth conductivity, the system configuration, high-voltage transformer type are, of course, also essential for the GIC value in a particular system. The possibility of using solar wind and IMF parameters as input data provides the potential for predicting $d B / d t$ with a lead time $\sim 30-60 \mathrm{~min}$. The most advanced and widely used are the following models.

The statistical model [Weimer, 2013] gives values of the vector magnetic field in Earth's surface. Its input parameters are data on IMF, solar wind velocity, tilt angle of Earth's magnetic dipole, and F10.7 solar radio flux. According to the values averaged over $25 \mathrm{~min}$, the model has a 20 min prediction horizon due to the time it takes a disturbance to propagate from a satellite to the front of a terrestrial shock wave. The spherical analysis coefficients for the field of geomagnetic disturbances have been calculated from observations made by the ACE satellite and at a network of 120 ground magnetometers.

The statistical model [Weigel et al., 2003] can predict $|d B / d t|$ with a lead time of $30 \mathrm{~min}$. The model was calculated from 1-min data obtained at the global network of magnetometers; the OMNI database [http://omniweb.gsfc.nasa.gov] is used as input information. The model predicts the expected geomagnetic disturbance $\Delta B$ and $d B / d t$ on Earth's surface from 6-hr previous measurements of interplanetary parameters. Success of the prediction depends significantly on the spatial position of the region of interest and on the local time. Wintoft [2005] has demonstrated that a 10-min value of root-mean-square $\log |d B / d t|$ at subauroral points can be predicted with a lead time of $30 \mathrm{~min}$ and a linear correlation coefficient of $\sim 0.8$.

To predict amplitudes of magnetic disturbances and the field derivative from solar wind and IMF data, models based on a neural network technique are being developed [Weigel et al., 2003; Lundstedt, 2005]. Existing models describe no more than $60 \%$ of variations for the auroral zone. It turns out that the amplitude of a magnetic 
disturbance and field derivative is not determined by the same process.

The advantage of empirical models is that they do not require powerful computational resources; therefore, they can be easily included in any systems for real-time forecasting of SW and risks for technological systems. More advanced numerical models can reproduce the evolution of an SW disturbance from the Sun to Earth, but they require powerful computational resources.

The Space Weather Modeling Framework (SWMF) [http://csem.engin.umich.edu/swmf] is a computer system for simulating plasma processes in NES [Tóth et al., 2005]. When simulated, NES is divided into several physical regions: the global magnetosphere (GM), the inner magnetosphere (IM), and the ionosphere (IE). The GM part has been built under a block-adaptive scheme (BATS-R-US) and is based on relativistic MHD equations. The computational domain extends from $32 R_{\mathrm{E}}$ upstream up to $224 R_{\mathrm{E}}$ to the magnetotail and up to $2.5 R_{\mathrm{E}}$ from Earth's center. The IM region is described by the Rice Convection Model (RCM), which calculates the bounce-averaged distributions of electrons and ions of different energies. The IE region is represented by the Ridley Ionosphere Model (RIM), which uses field-aligned currents from the GM block and the F10.7 parameter to calculate particle precipitation and ionospheric conductance. The SWMF model also contains a block that simulates the dynamics of Earth's radiation belt. This model has shown good results in the comparative analysis of different models [Pulkkinen et al, 2013]. It has been demonstrated to be able to reproduce the geomagnetic index Dst quite accurately. Reproducing magnetic variations at auroral latitudes is a much more challenging and still unresolved problem because it requires accurate reproduction of small-scale ionospheric current structures.

The Coupled Magnetosphere Ionosphere Thermosphere (CMIT) model [Wang et al., 2004] combines the Lyon-Fedder-Mobarry (LFM) model with the Thermosphere-Ionosphere-Electrodynamic Global Circulation Model (TIEGCM). The LFM block solves ideal MHD equations in order to describe the solar wind-magnetosphere interaction. The Open General Geospace Circulation Model (OpenGGCM) calculates the interaction between the solar wind and the magnetosphere-ionosphere-thermosphere system. In addition to the numerical solution of MHD equations with high spatial resolution in the magnetosphere, the model also includes ionospheric processes and their interrelation with the magnetosphere. Kinetic processes, which are not directly described by MHD equations, are taken into account in the model through parameterized empirical relations. OpenGGCM uses solar wind, IMF and F10.7 solar emission data as input parameters. At the output, the model gives all magnetospheric and ionospheric values needed to estimate GIC.

With the above global modeling methods, a picture of ionospheric currents and magnetic field variations near Earth's surface can be obtained. These findings can be used as input parameters for subsequent numerical simulation of telluric electric fields with modern 3D software [Kuvshinov, 2008; Ivannikova et al., 2018; Marshalko et al., 2020], which guarantees significantly higher modeling accuracy in high-contrast conductivity models.

\subsection{Predictive models of auroral oval intensity and position}

The most active SW effects occur in the auroral oval region [Vorobiev et al., 2018]. It features sharp gradients and a high level of ionospheric plasma turbulence, which provoke failures and significantly reduce the stability of the global navigation satellite systems GPS/GLONASS. There is a need to develop and test models for monitoring and real-time forecasting of the auroral oval dynamics under SW changes. A weatherindependent source of detailed information about the auroral oval structure is low-orbit satellite measurements of the auroral electron fluxes that generate auroras. The OVATION-prime (OP) auroral oval model is based on data gathered over more than 20 years of DMSP satellite observations of electron and proton fluxes with different energies [Newell et al., 2014]. Data on particle flux detection on board low-orbit satellites does not depend on the ionosphere illumination and the atmosphere cloudiness, is available for both hemispheres, and is more sensitive than ground or satellite optical observations. The OP model is parameterized by the solar wind and IMF parameters and calculates the expected 2D spatial distribution of the intensity of the main types of auroral electron and ion precipitation. All precipitation types are combined to produce maps of the total auroral power. The model uses the previously established statistical relationship between the interplanetary medium parameters and the auroral oval dynamics. The OP empirical model calculates the relationship between the intensity of auroral eruptions and the probability of their observation with naked eye and is implemented using the NOAA Web service [https://www.swpc.noaa.gov/products/aurora-30-minuteforecast], which predicts the probability of observing auroras for the next $30 \mathrm{~min}$.

There are currently available Web services focused on regional monitoring of the auroral oval, which have been developed by University of Alaska [https://www. gi.alaska.edu/monitors/aurora-forecast], the Icelandic Meteorological Office [https://en.vedur.is/weather/ forecasts/aurora], and the University Centre in Svalbard [http://kho.unis.no]. The OP model was employed to develop a Web service for visualizing the occurrence rate of auroras, built using geographic information system methods [Vorobev et al., 2020b; Vorobev et al., 2020c]. The input parameters of the model are real-time data on the solar wind and IMF from interplanetary satellites transfered to the NASA FTP site. The time shift $(\sim 1 \mathrm{hr})$ due to solar wind propagation from an interplanetary satellite to the magnetosphere boundary provides a short-term forecast of the expected intensity and position of auroras. 


\section{CONCLUSION: OBJECTIVES OF FURTHER RESEARCH}

To date, space geophysics has reached a level that allows us to raise the question about real SW forecast. The objective of SW research is, on the one hand, to identify the relationships between solar activity and processes occurring in the interplanetary space, Earth's magnetosphere, ionosphere, and atmosphere; on the other hand, to analyze the influence of these processes on technogenic and biological systems. This problem is becoming more and more urgent since modern hightech systems, especially space-borne ones, are very sensitive to the effects of electromagnetic fields and radiation. Despite the large arsenal of modern space geophysics - solar telescopes, space stations between Earth and the Sun, hundreds of satellites in different orbits, networks of ground radars and magnetometers, etc. - the problem of monitoring and forecasting the state of NES has not been reduced to purely engineering; many fundamental questions remain unresolved.

Unlike hurricanes and storms that have a regional effect and are quite successfully predicted 2-3 days in advance, SW disturbances can span continents and develop within minutes after the initial disturbances have been detected in the solar wind. Although visual registration of solar flares and coronal mass ejections is available several days before the occurrence of geomagnetic disturbances, only a small part of solar ejections pose a threat of magnetic storms and GIC. Exactly what solar events cause intense GIC to occur remains an unresolved and actively studied issue. The objective of forecasting GIC is not reduced to the forecasting of magnetic storms. The model required for assessing the influence of geomagnetic activity on technological systems in arctic and subarctic latitudes should describe not only the dynamics of the large-scale magnetosphericionospheric current system, but also the rapidly varying localized field-aligned currents sporadically arising in it.

Having a calculated pattern of telluric fields, we can make an engineering calculation of GIC in a given technological system with a known geometry and structure. Estimating possible effects for each specific system is a separate task. Then, by calculating the response of potentials along a given branch of a pipeline or a power grid to GIC, engineers can fully imagine the behavior of cathodic protection during magnetic storms and identify weak elements of the grid. Operators can use the realtime forecast of possible critical levels of GIC to reduce the risk of catastrophic consequences (load reduction, capacitive protection system connection, etc.). Information about GIC is important not only from a practical point of view, but also from a general scientific point of view as GIC is an important element of the influence of solar activity on the magnetosphere - ionosphere system.

The most active effects of geomagnetic disturbances occur at auroral latitudes; therefore, in Nordic countries since the 1970s the GIC influence on ground technological systems and possible measures to reduce negative consequences have been studied. Even countries located at low latitudes are concerned about the possible impact of GIC on technological systems. These factors pose a particular threat to the safe operation of technological systems in the Russian Arctic zone, since the Russian Federation has the longest oil and gas pipelines, power transmission lines, and main traffic arteries [Sushko, Kosykh, 2013]. Calculation of possible GIC levels during typical and extreme magnetic storms, which can be used by network operators to take the necessary measures to reduce the risk of catastrophic consequences, is a very urgent task. Despite the exceptional importance of such research, the Russian academic community is practically not engaged in such tasks, and manufacturing companies of the Russian Federation at the moment do not show any interest in sustainable management of technological systems. The level and scope of domestic research in this area clearly lag behind the works carried out in advanced countries. The domestic reference documentation still does not take into account the GIC impact on electric power systems and the reliability of electrical equipment, although the task of accounting for potentially dangerous geomagnetic disturbances is relevant specifically for Russia due to the great length of power networks and pipelines at high latitudes. In addition, unlike Nordic countries and Canada, the auroral regions of the Russian Federation do not have a sufficiently dense network of magnetic stations. In many cases, information on GIC is the property of commercial industrial companies and is not available to the global scientific community for in-depth analysis.

To clarify laws of manifestations of the impact of geomagnetic disturbances on the operation of railway automation and to search for ways to limit the impact, it is reasonable to continue the study of anomalies in the sections of railway networks located primarily in the Arctic and subarctic zones. While the maximum GIC values recorded in railway conductors $(>1 \mathrm{~A})$ are not extremely high, the intense operation of expressway and high risks require careful attention to the impact of geomagnetic disturbances.

The need to develop a domestic model capable of estimating the SW parameters critical for technological systems has become urgent. The key output parameters of the model are statistical maps of magnetic field and GIC variability during magnetic storms and substorms, parameterized using various sets of solar wind and interplanetary magnetic field parameters, and geomagnetic indices. Statistical maps of GIC are input parameters for calculating induced currents in given technological systems. Synthetic models will provide an opportunity to identify weak elements of the technological network in terms of GIC and to predict critical GIC levels (for $0.5-1 \mathrm{hr}$ ), thereby enabling operators to take the necessary measures to reduce the risk of catastrophic consequences. It is also necessary to develop a global statistical model of alternating magnetic field over the ionosphere, electric currents flowing between the magnetosphere and the ionosphere along the geomagnetic field lines (field-aligned currents), a numerical model of electric currents in the ionosphere, a model of distribution of the rate of change of the geomagnetic field on Earth's surface and associated variations in the telluric 
field, and ultimately a GIC model. Presumably, the intensity of expected GIC is sharply inhomogeneous in space and does not coincide with the region of maximum magnetic disturbances. An important element is the compilation of the atlas of the earth's crust conductivity at high latitudes from the available results of MT sounding of the earth's crust.

In addition to direct SW threats to technological systems mainly related to GIC, there are indirect threats. Among them is a decrease in the reliability and performance quality of technical infrastructure, which is currently used everywhere. First of all, extreme SW factors affect the stability of radio communication [Bernhardt, 2017] and sharply increase the positioning error of users of global navigation satellite systems [Demyanov, Yasyukevich, 2021]. As the final result, it is necessary to develop a Russian software-observational complex for monitoring and predicting direct and indirect threats from SW, which will take into account the experience of the forecast centers in US NOAA [https://www.swpc.noaa.gov] and ESA [https://www.esa.int/Safety_Security/Space_Weather_O ffice].

The work was financially supported by RFBR as part of scientific project No. 19-15-50240. Many of the results presented in the review have been obtained jointly with V.B. Belakhovsky, V.V. Vakhnina, O.V. Kozyreva, Ya.A. Sakharov, and N.V. Yagova, whose cooperation I sincerely appreciate. I express my gratitude to the reviewers for the careful analysis of the work and a large number of constructive comments.

\section{REFERENCES}

Albertson V.D. Geomagnetic disturbance effects on power systems. IEEE Transactions on Power Delivery. 1992, vol. 8, iss. 3, pp. 1206-1216. DOI: 10.1109/61.252646

Anderson C.W., Lanzerotti L.J., Maclennan C.G. Outage of the L4 system and the geomagnetic disturbances of August 4, 1972. Bell System. Technical. J. 1974, vol. 53, iss. 9, pp. 19171837.

Apatenkov S.V., Sergeev V.A., Pirjola R., Viljanen A. Evaluation of the geometry of ionospheric current systems related to rapid geomagnetic variations. Ann. Geophys. 2004, vol. 22, pp. 63-72.

Apatenkov S.V., Pilipenko V.A., Gordeev E.I., Viljanen A., Juusola L., Belakhovsky V.B., et al. Auroral omega bands are a significant cause of large geomagnetically induced currents. $G e$ ophys. Res. Lett. 2020, vol. 47, no. 6, e2019GL086677. DOI: 10.1029/2019GL086677.

Arrillaga J., Bradley D., Bodger P. Power system harmonics. 2003. DOI: 10.1002/0470871229.

Barannik M.B., Danilin A.N., Katkalov Yu.V., Kolobov B.B., Sakharov Ya.A., Selivanov V.N. A system for registering geomagnetically induced currents in the neutrals of power autotransformers. Instruments and Experimental Techniques. 2012, no. 1, pp. 118-123. (In Russian).

Bedrosian P.A., Love J.J. Mapping geoelectric fields during magnetic storms: Synthetic analysis of empirical United States impedances. Geophys. Res. Lett. 2015, vol. 42, no. 23, pp. 10160-10170. DOI: 10.1002/2015GL066636.

Beggan C.D. Sensitivity of geomagnetically induced currents to varying auroral electrojet and conductivity models. Earth, Planets and Space. 2015, vol. 67, no. 24. DOI: $10.1186 / \mathrm{s} 40623-014-0168-9$.
Beggan C.D., Beamish D., Richards A., Kelly G.S., Thomson A.W.P. Prediction of extreme geomagnetically induced currents in the UK high-voltage network. Space Weather. 2013, vol. 11, iss. 7, pp. 407-419. DOI: 10.1002/swe.20065.

Belakhovsky V.B., Pilipenko V.A., Sakharov Ya.A., Lorentzen D.A. Geomagnetic and ionospheric response to the interplanetary shock on January 24. Earth, Planets and Space. 2017, vol. 69, no. 1. DOI: 10.1186/s40623-017-0696-1.

Belakhovsky V.B., Pilipenko V.A., Sakharov Ya.A., Selivanov V.N. Characteristics of the variability of the geomagnetic field for studying the impact of magnetic storms and substorms on electric power systems. Izvestiya. Physics of the Solid Earth. 2018, no. 1, pp. 173-185. (In Russian).

Belakhovsky V., Pilipenko V., Engebretson M., Sakharov Y., Selivanov V. Impulsive disturbances of the geomagnetic field as a cause of induced currents of electric power lines. J. of Space Weather and Space Climate. 2019, vol. 9, no. A18. DOI: $10.1051 / \mathrm{swsc} / 2019015$.

Béland J., Small K. Space weather effects on power transmission systems: the cases of Hydro-Québec and transpower New Zealand Ltd. NATO Science Ser. II: Mathematics, Physics and Chemistry. 2005, vol. 176, pp. 287-299.

Belov A.V., Gaidash S.P., Kanonidi K.D., Kanonidi K.K., Kuznetsov V.D., Eroshenko E.A. Operative center of the geophysical prognosis in IZMIRAN. Ann. Geophys. 2005, vol. 23, iss. 9, pp. 3163-3170. DOI: 10.5194/angeo-23-3163-2005.

Bernabeu E.E. Modeling geomagnetically induced currents in the Dominion Virginia Power using extreme 100-year geoelectric field scenarios. Pt. 1. IEEE Transactions on Power Delivery. 2013, vol. 28, iss. 1, pp. 516-523.

Bernhardt O.I. Space weather impact on radio device operation. Solar-Terr. Phys. 2017, vol. 3, no. 3, pp. 37-53. DOI: $10.12737 /$ stp-33201705.

Bolduc L. GIC observations and studies in the HydroQuebec power system. J. Atmos. Terr. Phys. 2002, vol. 64, iss. 16, pp. 1793-1802. DOI: 10.1016/S1364-6826(02)00128-1.

Bolduc L., Langlois P., Boteler D., Pirjola R. A study of geoelectromagnetic disturbances in Quebec. 1. General results. IEEE Transactions on Power Delivery. 1998, vol. 13, iss. 4, pp. 12511256. DOI: $10.1109 / 61.714492$.

Bolduc L., Langlois P., Boteler D., Pirjola R. A study of geoelectromagnetic disturbances in Quebec, 2. Detailed analysis of a large event. IEEE Transactions on Power Delivery. 2000 , vol. 15 , iss. 1 , pp. $272-278$.

Bonner L.R., Schultz A. Rapid predictions of electric fields associated with geomagnetically induced currents in the presence of three-dimensional ground structure: Projection of remote magnetic observatory data through magnetotelluric impedance tensors. Space Weather. 2017, vol. 15, pp. 204227. DOI: 10.1002/2016SW001535.

Boteler D.H. Distributed-source transmission line theory for electromagnetic induction studies. Proc. the $12^{\text {th }}$ International Zurich Symposium and Technical Exhibition on Electromagnetic Compatibility. Zürich, Switzerland, 1997, pp. 401-408.

Boteler D.H. Assessment of geomagnetic hazard to power systems in Canada. Natural Hazard. 2001, vol. 23, no. 2-3, pp. 101-120.

Boteler D.H. A new versatile method for modelling geomagnetic induction in pipelines. Geophysical Journal International. 2013, vol. 193, pp. 98-109.

Boteler D.J., Cookson V.J. Telluric currents and their effects on pipelines in the Cook Strait region of New Zealand. Materials Performance. 1986, vol. 25, no. 3, pp. 27-32.

Boteler D.H., Pirjola R.J. The complex image method for calculating the magnetic and electric fields produced at the surface of the Earth by the auroral electrojet. Geophysical Journal International. 1998, vol. 132, pp. 31-40. 
Boteler D.H., Jansen van Beek G. August 4, 1972 revisited: A new look at the geomagnetic disturbance that caused the L4 cable system outage. Geophys. Res Lett. 1999, vol. 26, no. 5, pp. 577-580.

Boteler D.H., Trichtchenko L. Telluric influence on pipelines. Oil and Gas Pipelines: Integrity and Safety Handbook. 2015, pp. 275-285.

Boteler D.H., Pirjola R.J. Modeling geomagnetically induced currents. Space Weather. 2017, vol. 15, pp. 258-276. DOI: $10.1002 / 2016$ SW001499.

Boteler D.H., Pirjola R.J. Numerical calculation of geoelectric fields that affect critical infrastructure. International $J$. Geosciences. 2019, vol. 10, pp. 930-949.

Boteler D.H., Shier R.M., Watanabe T., Horita R.E. Effects of geomagnetically induced currents in the BC Hydro $500 \mathrm{kV}$ system. IEEE Transactions on Power Delivery. 1989, vol. 4, no. 1, pp. 818-823.

Boteler D.H., Pirjola R.J., Nevalinna H. The effects of geomagnetic disturbances on electrical systems at the Earth's surface. Adv. Space. Res. 1998, vol. 22, pp. 17-27.

Boteler D.H., Pirjola R., Trichtchenko L. On calculating the electric and magnetic fields produced in technological systems at the Earth's surface by a "wide" electrojet. J. Atmos. Solar-Terr. Phys. 2000. vol. 14. pp. 1311-1315.

Bozoki B. The effects of GIC on protective relaying. IEEE Transactions on Power Delivery. 1996, vol. 11, pp. 725-739.

Brasse H., Junge A. The influence of geomagnetic variations on pipelines and an application for large-scale magnetotelluric depth sounding. J. Geophys. 1984, vol. 55, no. 1, pp. 31-36.

Campbell W.H. Induction of auroral zone electric currents within Alaska pipeline. Pure and Applied Geophysics. 1978 vol. 116, pp. 1143-1173.

Campbell W.H. Observation of electric currents in the Alaska oil pipeline resulting from auroral electrojet current sources. Geophys. J. Royal Astron. Soc. 1980, vol. 61, pp. 437-449.

Campbell W.H., Zimmerman J.E. Induced electric currents in the Alaska oil pipeline measured by gradient fluxgate and SQUID magnetometers. IEEE Transactions on Geoscience and Remote Sensing. 1980, vol. GE-18, no. 3, pp. 244 250. DOI: 10.1109/TGRS.1980.4307498.

Carter B.A., Yizengaw E., Pradipta R., Halford A.J., Norman R., Zhang K. Interplanetary shocks and the resulting geomagnetically induced currents at the equator. Geophys. Res. Lett. 2015, vol. 42, pp. 6554-6559. DOI: 10.1002/2015GL065060.

Chinkin V.E., Soloviev A.A., Pilipenko V.A. Identification of vortex currents in the ionosphere and estimation of their parameters based on ground magnetic data. Geomagnetism and Aeronomy. 2020, vol. 60, no. 5, pp. 559-569. DOI: $10.1134 / \mathrm{S} 0016793220050035$.

Chinkin V.E., Soloviev A.A., Pilipenko V.A., Engebretson M.J., Sakharov Ya.A. Determination of vortex current structure in the high-latitude ionosphere with associated GIC bursts from ground magnetic data. J. Atmos. Solar-Terr. Phys. 2021, vol. 212, 105514. DOI: 10.1016/j.jastp.2020.105514.

Cid C., Saiz E., Guerrero A., Palacios J., Cerrato Y. A Carrington-like geomagnetic storm observed in the 21 st century. J. Space Weather and Space Climate. 2015, vol. 5, no. A16. DOI: 10.1051/Swsc/2015017.

Clilverd M.A., Rodger C.J., Brundell J.B., Dalzell M., Martin I.,Mac Manus D.H., Thomson N.R., Petersen T., Obana Y. Long-lasting geomagnetically induced currents and harmonic distortion observed in New Zealand during the 7-8 September 2017 disturbed period. Space Weather. 2018, vol. 16, iss. 6, pp. 704-717. DOI: 10.1029/2018SW001822.

Coles R.L., Lam H.-L. Geomagnetic forecasting in Canada: A review. Physics in Canada. 1998, vol. 54, pp. 327-331.
Demyanov V.V., Yasyukevich Yu.V. Space weather: Risk factors for Global Navigation Satellite Systems, SolarTerrestrial Physics. 2021, vol. 7, 28-47, DOI: 10.12737/szf72202104

Dimmock A.P., Rosenqvist L., Hall J.O., Viljanen A., Yordanova E., Honkonen I., André M., Sjöberg E.C. The GIC and geomagnetic response over Fennoscandia to the 7-8 September 2017 geomagnetic storm. Space Weather. 2019, vol. 17, iss. 7, pp. 989-1010. DOI: 10.1029/2018SW002132.

Divett T., Ingham M., Beggan C.D., Richardson G.S., Rodger C.J., Thomson A.W.P., Dalzell M. Modeling geoelectric fields and geomagnetically induced currents around New Zealand to explore GIC in the South Island's electrical transmission network. Space Weather. 2017, vol. 15, iss. 10, pp. 1396-1412. DOI: 10.1002/2017SW001697.

Divett T., Richardson G.S., Beggan C.D., Rodger C.J., Boteler D.H., Ingham M., et al. Transformer level modeling of geomagnetically induced currents in New Zealand's South Island. Space Weather. 2018, vol. 16, iss. 6, pp. 718-735. DOI: 10.1029/2018SW001814.

Doumbia V., Boka K., Kouassi N., Grodji O.D.F., Amory-Mazaudier C., Menvielle M. Induction effects of geomagnetic disturbances in the geoelectric field variations at low latitudes. Ann. Geophys. 2017, vol. 35, iss. 1, pp. 3951. DOI: 10.5194/angeo-35-39-2017.

Eastwood J.P., Biffis E., Hapgood M.A., Green L., Bisi M.M., Bentley R.D., et al. The economic impact of space weather: where do we stand? Risk Analysis. 2017, vol. 37, iss. 2, pp. 206-218. DOI: 10.1111/risa.12765.

Efimov B., Sakharov Ya., Selivanov V. Geomagnetic storms. Research impacts on the energy system of Karelia and the Kola Peninsula. News of Electrical Engineering. 2013, no. 2, p. 80 .

Engebretson M.J., Steinmetz E.S., Posch J.L., Pilipenko V.A., Moldwin M.B., Connors M.G., et al. Nighttime magnetic perturbation events observed in Arctic Canada: 2. Multiple-instrument observations. J. Geophys. Res. 2019, vol. 124, no. 9, pp. 7459 7476. DOI: 10.1029/2019JA026797.

Erinmez I.A., Kappenman J.G., Radasky W.A. Management of the geomagnetically induced current risks on the national grid company's electric power transmission system. $J$. Atmos. Terr. Phys. 2002, vol. 64, pp. 743-756.

Eroshenko E.A., Belov A.V., Boteler D., Gaidash S.P., Lobkov S.L., Pirjola R., Trichtchenko L. Effects of strong geomagnetic storms on Northern railways in Russia. Adv. Space Res. 2010, vol. 46, iss. 9, pp. 1102-1110. DOI: 10.1016/ j.asr.2010.05.017.

Extreme Space Weather: Impacts on Engineered Systems and Infrastructure. London: Royal Academy of Engineering, 2013. 70 p. ISBN 1-903496-95-0.

Fernberg P.A., Samson C., Boteler D.H., Trichtchenko L., Larocca P. Earth conductivity structures and their effects on geomagnetic induction in pipelines. Ann. Geophys. 2007, vol. 25, pp. 207-218. DOI: 10.5194/angeo-25-207-2007.

Fiori R.A.D., Boteler D.H., Gillies D.M. Assessment of GIC risk due to geomagnetic sudden commencements and identification of the current systems responsible. Space Weather. 2014, vol. 12, pp. 76-91. DOI: 10.1002/2013SW000967.

Forbes K.F. Space weather and the electricity market. Space Weather. 2004, vol. 2, iss. 10, S10003.

Forbes K.F., St. Cyr O.C. Solar activity and economic fundamentals: Evidence from 12 geographically disparate power grids. Space Weather. 2008, vol. 6, iss. 10, S10003. DOI: 10.1029/2007SW000350.

Gaunt C.T. Why space weather is relevant to electrical power systems. Space Weather. 2016, vol. 14, iss. 1, pp. 2-9. DOI: 10.1002/2015SW001306. 
Gaunt C.T., Coetzee G. Transformer failure in regions incorrectly considered to have low GIC-risks. IEEE Power Tech. 2007, Conference Paper 445, Lausanne, July, pp. 807812.

Girgis R., Vedante K. Impact of GICs on power transformers: overheating is not the real issue. Electrification Magazine, IEEE. 2015, vol. 3, pp. 8-12. DOI: 10.1109/MELE.2015.2480355.

Gleisner H., Lundstedt H. A neural network-based local model for prediction of geomagnetic disturbances. J. Geophys. Res. 2001, vol. 106, pp. 8425-8434.

Guillon S., Toner P., Gibson L., Boteler D.A. Colorful blackout: the havoc caused by auroral electrojet generated magnetic field variations in 1989. IEEE Power and Energy. 2016, pp. 59-71. DOI: 10.1109/MPE.2016.2591760.

Gummow R., Eng P. GIC effects on pipeline corrosion and corrosion control systems. J. Atmos. Solar-Terr. Phys. 2002, vol. 64, iss. 16, pp. 1755-1764. DOI: 10.1016/s13646826(02)00125-6.

Gurevich V.I. The problem of electromagnetic influences on microprocessor-based relay protection devices. Components and Technologies. 2010, pp. 46-51. (In Russian).

Gurevich V.I. Vulnerabilities of Microprocessor-Based Protection Relays: Problems and Solutions. Moscow, InfraEngineering, 2014. 256 p. (In Russian).

Gusev Yu.P., Lkhamdondog A., Monakov Yu.V., Yagova N.V., Pilipenko V.A. Assessment of the impact of geomagnetically induced currents on the starting modes of power transformers. Electric Stations. 2020, no. 2. pp. 54-59.

Hakkinen L., Pirjola R. Calculation of electric and magnetic fields due to an electrojet current system above a layered Earth. Geophysica. 1986, vol. 22, pp. 31-44.

Hapgood M. A. Toward a scientific understanding of the risk from extreme space weather. Adv. Space Res. 2011, vol. 47, pp. 2059-2072.

Hapgood M. Prepare for the coming space weather storm. Nature. 2012, vol. 484, pp. 311-313.

Hapgood M. The great storm of May 1921: An exemplar of a dangerous space weather event. Space Weather. 2019, vol. 17, pp. 950-975. DOI: 10.1029/2019SW002195.

Hejda P., Bochnicek J. Geomagnetically induced pipe-tosoil voltages in the Czech oil pipelines during OctoberNovember 2003. Ann. Geophys. 2005, vol. 23, pp. 3089-3093.

Henriksen J.F., Elvik R., Gransen L. Telluric currents corrosion on buried pipelines. Proc. the 8th Scandinavian Corrosion Congress. Helsinki, Finland, 1978, vol. 2, pp. 167-176.

Huttunen K.E., Kilpua S.P., Pulkkinen A., Viljanen A., Tanskanen E. Solar wind drivers of large geomagnetically induced currents during the solar cycle 23. Space Weather. 2008, vol. 6, iss. 10, S10002. DOI: 10.1029/2007SW000374.

Ingham M., Rodger C.J. Telluric field variations as drivers of variations in cathodic protection potential on a natural gas pipeline in New Zealand. Space Weather. 2018, vol. 16, pp. 1396-1409. DOI: 10.1029/2018SW001985.

Ingham M., Rodger C.J., Divett T., Dalzell M., Petersen T. Assessment of GIC based on transfer function analysis. Space Weather. 2017, vol. 15, iss. 12, pp. 1615-1627. DOI: 10.1002/ 2017 SW001707.

Ivannikova E., Kruglyakov M., Kuvshinov A., Rastätter L., Pulkkinen A. Regional 3D modeling of ground electromagnetic field due to realistic geomagnetic disturbances. Space Weather 2018, vol. 16, iss. 5, pp. 476-500. DOI: 10.1002/2017SW001793.

Ivonin A.A. Influence of the Earth's geomagnetic field on corrosion protection of MGP of Gazprom Transgaz Ukhta. Corrosion of the Neftegaz Territories. 2015, no. 1, pp. 88-89. (In Russian).

Jonas S., McCarron E. Recent U.S. policy developments addressing the effects of geomagnetically induced currents. Space Weather. 2015, vol. 13, iss. 11, pp. 730 733. DOI: $10.1002 / 2015$ SW001310.

Kappenman J.G. Geomagnetic storms and their impact on power systems. IEEE Power Engineering Review. 1996, pp. 5-8.

Kappenman J. Systemic failure on a grand scale: The 14 August 2003 North American blackout. Space Weather. 2003, vol. 1, iss. 2. DOI: $10.1029 / 2003$ SW000027.

Kappenman J.G. An overview of the impulsive geomagnetic field disturbances and power grid impacts associated with the violent Sun-Earth connection events of 29-31 October 2003 and a comparative evaluation with other contemporary storms. Space Weather. 2005, vol. 3, iss.8, SO8C01. DOI: 10.1029/2004SW000128.

Kappenman J.G. Geomagnetic storms and their impact on the US power grid. Meta-R-319 Report, 2010.

Kappenman J.G., Albertson V.D., Mohan N. Current transformer and relay performance in the presence of geomagnetically induced currents. IEEE Transactions on Power Systems. 1981, vol. PAS-100, iss. 3, pp. 1078-1088.

Kartashev I.I. Din-Duc N. Influence of the characteristics of magnetization of a transformer on the spectrum of higher harmonics. Vestnik MEI. 2007, pp. 56-63. (In Russian).

Kasinsky V.V., Ptitsyna N.G., Lyakhov N.N., Tyasto M.I., Villoresi J., Yuchi N. Influence of geomagnetic disturbances on the operation of railway automation and telemechanics systems. Geomagnetism and Aeronomy. 2007, vol. 47, no. 5, pp. 714-718. (In Russian).

Kataoka R., Pulkkinen A. Geomagnetically induced currents during intense storms driven by coronal mass ejections and corotating regions. J. Geophys. Res. 2008, vol. 113, iss. A3, A03S12. DOI: 10.1029/2007JA012487.

Kelbert A., Balch C.C., Pulkkinen A., Egbert G.D., Love J.J., Rigler J.E., Fujii I. Methodology for time-domain estimation of storm time geoelectric fields using the 3D magnetotelluric response tensors. Space Weather. 2017, vol. 15, iss. 7, pp. 874-894. DOI: 10.1002/2017SW001594.

Kelly G.S., Viljanen A., Beggan C.D., Thomson A.W.P. Understanding GIC in the UK and French high-voltage transmission systems during severe magnetic storms. Space Weather. 2017, vol. 15, pp. 99-114. DOI: 10.1002/2016SW001469.

Khanal K., Adhikari B., Chapagain N.P., Bhattarai B. HILDCAA-related GIC and possible corrosion hazard in underground pipelines: A comparison based on wavelet transform. Space Weather. 2019, vol. 17, iss. 2, pp. 238-251. DOI: 10.1029/2018SW001879.

Knipp D. J. Synthesis of geomagnetically induced currents: Commentary and research. Space Weather. 2015, vol. 13, iss. 11, pp. 727-729. DOI: 10.1002/2015SW001317.

Kobelev A.V., Zybin A.A. Modern problems of higher harmonics in urban power supply systems. Bulletin of TSTU. 2011, vol. 17, no. 1, pp. 181-191.

Korja T., Zhamaletdinov A.A., Engels M., Kovtun A.A. Crustal conductivity in Fennoscandia - a compilation of a database on crustal conductance in the Fennoscandian Shield. Earth, Planets and Space. 2002, vol. 54, iss. 5, pp. 535-558. DOI: $10.1186 / \mathrm{BF} 03353044$.

Kozyreva O.V., Pilipenko V.A., Belakhovsky V.V., Sakharov Ya.A. Ground geomagnetic field and GIC response to March 17, 2015 storm. Earth, Planets and Space. 2018, vol. 70, no. 157. DOI: 10.1186/s40623-018-0933-2.

Kozyreva O., Pilipenko V., Sokolova E., Epishkin D. Geomagnetic and telluric field variability as a driver of geomagnetically induced currents. Springer Proc. in Earth and Environmental Sciences "Problems of Geocosmos-2018". Springer Nature Switzerland, AG 2019, pp. 297-307. DOI: 10.1007/978-3030-21788-4_26. 
Kozyreva O., Pilipenko V., Krasnoperov R., Baddeley L.J. Fine structure of substorm and geomagnetically induced currents. Ann. Geophys. 2020, vol. 63, no. 2, GM219. DOI: 10.4401/ ag-8198.

Krausmann E., Andersson E., Russell T., Murtagh W. Space Weather and Rail: Findings and Outlook. Joint Research Centre Report. JRC98155. Luxembourg, Publications Office of the European Union, 2015. DOI: 10.2788/211456.

Kuvshinov A. 3-D global induction in the oceans and solid Earth: Recent progress in modeling magnetic and electric fields from sources of magnetospheric, ionospheric, and oceanic origin. Survey in Geophysics. 2008, vol. 29, iss. 2, pp. 139-186. DOI: 10.1007/s10712-008-9045-z.

Kuvshinov A., Olsen N. A global model of mantle conductivity derived from 5 years of CHAMP, Orsted, and SACC magnetic data. Geophys. Res. Lett. 2006, vol. 33, iss. 18 L18301. DOI: 10.1029/2006GL027083.

Langlois P., Bolduc L., Chouteau M.C. Probability of occurrence of geomagnetic storms based on a study of the distribution of the electric field amplitudes measured in Abitibi, Québec, in 1993-1994. J. Geomagnetism and Geoelectricity. 1996, vol. 48, pp. 1033-1041.

Lanzerotti L.J. Geomagnetic influences on man-made systems. J. Atmos. Terr. Phys. 1979, vol. 41, pp. 787-796.

Lanzerotti L.J. Geomagnetic induction effects in groundbased systems. Space Sci. Rev. 1983, vol. 34, pp. 347-356. DOI: $10.1007 / \mathrm{BF} 00175289$.

Lanzerotti L.J. Space weather effects on technologies. Space Weather. 2001, vol. 125, iss. 11. DOI: 10.1029/GM125p0011.

Lanzerotti L.J., Medford L.V., MacLennan C.G., Thomson D.J. Studies of large-scale Earth potential across oceanic distances. ATT Technical Journal. 1995, pp. 73-84.

Lehtinen M., Pirjola R. Currents produced in earthed conductor networks by geomagnetically induced electric fields. Ann. Geophys. 1985, vol. 3, pp. 479-484.

Liu C.-M., Liu L.-G., Pirjola R., Wang Z.-Z. Calculation of geomagnetically induced currents in mid- to low-latitude power grids based on the plane wave method: A preliminary case study. Space Weather. 2009, vol. 7, iss. 4. S04005. DOI: 10.1029/2008SW000439.

Liu L., Ge X., Zong W., Zhou Y., Liu M. Analysis of the monitoring data of geomagnetic storm interference in the electrification system of a high-speed railway. Space Weather. 2016, vol. 14, iss. 10, pp. 754-763. DOI: 10.1002/2016SW001411.

Lotz S.I., Danskin D.W. Extreme value analysis of induced geoelectric field in South Africa. Space Weather. 2017, vol. 15 , iss. 10 , pp. $1347-1356$.

Love J.J. Magnetic monitoring of Earth and space. Phys. Today. 2008, vol. 61, iss. 2, pp. 31-37. DOI: 10.1063/1.2883907.

Love J.J. Credible occurrence probabilities for extreme geophysical events: Earthquakes, volcanic eruptions, magnetic storms. Geophys. Res. Lett. 2012, vol. 39, iss. 10, L10301. DOI: $10.1029 / 2012$ GL051431.

Love J.J., Swidinsky A. Time causal operational estimation of electric fields induced in the Earth's lithosphere during magnetic storms. Geophys. Res. Lett. 2014, vol. 41, pp. 22662274. DOI: $10.1002 / 2014 G L 059568$.

Love J.J., Cosson P., Pulkkinen A. Global statistical maps of extreme-event magnetic observatory $1 \mathrm{~min}$ first differences in horizontal intensity. Geophys. Res. Lett. 2016, vol. 43, iss. 9, pp. 4126-4135. DOI: 10.1002/2016GL068664.

Love J.J., Bedrosian P.A., Schultz A. Down to Earth with an electric hazard from space. Space Weather. 2017, vol. 15, iss. 5, pp. 658-662.

Love J.J., Lucas G.M., Kelbert A., Bedrosian P.A. Geoelectric hazard maps for the mid-Atlantic United States: 100 year extreme values and the 1989 magnetic storm. Geophys. Res. Lett. 2018, vol. 44. DOI: 10.1002/2017GL076042.
Love J. J., Hayakawa H., Cliver E. W. Intensity and impact of the New York Railroad superstorm of May 1921. Space Weather. 2019, vol. 17, pp. 1281-1292. DOI: 10.1029/2019SW002250.

Lucas G.M., Love J.J., Kelbert A. Calculation of voltages in electric geomagnetic storms: an investigation using realistic power transmission lines during historic Earth impedances. Space Weather. 2018, vol. 16, iss. 2, pp. 185-195. DOI: 10.1002/2017SW001779.

Lundstedt H. Solar caused potential in gas-pipelines in southern Sweden. Proc. Solar-Terrestrial Predictions Workshop (STPW-IV), Ottava, Canada, 1992, vol. I, pp. 233-237.

Lundstedt H. Progress in space weather predictions and applications. Adv. Space Res. 2005, vol. 36, pp. 2516-2523.

Lundstedt $\mathrm{H}$. The sun, space weather and GIC effects in Sweden. Adv. Space Res. 2006, vol. 37, pp. 1182-1191. DOI: 10.1016/j.asr.2005.10.023.

Mäkinen T. Geomagnetically Induced Currents in the Finnish Power Transmission System. Finnish Meteorological Institute, Geophys. Publ., Helsinki, Finland, 1993, no. 32, 101 p.

Marin J., Pilipenko V., Kozyreva O., Stepanova M., Engebretson M., Vega P., Zesta E. Global Pc5 pulsations during strong magnetic storms: excitation mechanisms and equatorward expansion. Ann. Geophys. 2014, vol. 32, iss. 4, pp. 319-331. DOI: 10.5194/angeo-32-319-2014.

Marshalko E., Kruglyakov M., Kuvshinov A., Murphy B.S., Rastätter L., Ngwira C., Pulkkinen A. Exploring the influence of lateral conductivity contrasts on the storm time behavior of the ground electric field in the eastern United States. Space Weather. 2020, vol. 18, iss. 3, e2019SW002216. DOI: 10.1029/2019SW002216.

Marshall R.A., Waters C.L., Sciffer M.D. Spectral analysis of pipe-to-soil potentials with variations of the Earth's magnetic field in the Australian region. Space Weather. 2010, vol. 8, iss. 5, S05002. DOI: 10.1029/2009SW000553.

Marshall R.A., Dalzell M., Waters C.L., Goldthorpe P., Smith E.A. Geomagnetically induced currents in the New Zealand power network. Space Weather. 2012, vol. 10, iss. 8, S08003. DOI: 10.1029/2012 SW000806.

Marshall R.A., Kelly A., Van der Walt T., Honecker A., Ong C., Mikkelsen D., et al. Modelling geomagnetic induced currents in Australian power networks. Space Weather. 2017, vol. 15, iss. 7. DOI: 10.1002/2017SW001613.

Marti L., Rezaei-Zare A., Narang A. Simulation of transformer hotspot heating due to geomagnetically induced currents. IEEE Transaction on Power Delivery. 2013, vol. 28, iss. 1, pp. 320-327.

Marti L., Yiu C. Real-Time Management of Geomagnetic Disturbances: Hydro One's eXtreme Space Weather control room tools. IEEE Electrification Magazine. 2015. Vol. 3, no. 4. P. 46-51. DOI: 10.1109/MELE.2015.2480637.

Martin B.A. Telluric effects on a buried pipeline. Corrosion. 1993, vol. 49, iss. 4, pp. 343-350.

McKay A.J., Whaler K.A. The electric field in northern England and southern Scotland: Implications for geomagnetically induced currents. Geophysical Journal International. 2006, vol. 167, pp. 613-625.

Medford L.V., Meloni A., Lanzerotti L.J., Gregori G.P. Geomagnetic induction on a transatlantic communication cable. Nature. 1981, vol. 290, pp. 392-393.

Meloni A., Lanzerotti L.J., Gregori G.P. Induction of currents in long submarine cables by natural phenomena. Rev. Geophys. Space Phys. 1983, vol. 21, pp. 795-803.

Messerotti M., Zuccarello F., Guglielmino S., Bothmer V., Lilensten J., Noci G., et al. Solar weather modelling and predicting. Space Sci. Rev. 2009, vol. 147, pp. 121-185. DOI: 10.1007/s11214-009-9574-x. 
Molinski T.S. Why utilities respect geomagnetically induced currents. J. Atmos. Terr. Phys. 2002, vol. 64, pp. 17651778.

Mullayarov V.A., Kozlov V.I., Grigoriev Yu.M., Romashchenko Yu.A. Current induced in a gas pipeline from a large magnetic disturbance 01.21.05. Science and Education. 2006, no. 1 , pp. $53-55$.

Myllys M., Viljanen A., Rui Ø.A., Ohnstad T.M. Geomagnetically induced currents in Norway: the northernmost highvoltage power grid in the world. J. Space Weather and Space Climate. 2014, vol. 4, no. A10. DOI: 10.1051/swsc/2014007.

National Research Council. 2008. Severe Space Weather Events: Understanding Societal and Economic Impacts: A Workshop Report. Washington, DC: The National Academies Press. DOI: 10.17226/12507.

Newell P.T., Liou K., Zhang Y., Sotirelis T., Paxton L.J., Mitchell E.J. OVATION Prime- 2013: Extension of auroral precipitation model to higher disturbance levels, Space Weather. 2014. Vol. 12, P. 368-379. DOI 10.1002/2014sw001056.

Ngwira C.M., Pulkkinen A., McKinnell L.-A., Cilliers P.J. Improved modeling of geomagnetically induced currents in the South African power network. Space Weather. 2008, vol 40, iss. 11, S11004. DOI: 10.1029/2008SW000408.

Ngwira C.M., Pulkkinen A., Wilder F.D., Crowley G. Extended study of extreme geoelectric field event scenarios for geomagnetically induced current applications. Space Weather. 2013a, vol. 11, pp. 121-131. DOI: 10.1002/swe.20021.

Ngwira C.M., Pulkkinen A., Mays L.M., Kuznetsova M.M., Galvin A.B., Simunac K., et al. Simulation of the 23 July 2012 extreme space weather event: What if this extremely rare CME was Earth directed? Space Weather. 2013b, vol. 11, pp. 671-679. DOI: 10.1002/2013SW000990.

Ngwira C.M., Pulkkinen A., Kuznetsova M.M., Glocer A. Modeling extreme "Carrington-type" space weather events using three-dimensional MHD code simulations. J. Geophys. Res.: Space Phys. 2014, vol. 119, pp. 4456-4474. DOI 10.1002/2013JA019661.

Ngwira C.M., Pulkkinen A.A., Bernabeu E., Eichner J., Viljanen A., Crowley G. Characteristics of extreme geoelectric fields and their possible causes: Localized peak enhancements. Geophys. Res. Lett. 2015, vol. 42, iss. 17, pp. 69166921. DOI: 10.1002/2015GL065061.

Ngwira C.M., Sibeck D., Silveira M.D., Georgiou M., Weygand J.M., Nishimura Yu., Hampton D. A study of intense local $d B / d t$ variations during two geomagnetic storms. Space Weather. 2018, vol. 16, iss. 6, pp. 676-693. DOI: 10.1029/2018SW001911.

Nikitina L., Trichtchenko L., Boteler D.H. Assessment of extreme values in geomagnetic and geoelectric field variations for Canada. Space Weather. 2016, vol. 14, pp. 481-494. DOI: 10.1002/2016SW001386.

Oliveira D.M., Ngwira C.M Geomagnetically Induced Currents: Principles. Brazilian J. Phys. 2017, vol. 47, no. 5, pp. 552-560. DOI: 10.1007/s13538-017-0523-y.

Oughton E.J., Skelton A., Horne R.B., Thomson A.W.P., Gaunt C.T. Quantifying the daily economic impact of extreme space weather due to failure in electricity transmission infrastructure. Space Weather. 2017, vol. 15, pp. 65-83. DOI: 10.1002/2016SW001491.

Overbye T.J., Shetye K.S., Hutchins T.R., Qiu Q., Weber J.D. Power grid sensitivity analysis of geomagnetically induced currents. IEEE Transactions on Power Systems. 2013, vol. 28. pp. 4821-4828. DOI: 10.1109/TPWRS.2013.2274624.

Panyushkin G.N. Kinetics of geomagnetic influence on underground corrosion of main pipelines. Pipeline Transport. 2014, no. 3-4, pp. 34-35.
Piccinelli R., Krausmann E. Space Weather and Power Grids - A Vulnerability assessment. Report to European Union, Luxembourg, 2014, 53 p. DOI: 10.2788/20848.

Pilipenko V.A., Belakhovsky V.B., Sakharov Ya.A., Selivanov V.N. Irregular geomagnetic disturbances embedded into substorms as a cause of induced currents in electric power lines. Proc. XLI Annual Seminar "Physics of Auroral Phenomena”. Apatity, 2018a, pp. 26-29.

Pilipenko V.A., Bravo M., Romanova N.V., Kozyreva O.V., Samsonov S.N., Sakharov Ya.A. Geomagnetic and ionospheric responses to the interplanetary shock wave of March 17, 2015. Izvestiya. Physics of the Solid Earth. 2018b, no. 5, pp. 61-80. DOI: 10.1134/S0002333718050125. (In Russian).

Pirjola R. Electromagnetic induction in the Earth by a plane wave or by fields of line currents harmonic in time and space. Geophysica. 1982, vol. 18, pp. 1-161.

Pirjola R. On currents induced in power transmission systems during geomagnetic variations. IEEE Transactions on Power Systems. 1985a, vol. 104, pp. 2825-2831.

Pirjola R. Effect of series capacitors, neutral point reactor, autotransformers and overhead shield wires on geomagnetically induced currents (GIC) in electric power transmission systems. Ann. Geophys. 1985b, pp. 479-484.

Pirjola R., Viljanen A., Complex image method for calculating electric and magnetic fields produced by an auroral electrojet of finite length, Ann. Geophysicae. 1998, vol. 16, pp. 1434-1444. DOI: 10.1007/s00585-998-1434-6.

Pirjola R. Review on the calculation of surface electric and magnetic fields and of geomagnetically induced currents in ground-based technological systems. Survey Geophysics. 2002, vol. 23, pp. 71-90.

Pirjola R., Pulkkinen A., Viljanen A. Studies of space weather effects on the Finnish natural gas pipeline and on the Finnish high-voltage power system. Adv. Space Res. 2003, vol. 31, iss. 4, pp. 795-805.

Pirjola R., Kauristie K., Lappalainen H., Viljanen A., Pulkkinen A. Space weather risk. Space Weather. 2005, vol. 3, iss. 2, S02A02. DOI: 10.1029/2004SW000112.

Pisarenko V.F., Rodkin M.V. Heavy-Tailed Distributions: Applications to Catastrophe Analysis. Moscow, GEOS, 2007, $242 \mathrm{p}$.

Ptitsyna N.G., Tyasto M.I., Kassinskii V.V., Lyakhov N.N. Do natural magnetic fields disturb railway telemetry? Proc. $7^{\text {th }}$ International Symposium on Electromagnetic Compatibility and Electromagnetic Ecology. St. Petersburg, 2007. pp. 281-290. DOI: 10.1109/EMCECO.2007.4371713.

Ptitsyna N.G., Kasinsky V.V., Villoresi G., Lyahov N.N., Dormande L.I., Iuccic N. Geomagnetic effects on mid-latitude railways: A statistical study of anomalies in the operation of signaling and train control equipment on the East-Siberian Railway. Adv. Space Res. 2008, vol. 42, iss. 9, pp. 1510-1514. DOI: 10.1016/j.asr.2007.10.015.

Pulkkinen A., Pirjola R., Boteler D., Viljanen A., Yegorov I. Modeling of space weather effects on pipelines. J. Applied Geophysics. 2001a, vol. 48, iss. 4, pp. 233-256. DOI: 10.1016/S0926-9851(01)00109-4.

Pulkkinen A., Viljanen A., Pajunpaa K., Pirjola R. Recordings and occurrence of geomagnetically induced currents in the Finnish natural gas pipeline network. J. Applied Geophysics. 2001b, vol. 48, pp. 219-231.

Pulkkinen A., Thomson A., Clarke E., McKay A. April 2000 geomagnetic storm: ionospheric drivers of large geomagnetically induced currents. Ann. Geophys. 2003, vol. 21, pp. 709-717.

Pulkkinen A., Lindal S., Viljanen A., Pirjola R. 2005 Geomagnetic storm of 29-31 October 2003: Geomagnetically induced currents and their relation to problems in the Swedish 
high-voltage power transmission system. Space Weather. 2005, vol. 3, iss. 8, S08C03. DOI: 10.1029/2004SW000123.

Pulkkinen A., Klimas A., Vassiliadis D., Uritsky V., Tanskanen E. Spatiotemporal scaling properties of the ground geomagnetic field variations. J. Geophys. Res.: Space Physics. 2006, vol. 111, iss. A3, A03305. DOI: 10.1029/2005JA011294.

Pulkkinen A., Hesse M., Kuznetsova M., Rastätter L. Firstprinciples modeling of geomagnetically induced electromagnetic fields and currents from upstream solar wind to the surface of the Earth. Ann. Geophys. 2007, vol. 25, pp. 881-893.

Pulkkinen A., Pirjola R., Viljanen A. Statistics of extreme geomagnetically induced current events. Space Weather. 2008, vol. 6, iss. 7, S07001. DOI: 10.1029/2008SW000388.

Pulkkinen A., Hesse M., Habib S., Van der Zel L., Damsky B., Policelli F., et al. Solar shield: Forecasting and mitigating space weather effects on high-voltage power transmission systems. Natural Hazards. 2010, vol. 53, pp. 333-345. DOI: 10.1007/s11069-009-9432-x.

Pulkkinen A.A., Bernabeu E., Eichner J., Beggan C., Thomson A.W.P. Generation of 100-year geomagnetically induced current scenarios. Space Weather. 2012, vol. 10, iss. 4, S04003. DOI: 10.1029/2011SW000750.

Pulkkinen A., Rastätter L., Kuznetsova M., Singer H., Balch C., Weimer D., et al. Communitywide validation of geospace model ground magnetic field perturbation predictions to support model transition to operations. Space Weather. 2013, vol. 11, iss. 6, pp. 369-385. DOI: 10.1002/swe.20056.

Pulkkinen A., Bernabeu E., Eichner J., Viljanen A., Ngwira C. Regional-scale high-latitude extreme geoelectric fields pertaining to geomagnetically induced currents. Earth, Planets and Space. 2015, vol. 67, no. 93. DOI: 10.1186/s40623-015-0255-6.

Pulkkinen A., Bernabeu E., Thomson A., Viljanen A., Pirjola R., Boteler D., et al. Geomagnetically induced currents: science, engineering and applications readiness. Space Weather. 2017, vol. 15, iss. 7, pp. 828-856. DOI: 10.1002/2016SW001501.

Püthe C., Kuvshinov A. Towards quantitative assessment of the hazard from space weather. Global 3D modellings of the electric field induced by a realistic geomagnetic storm. Earth, Planets and Space. 2013, vol. 65, pp. 1017.

Qiu Q., Fleeman J.A., Ball D.R. Geomagnetic disturbance. A comprehensive approach by American Electric Power to address the impacts. IEEE Electrification Magazine. 2015, vol. 3, no. 4, pp. 22-33.

Riley P. On the probability of occurrence of extreme space weather events. Space Weather. 2012, vol. 10, iss. 2, S02012. DOI: 10.1029/2011SW000734.

Rodger C.J., Mac Manus D.H., Dalzell M., Thomson A.W.P., Clarke E., Petersen T., et al. Long-term geomagnetically induced current observations from New Zealand: Peak current estimates for extreme geomagnetic storms. Space Weather. 2017, vol. 15, iss. 11, pp. 1447-1460. DOI: 10.1002/2017SW001691.

Sackinger W.M. The Relationship of Telluric Currents to the Corrosion of Warm Arctic Pipelines. Society of Petroleum Engineer Publ. (SPE), 22099, 1991, pp. 361-366.

Sakharov Ya.A, Danilin A.N., Ostafiychuk R.M. Registration of GIC in power systems of the Kola Peninsula. Proc. 7th Symposium on Electromagnetic Compatibility and Electromagnetic Ecology. St. Petersburg: 2007, pp. 291-293.

Sakharov Ya.A., Kudryashova N.V., Danilin A.N., Kokin S.M., Shabalin A.N., Pirjola R. Influence of geomagnetic disturbances on the operation of railway automation. Vestnik MIIT. 2009, iss. 21, pp. 107-111. (In Russian).

Sakharov Ya.A., Selivanov V.N., Bilin V.A., Nikolaev V.G. Extreme values of geomagnetically induced currents in the regional power system. Proc. XLII Annual Seminar "Physics of Auroral Phenomena". Apatity, 2019, pp. 53-56. DOI: 10.25702/KSC.2588-0039.2019.42.53-56.

Sakharov Ya.A., Yagova N.V., Pilipenko V.A. Geomagnetic pulsations Pc5/Pi3 and geomagnetically induced currents. Bulletin of the Russian Academy of Sciences: Physics. 2021, vol. 85, no. 3, pp. 445-450. DOI: 10.31857/s0367676521030236. (In Russian).

Schrijver C.J., Dobbins R., Murtagh W., Petrinec S.M. Assessing the impact of space weather on the electric power grid based on insurance claims for industrial electrical equipment. Space Weather. 2014, vol. 12, iss. 7, pp. 487-498. DOI: 10.1002/2014SW001066.

Schrijver C.S., Kauristie K., Aylward A.D., Denardini C.M., Gibson S.E., Glover A., et al. Understanding space weather to shield society: A global road map for 2015-2025 commissioned by COSPAR and ILWS. Adv. Space Res. 2015, vol. 55, no. 12, pp. 2745-2807. DOI: 10.1016/ j.asr.2015.03.023.

Schultz A. EMScope: A continental scale magneto-telluric observatory and data discovery resource. Data Sci. J. 2009, vol. 8, pp. IGY6-IGY20.

Schulte in den Baumen H., Moran D., Lenzen M., Cairns I., Steenge A. How severe space weather can disrupt global supply chains? Natural Hazards and Earth System Sciences. 2014, vol. 14, iss. 10, pp. 2749-2759. DOI: 10.5194/nhess-14-27492014.

Selivanov V.N., Barannik M.B., Danilin A.N., Kolobov V.V., Sakharov Ya.A. Study of the influence of geomagnetic disturbances on the harmonic composition of currents in neutrals of autotransformers. Proc. KSC RAS: Energetika. Apatity: Kola Scientific Center of the Russian Academy of Sciences, 2012, iss. 4, pp. 60-68. (In Russian).

Selivanov V.N., Barannik M.B., Bilin V.A., Efimov B.V., Kolobov V.V., Sakharov Ya.A. Investigation of the harmonic composition of the current in the neutral of a transformer during periods of geomagnetic disturbances. Proc. KSC RAS: Energetika. Apatity: Kola Scientific Center of the Russian Academy of Sciences. 2017, no. 1-14 (8), pp. 43-52. (In Russian).

Selivanov V.N., Danilin A.N., Kolobov V.V., Sakharov Ya.A., Barannik M.B. Results of long-term registration of currents in neutrals of power transformers. Trans. KSC RAS: Energetika. Apatity: Kola Scientific Center of the Russian Academy of Sciences, 2010. Iss. 1, pp. 84-90. (In Russian).

Sivokon V.P., Serovetnikov A.S. Geomagneticallyinduced currents in the electrical network of Kamchatka. Electro. 2013, pp. 19-22. (In Russian).

Sivokon V.P., Serovetnikov A.S. Variations in the current spectrum of a transformer exposed to geomagnetically induced currents. Electro. 2015, no. 1, pp. 18-21. (In Russian).

Sivokon V.P., Serovetnikov A.S., Pisarev A.V. Higher harmonics as indicators of geomagnetically induced currents. Electro. 2011, pp. 44-51. (In Russian).

Sokolova O., Korovkin N., Hayakawa M. Geomagnetic Disturbances Impacts on Power Systems: Risk Analysis and Mitigation Strategies. CRC Press, 2021, 268 p. DOI: 10.1201/9781003134152.

Space Storms and Space Weather Hazards. Ed. I.A. Daglis. NATO Sci. Ser., Kluwer, 2000. DOI: 10.1007/978-94-0100983-6.

Space Weather. Geophys. Monogr. Ser. Ed. Song P., H.J. Singer, G.L. Siscoe, AGU, Washington, D.C. 2001. vol. 125. pp. 353-358. DOI: 10.1029/GM125p0353.

Space Weather - Research Towards Applications in Europe. Ed. J. Lilensten. Astrophysics and Space Science Library, Springer. 2007, vol. 344, pp. 311-326. DOI: 10.1007/14020-5446-7. 
Stauning P. Power grid disturbances and polar cap index during geomagnetic storms. J. Space Weather Space Climate. 2013, vol. 3, no. A22. DOI: 10.1051/swsc/2013044.

Sushko V.A., Kosykh D.A. Geomagnetic storms. Threat to the national security of Russia. News of Electrical Engineering. 2013, no. 4, pp. 25-28.

Thomson A.W.P., McKay A.J., Clarke E., Reay S.J. Surface electric fields Power grid during the 30 October 2003 geomagnetic sand geomagnetically induced currents in the Scottish storm. Space Weather. 2005, vol. 3, iss. 11, S11002. DOI: 10.1029/2005SW000156.

Thomson A.W.P., McKay A.J., Viljanen A. A review of progress in modelling of induced geoelectric and geomagnetic fields with special regard to induced currents. Acta Geophys. 2009, vol. 57. pp. 209-219.

Thomson A.W.P., Gaunt C.T., Cilliers P., Wild J.A., Opperman B., L.-A. McKinnell, et al. Present day challenges in understanding the geomagnetic hazard to national power grids. Adv. Space Res. 2010, vol. 45, iss. 10, pp. 1182-1190. DOI: 10.1016/j.asr.2009.11.023.

Thomson A.W.P., Dawson E.B., Reay S.J. Quantifying extreme behavior in geomagnetic activity. Space Weather. 2011, vol. 9, iss. 10, S10001. DOI: 10.1029/2011SW000696.

Torta J.M., Marsal S., Quintana M. Assessing the hazard from geomagnetically induced currents to the entire highvoltage power network in Spain. Earth, Planets and Space. 2014, vol. 66, no. 87. DOI: 10.1186/1880-5981-66-87.

Tóth G., Sokolov I.V., Gombosi T.I., Chesney D.R., Clauer C.R., De Zeeuw D.L., et al. Space weather modeling framework: A new tool for the space science community. $J$. Geophys. Res. 2005, vol. 110, iss. A12, A12226. DOI: 10.1029/2005JA011126.

Tozzi R., de Michelis P., Coco I., Giannattasio F. A preliminary risk assessment of geomagnetically induced currents over the Italian territory. Space Weather. 2019, vol. 17, iss. 1, pp. 46-58. DOI: 10.1029/2018SW002065.

Trivedi N.B., Vitorello Í., Kabata W., Dutra S.L.G., Padilha A.L., Bologna M.S., de Pádua M.B., et al. Geomagnetically induced currents in an electric power transmission system at low latitudes in Brazil: A case study. Space Weather. 2007, vol. 5. S04004. DOI: 10.1029/2006SW000282.

Trishchenko L.D. Geomagnetic Disturbances and Power Supply and Wire Communication Systems. Plasma Heliophysics. Moscow: Fizmatlit, 2008, vol. 2, pp. 213-29. (In Russian).

Trichtchenko L., Boteler D.H. Modelling of geomagnetic induction in pipelines. Ann. Geophys. 2002, vol. 20, pp. 1063 1072. DOI: 10.5194/angeo-20-1063-2002.

Trichtchenko L.D., Boteler D. Modeling geomagnetically induced currents using geomagnetic indices and data. IEEE Transactions on Plasma Science. 2004, vol. 32, pp. 14591467. DOI: 10.1109/TPS.2004.830993.

Troshichev O., Janzhura A. Space Weather Monitoring by Ground-Based Means: PC Index. Springer, 2012, 288 p. DOI: 10.1007/978-3-642-16803-1.

Tsagouri I., Belehaki A., Bergeot N., Cid C., Delouille V., Egorova T., et al. Progress in space weather modeling in an operational environment. J. Space Weather Space Climate. 2013, vol. 3, no. A17. DOI: 10.1051/swsc/2013037.

Tsubouchi K., Omura Y. Long-term occurrence probabilities of intense geomagnetic storm events. Space Weather. 2007, vol. 5, iss. 12, S12003. DOI: 10.1029/2007SW000329.

Uspensky M.I. Basic concepts and ways of influence of geomagnetic storms on the electric power system. Izvestia of the Komi Scientific Center of the Ural Branch of the Russian Academy of Sciences. 2017, no. 1, pp. 72-81. (In Russian).

Vakhnina V.V. Modeling the Operating Modes of Power Transformers of Power Supply Systems During Geomagnetic Storms. Togliatti: TSU Publ. House, 2012, 103 p. (In Russian).
Vakhnina V.V., Kretov D.A. Mathematical model of a power transformer under the influence of magnetic storms on power supply systems. Vector of Science of Togliatti State University. 2012a, no. 4, pp. 141-144. (In Russian).

Vakhnina V.V., Kretov D.A. Determination of permissible levels of geomagnetically induced currents to ensure the operability of power transformers during geomagnetic storms. Internet-Journal "Science". 2012b, no. 4, pp. 1-7. (In Russian).

Vakhnina V.V., Kuznetsov V.A. Development of a monitoring system for geomagnetically induced currents in neutrals of power transformers during geomagnetic storms. Vector of Science of Togliatti State University. 2013, no. 2, pp. 108-111. (In Russian).

Vakhnina V.V., Chernenko A.N., Kuznetsov V.A. Influence of geomagnetically induced currents on saturation of the magnetic system of power transformers. Vector of Science of Togliatti State University. 2012, no. 3, pp. 65-69. (In Russian).

Vakhnina VV, Kuvshinov AA, Shapovalov VA, Selemir V.D., Karelin V.I.Mechanisms of the Impact of Quasi-DC Geomagnetically Induced Currents on Electrical Networks. Moscow, Infra-Engineering, 2018, 256 p. (In Russian).

Veeramany A., Unwin S.D., Coles G.A., Dagle J.E., Millard D.W., Yao J., et al. Framework for modeling high-impact, low-frequency power grid events to support risk-informed decisions. International Journal of Disaster Risk Reduction. 2016, vol. 18, pp. 125-137. DOI: 10.1016/j.ijdrr.2016.06.008.

Viljanen A. Geomagnetically induced currents in the Finnish natural gas pipeline. Geofisica. 1989, vol. 25, pp. 135-159.

Viljanen A. The relation between geomagnetic variations and their time derivatives and implications for estimation of induction risks. Geophys. Res. Lett. 1997, vol. 24, pp. 631634.

Viljanen A. Relation of geomagnetically induced currents and local geomagnetic variations. IEEE Transactions Power Delivery. 1998, vol. 13, pp. 1285-1290.

Viljanen A., Pirjola R. Geomagnetically induced currents in the Finnish high-voltage power system, A geophysical review. Survey Geophys. 1994, vol. 15, no. 4, pp. 383-408.

Viljanen A., Tanskanen E. Climatology of rapid geomagnetic variations at high latitudes over two solar cycles. Ann. Geophys. 2011, vol. 29, iss. 10, pp. 1783-1792. DOI: 10.5194/angeo-29-1783-2011.

Viljanen A., Amm O., Pirjola R. Modelling geomagnetically induced currents during different ionospheric situations. J. Geophys. Res. 1999, vol. 104, pp. 28059-28072. DOI: 10.1029/1999JA900337.

Viljanen A., Nevanlinna H., Pajunpaa K., Pulkkinen A. Time derivative of the horizontal geomagnetic field as an activity indicator. Ann. Geophys. 2001, vol. 19, pp. 1107-1118.

Viljanen A., Pulkkinen A., Amm O., Pirjola R., Korja T., BEAR Working Group. Fast computation of the geoelectric field using the method of elementary current systems and planar Earth model. Ann. Geophys. 2004, vol. 22, iss. 1, pp. 101113. DOI: 10.5194/angeo-22-101-2004.

Viljanen A., Tanskanen E. I., Pulkkinen A. Relation between substorm characteristics and rapid temporal variations of the ground magnetic field. Ann. Geophys. 2006a, vol. 24, iss. 2, pp. 725-733. DOI: 10.5194/angeo-24-725-20066.

Viljanen A., Pulkkinen A., Pirjola R., Pajunpää K., Posio P., Koistinen A. Recordings of geomagnetically induced currents and a nowcasting service of the Finnish natural gas pipeline. Space Weather. 2006b, vol. 4, iss. 10, S10004. DOI: 10.1029/2006SW000234.

Viljanen A, Pirjola R., Wik M., Ádám A., Prácser E., Sakharov Ya., Katkalov J. Continental scale modelling of geomagnetically induced currents. J. Space Weather and 
Space Climate. 2012, vol. 2, no. A17. DOI: 10.1051/swsc/ 2012017.

Viljanen A., Pirjola R., Pracser E., Ahmadzai S.,Singh V. Geomagnetically induced currents in Europe: Characteristics based on a local power grid model. Space Weather. 2013, vol. 11, iss. 10, pp. 575-584. DOI: 10.1002/swe.20098.

Viljanen A, Pirjola R, Prácser E., Katkalov J., Wik M. Geomagnetically induced currents in Europe. J. Space Weather and Space Climate. 2014, vol. 4, no. A09. DOI: 10.1051/swsc/2014006.

Viljanen A., Wintoft P., Wik M. Regional estimation of geomagnetically induced currents based on the local magnetic or electric field. J. Space Weather and Space Climate. 2015, vol. 5, iss. A24. DOI: 10.1051/swsc/2015022.

Vorobiev V.G., Sakharov Ya.A., Yagodkina O.I, Petrukovich A.A., Selivanov V.N. Geomagnetically induced currents and their relationship with the position of the western electrojet and the boundaries of auroral precipitation. Trans. of the Kola Scientific Center of the Russian Academy of Sciences. 2018, vol. 5, iss. 4, pp. 16-28. DOI: 10.25702/KSC.23075252.2018.9.5.16-28. (In Russian).

Vorobev A.V., Pilipenko V.A., Sakharov Ya.A., Selivanov V.N. Statistical relationships of variations in the geomagnetic field, auroral electrojet and geomagnetically induced currents. Solar-Terr. Phys. 2019, vol. 5, no. 1. pp. 35-42. DOI: 10.12737/stp-51201905. (In Russian).

Vorobev A.V., Pilipenko V.A., Enikeev T.A., Vorobieva G.R. Geographic information system for analyzing the dynamics of extreme geomagnetic disturbances based on observations of ground-based stations. Computer Optics. 2020a, vol 44, no. 5, pp. 782-790. DOI: 10.18287/2412-6179-CO-707. (In Russian).

Vorobev A.V., Pilipenko V.A. Reshetnikov A.G., Vorobeva G.R., Belov M.D. Web-oriented visualization of auroral oval geophysical parameters. Scientific Visualization. 2020b, vol. 12 , no. 3, pp. 108-118. DOI: 10.26583/sv.12.3.10. (In Russian).

Vorobev A.V., Pilipenko V.A., Krasnoperov R.I., Vorobeva G.R., Lorentzen D.A. Short-term forecast of the auroral oval position on the basis of the "virtual globe" technology. Russian J. Earth Sciences. 2020c, vol. 20, ES6001. DOI: 10.2205/2020ES000721. $278 \mathrm{p}$.

Wait J. Geo-Electromagnetism. New York: Elsevier, 1982,

Wang W., Wiltberger M., Burns A.G., Solomon S.C., Killeen T.L., Maruyama N., Lyon J.G. Initial results from the coupled magnetosphere-ionosphere-thermosphere model: thermosphere-ionosphere responses. J. Atmos. Solar-Terr. Phys. 2004, vol. 66, pp. 1425-1441. DOI 10.1016/j.jastp.2004.04.008.

Watari S., Kunitake M., Kitamura K., Hori T., Kikuchi T., Shiokawa K., et al. Measurements of geomagnetically induced current in a power grid in Hokkaido, Japan. Space Weather. 2009, vol. 7, iss. 3. DOI: 10.1029/2008SW000417.

Wei L.H., Homeier N., Gannon J. L. Surface electric fields for North America during historical geomagnetic storms. Space Weather. 2013, vol. 11, pp. 451-462. DOI: 10.1002/swe.20073.

Weigel R.S., Klimas A.J., Vassiliadis D. Solar wind coupling to and predictability of ground magnetic fields and their time derivatives. J. Geophys. Res. 2003, vol. 108, iss. A7, 1298. DOI: 10.1029/2002JA009627.

Weimer D.R. An empirical model of ground-level geomagnetic perturbations. Space Weather. 2013, vol. 11, pp. 107-120. DOI: 10.1002/swe.20030.
Wik M., Viljanen A., Pirjola R., Pulkkinen A., Wintoft P., Lundstedt $\mathrm{H}$. Calculation of geomagnetically induced currents in the $400 \mathrm{kV}$ power grid in southern Sweden. Space Weather. 2008, vol. 6, iss. 7, S07005. DOI: 10.1029/2007SW000343.

Wik M., Pirjola R., Lundstedt H., Viljanen A., Wintoft P., Pulkkinen A. Space weather events in July 1982 and October 2003 and the effects of geomagnetically induced currents on Swedish technical systems. Ann. Geophys. 2009, vol. 27, no. 4, pp. 1775-1787.

Wintoft P. Study of the solar wind coupling to the time difference horizontal geomagnetic field. Ann. Geophys. 2005, vol. 23, pp. 1949-1957. DOI: 10.5194/angeo-23-1949-2005.

Yagova N.V., Pilipenko V.A., Fedorov E.N., Lhamdondog A.D., Gusev Yu.P. Geomagnetically induced currents and space weather: $\mathrm{Pi} 3$ pulsations and extreme values of the time derivatives of the horizontal components of the geomagnetic field. Izvestiya, Physics of the Solid Earth. 2018, no. 5, pp. 89-103.

Yagova N.V., Pilipenko V.A., Sakharov Y.A., Selivanov V.A. Spatial scale of geomagnetic Pc5/Pi3 pulsations as a factor of their efficiency in generation of geomagnetically induced currents. Earth, Planets and Space. 2021, vol. 73, DOI: 10.21203/rs.3.rs-39394/v2.

Zhang J.J., Wang C., Tang B.B. Modeling geomagnetically induced electric field and currents by combining a global MHD model with a local one-dimensional method. Space Weather. 2012, vol. 10, S05005. DOI: 10.1029/2012SW000772.

Zhang J.J., Wang C., Sun T.R., Liu C.M., Wang K.R. GIC due to storm sudden commencement in low-latitude highvoltage power network in China: Observation and simulation. Space Weather. 2015, vol. 13, iss. 10, pp. 643-655. DOI: 10.1002/2015SW001263.

Zheng K., Trichtchenko L., Pirjola R., Liu L.G. Effects of geophysical parameters on GIC illustrated by benchmark network modeling. IEEE Transactions Power Delivery. 2013, vol. 28, pp. 1183-1191. DOI: 10.1109/TPWRD.2013.2249119.

URL: http://eurisgic.orgl (accessed November 11, 2020).

URL: https://www.earthscope.org (accessed November 11, 2020) 2020).

URL: www.geo.fmi.fi/image (accessed November 11,

URL: http://omniweb.gsfc.nasa.gov (accessed November 11, 2020).

URL: http://csem.engin.umich.edu/swmf (accessed November 11, 2020).

URL: https://www.swpc.noaa.gov/products/aurora-30minute-forecast (accessed November 11, 2020).

URL: https://www.gi.alaska.edu/monitors/aurora-forecast (accessed November 11, 2020).

URL: https://en.vedur.is/weather/forecasts/aurora (accessed November 11, 2020).

URL: http://kho.unis.no ((accessed June 11, 2021).

URL: https://www.swpc.noaa.gov (accessed November 11, 2020).

URL: https://www.esa.int/Safety_Security/Space_Weather _Office (accessed November 11, 2020).

How to cite this article:

Pilipenko V.A. Space weather impact on ground-based technological systems. Solar-Terrestrial Physics. 2021. Vol. 7. Iss. 2. P. 68-104. DOI: 10.12737/stp-73202106. 